\title{
FRICTION STIR WELDING OF AZ31B-H24 MAGNESIUM ALLOY IN LAP CONFIGURATION
}

\author{
By \\ BHUKYA SRINIVASA NAIK \\ Master of Engineering in Mechanical Engineering \\ Indian Institute of Technology (IIT), Guwahati, INDIA, 2009
}

\author{
A dissertation \\ presented to Ryerson University \\ in partial fulfillment of the \\ requirements for the degree of
}

Doctor of Philosophy

in the Program of

Mechanical Engineering

Toronto, Ontario, Canada, 2015

CBhukya Srinivasa Naik, 2015 


\section{AUTHOR'S DECLARATION FOR ELECTRONIC SUBMISSION OF A DISSERTATION}

I hereby declare that I am the sole author of this dissertation. This is a true copy of the dissertation, including any required final revisions, as accepted by my examiners.

I authorize Ryerson University to lend this dissertation to other institutions or individuals for the purpose of scholarly research.

I further authorize Ryerson University to reproduce this dissertation by photocopying or by other means, in total or in part, at the request of other institutions or individuals for the purpose of scholarly research.

I understand that my dissertation may be made electronically available to the public. 


\title{
FRICTION STIR LAP WELDING OF AZ31B-H24 MAGNESIUM ALLOY
}

\author{
C Bhukya Srinivasa Naik, 2015 \\ Doctor of Philosophy \\ Department of Mechanical and Industrial Engineering \\ Ryerson University
}

\begin{abstract}
Friction stir welding (FSW) being an enabling solid-state joining technology can be suitably applied for the assembly of lightweight magnesium alloys. In this study, AZ31B-H24 Mg alloy sheets with a thickness of $2 \mathrm{~mm}$ were friction stir welded in lap configuration using two tool rotational rates of 1000 and $1500 \mathrm{rpm}$ and two welding speeds of 10 and $20 \mathrm{~mm} / \mathrm{s}$. The joint quality was characterized in terms of the residual stresses, welding defects, microstructure, and texture. The mechanical properties including hardness, room and elevated temperature tensile and fatigue properties were also evaluated and correlated to the structure and defects. It was observed that the hardness decreased from the base metal (BM) to the stir zone (SZ) across the heat-affected zone (HAZ) and thermomechanically-affected zone (TMAZ). The lowest value of hardness appeared in the SZ. With increasing tool rotational rate or decreasing welding speed, the average hardness in the SZ decreased owing to increasing grain sizes, and a Hall-Petch-type relationship was established. The shear tensile behavior of the lap joints was evaluated at low $\left(-40^{\circ} \mathrm{C}\right)$, room $\left(25^{\circ} \mathrm{C}\right)$, and elevated $\left(180^{\circ} \mathrm{C}\right)$ temperatures. The failure load was highest in the lower heat input condition that was
\end{abstract}


obtained at a tool rotational rate of $1000 \mathrm{rpm}$ and a welding speed of $20 \mathrm{~mm} / \mathrm{s}$ at all the test temperatures, due to a smaller hooking height, larger effective sheet thickness, and lower tensile residual stress, as compared with other two welding conditions that were obtained at a higher tool rotational rate or lower welding speed. The lap joints usually fractured on the advancing side of the top sheet near the interface between the TMAZ and the SZ. Elevated temperature testing of the weld assembled at a tool rotational rate of $1000 \mathrm{rpm}$ and a welding speed of $20 \mathrm{~mm} / \mathrm{s}$ led to the failure along the sheet interface in a shear fracture mode due to the high integrity of the joint that exhibited large plastic deformation and increased total energy absorption. Fatigue fracture of the lap welds always occurred at the interface between the SZ and TMAZ on the advancing side where a larger hooking defect was present (in comparison with the retreating side). The welding parameters had a significant influence on the hook height and the subsequent fatigue life. A relatively "cold" weld, conducted at a rotational rate of $1000 \mathrm{rpm}$ and welding speed of $20 \mathrm{~mm} / \mathrm{s}$, gave rise to almost complete elimination of the hooking defect, thus considerably (over two orders of magnitude) improving the fatigue life. Fatigue crack propagation was basically characterized by the formation of fatigue striations concomitantly with secondary cracks. 


\section{ACKNOWLEDGEMENTS}

I would like to express my sincere thanks to my supervisors Dr. Daolun Chen at Ryerson University and Dr. Xinjin Cao at National Research Council Canada (NRC), who have given me this great opportunity and also continuous guidance, support and encouragement during my studies at Ryerson University. I was privileged to have them as my supervisors and it was my pleasure to work with them who have broad and profound knowledge, not only in the academic field, but also in many other aspects. I highly appreciate their scientific rigorness and encouragement from different perspectives for my academic research and future professional life. Great thanks are also due to Dr. Priti Wanjara.

I would also like to thank the Natural Sciences and Engineering Research Council of Canada (NSERC) and AUTO21 for providing financial support. This investigation involves part of the Canada-China-USA Collaborative Research Project on the Magnesium Front End Research and Development (MFERD), and financial support from NRC is also acknowledged.

I am grateful to my committee members for their precious time in evaluating and subsequently raising several valuable points during the course of this work. I would like to extend my thanks to all my friends and colleagues at Ryerson University for helping me in the labs and performing experiments; you have all made me feel so easy and it has been a pleasure working with you. I will treasure this experience throughout my life. 
Special thanks are owed to A. Machin, J. Amankrah, Q. Li and R. Churaman for their strong support in providing easy access to the research facilities.

Finally, I cannot forget the great struggle of my loving wife, Jyothi Priya Jadhav. Words alone cannot express what I owe her for her persistent encouragement, understanding, emotional support, and great patience during my 4 years graduate study. I dedicate this particular piece of work especially to my parents Mr. Bhukya Huna and Mrs. Bhukya Kanthamma who are the rock upon which all of my current and future success has been and will be built. Last but not least, words cannot express my deepest gratitude towards my brothers and Sister Bhukya Kotya Naik, Bhukya Rajagopala Naik and Bhukya Bhanu who constantly encourages me to complete this work. 


\title{
Dedicated to my Parents
}

\author{
Mrs. Bhukya Huna \\ \& \\ Mrs. Bhukya Kanthamma
}

My family, for their encouragement

My wife, Jyothi Priya Jadhav

$$
\text { My Son, Abhyansh Naik }
$$

For her endless love and support

It would have been just impossible, without you 


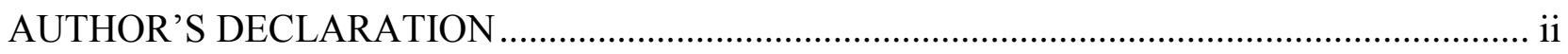

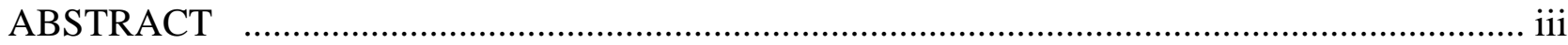

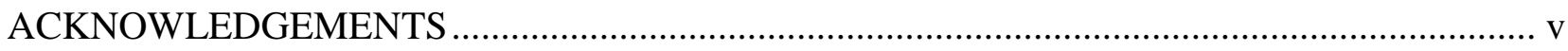

TABLE OF CONTENTS ................................................................................................. viii

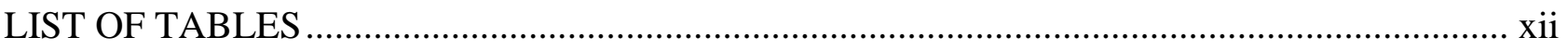

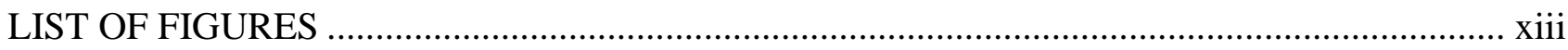

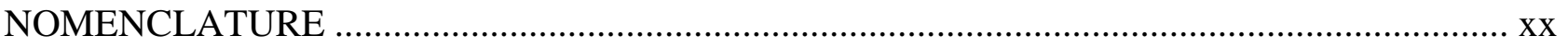

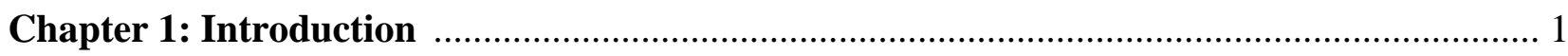

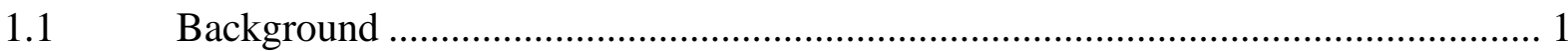

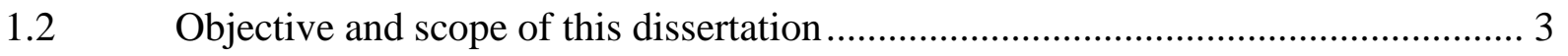

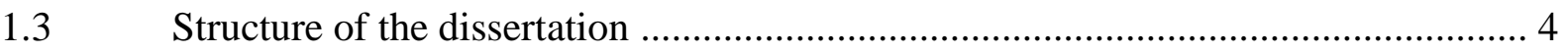

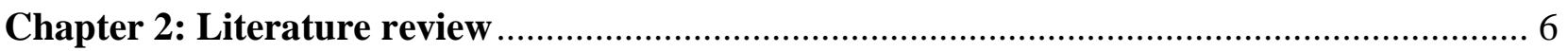

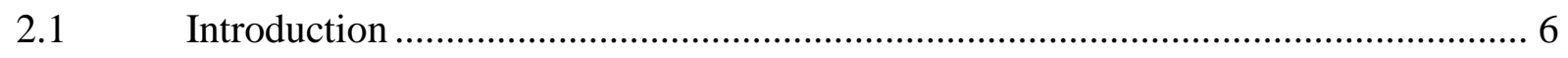

2.2 Friction stir welding (FSW) process ................................................................ 8

2.2.1 Advantages of FSW process ……………………............................ 9

2.2.2 Disadvantages of FSW process ……………………............................ 10

2.3 Friction stir welding terminology .................................................................. 11

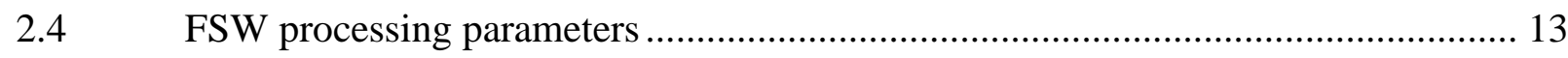

2.4.1 Tool rotational rate and welding speed ..................................................... 13

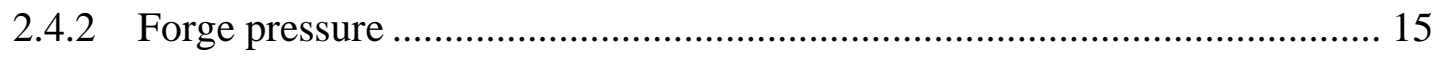

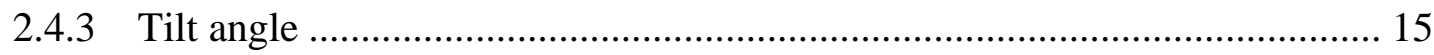




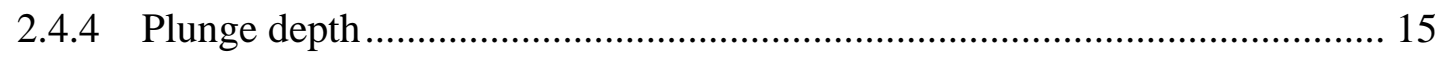

2.4.5 Preheating or cooling .............................................................................. 16

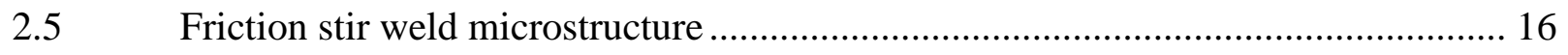

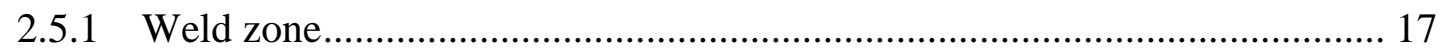

2.5.2 Thermomechanically affected zone (TMAZ) ……………….................... 18

2.5.3 Heat affected zone (HAZ) .................................................................. 18

2.6 Different types of weld joint configuration ......................................................... 18

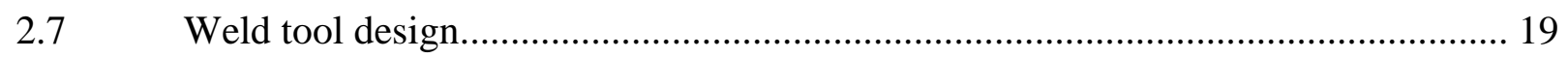

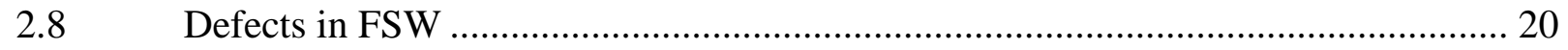

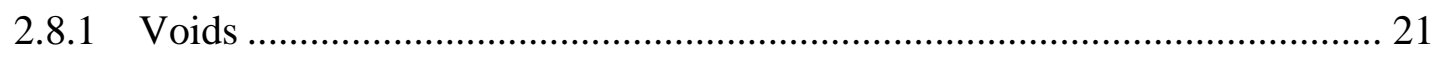

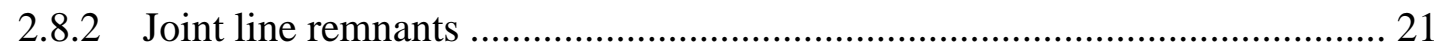

2.8.3 Lack of penetration............................................................................. 23

2.9 Material Properties and Characteristics of a AZ31B H24 Mg alloy ........................ 23

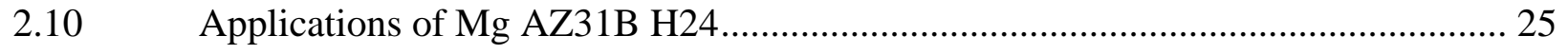

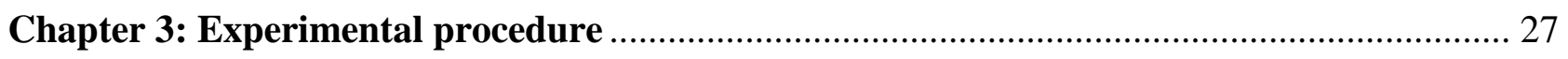

3.1 Experimental materials .................................................................................... 27

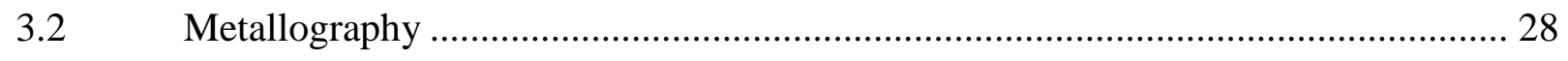

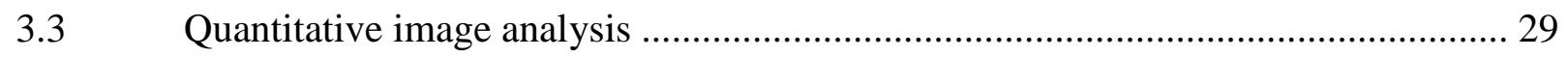

3.4 X-Ray diffraction for phase identification ……….................................................. 30

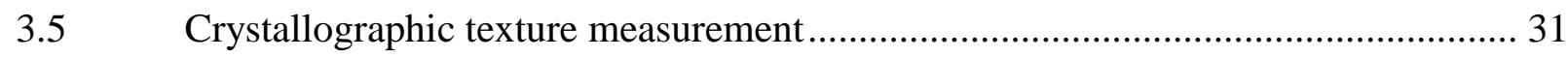

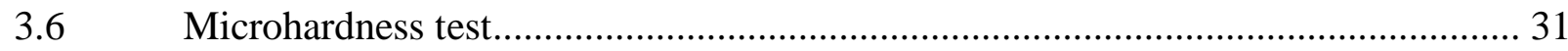

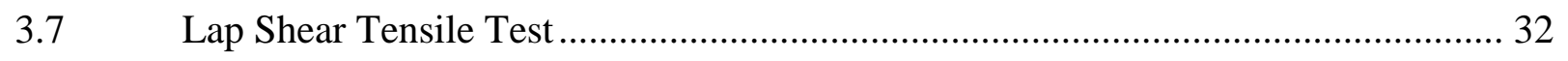

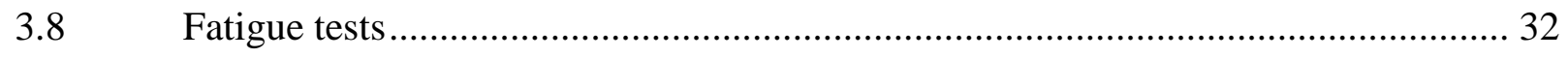


Residual stress measurement.................................................................. 33

Chapter 4: Microstructure and fatigue properties ..................................................... 37

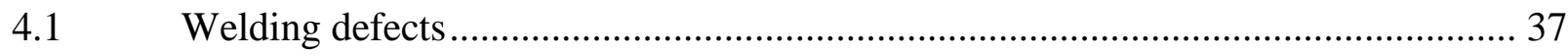

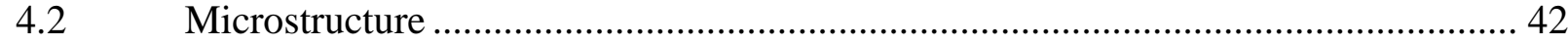

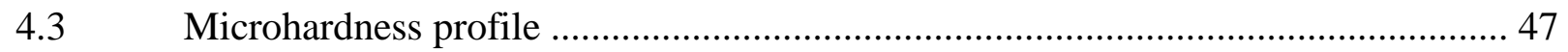

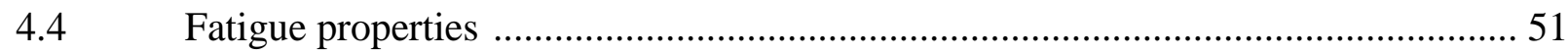

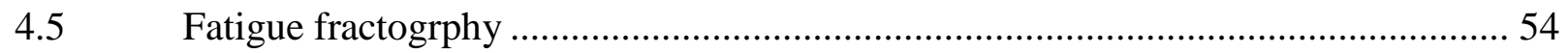

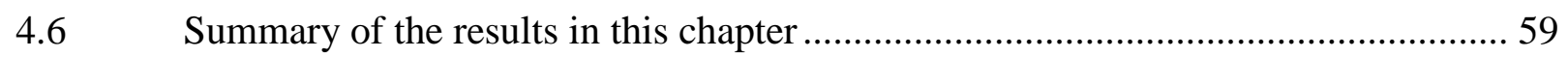

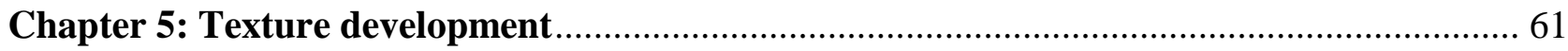

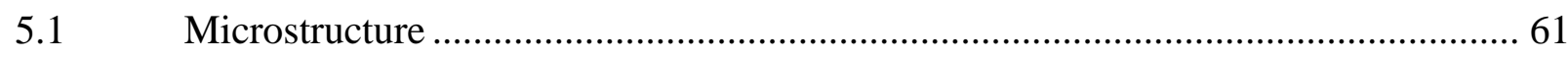

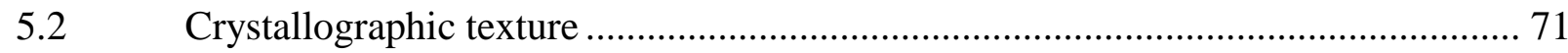

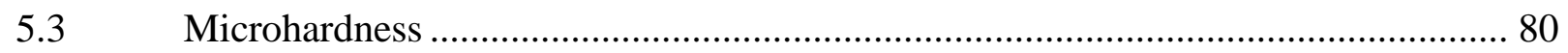

Lap shear tensile properties of joints...................................................... 82

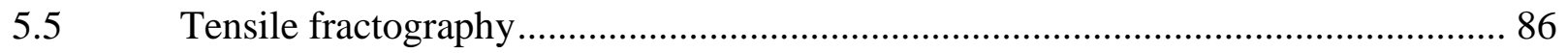

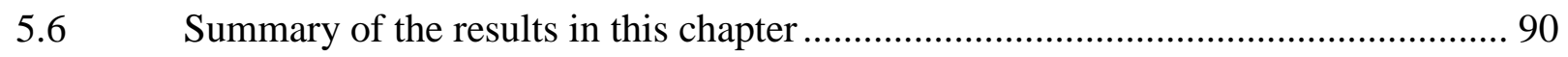

Chapter 6: Residual stresses and tensile properties .................................................. 92

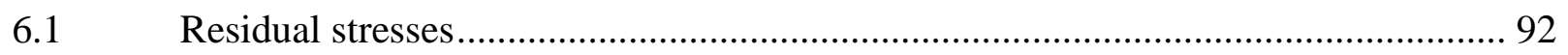

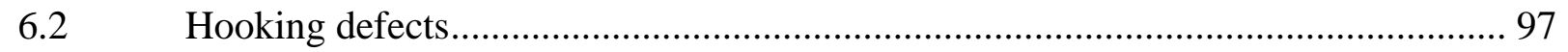

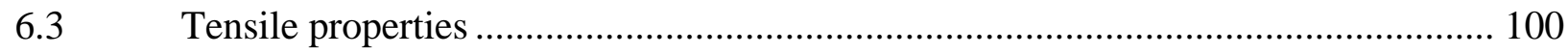

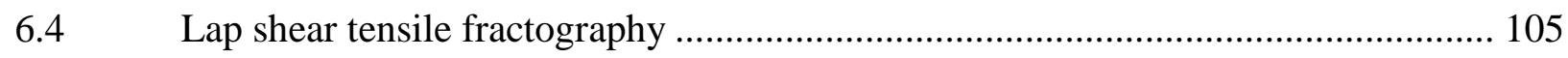

Summary of the results in this chapter ....................................................... 111

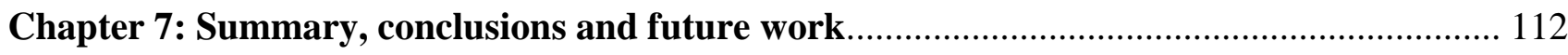

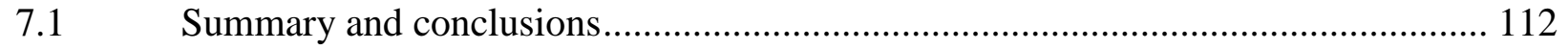


Recommendations for future work......................................................... 115

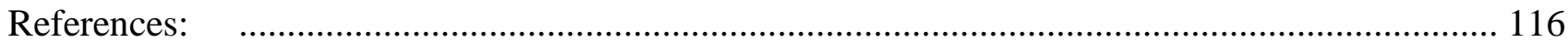

\section{LIST OF TABLES}




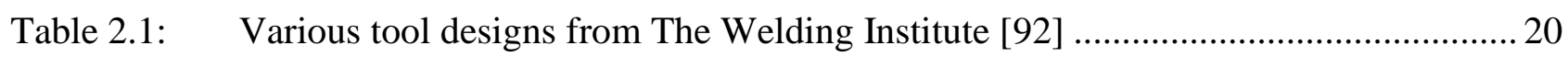

Table 2.2: $\quad$ Chemical composition of AZ31B Mg ........................................................ 23

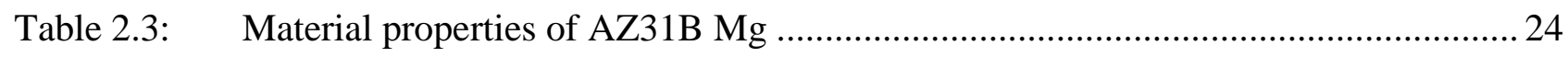

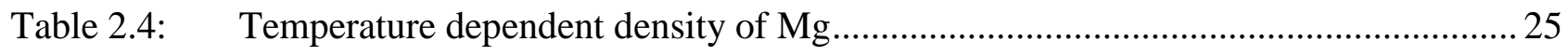

Table 5.1: Effect of tool rotational rate and welding speed on the grain size (mean value $\pm \mathrm{SD})$ and failure load of FSLWed AZ31B-H24 Mg alloy................................ 63

Table 5.2: $\quad$ EDS analysis results on the particles observed in the BM and SZ of FSLWed AZ31B-H24 Mg

Table 5.3: Effect of tool rotational rate and welding speed on the maximum pole intensities (in multiples of random distribution (MRD)) in the FSLWed AZ31B-H24 Mg alloy 78

Table 6.1: Hooking height and effective sheet thickness for FSLWed AZ31B-H24 Mg alloy assembled at different tool rotational rates and welding speeds 98

Table 6.2: $\quad$ Effect of test temperature on tensile failure load, energy absorption and failure mode of the FSLWed AZ31B-H24 Mg alloy obtained at different tool rotational rates and welding speeds 


\section{LIST OF FIGURES}

Figure 2.1: $\quad$ FSW schematic diagram for a typical lap weld configuration.

Figure 2.2: Cross section of a FSLWed AZ31B-H24 Mg alloy indicating the 'welding zones' of FSW .....

Figure 2.3: Standard weld configurations. a) square butt b) edge butt c) T joint butt d) lap joint e) multiple lap joint f) T lap joint g) fillet joint [Mishra 2005]

Figure 3.1: $\quad$ Schematic diagrams of the experimental setup showing (a) the side view of the overlapped $\mathrm{Mg} / \mathrm{Mg}$ joint, (b) the top view of the welded coupon... 29

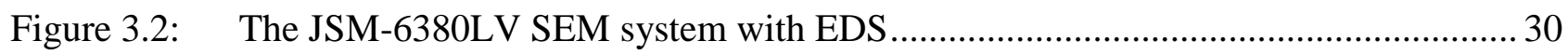

Figure 3.3: $\quad$ Schematic diagrams of the texture measurement at different welding zones ........... 31

Figure 3.4: A Buehler Micromet-5100 Vickers microhardness tester................................... 32

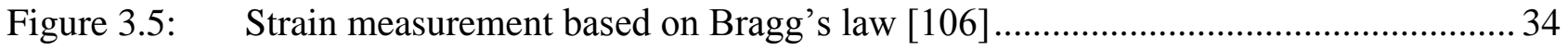

Figure 3.6: Schematic diagrams of the residual stress measurement at different welding zones on both advancing and retreating sides 36

Figure 4.1: Macroscopic images of the lap joints obtained at various combinations of rotational rate and welding speed of (a) $1000 \mathrm{rpm}, 20 \mathrm{~mm} / \mathrm{s}$, (b) $1500 \mathrm{rpm}, 20$ $\mathrm{mm} / \mathrm{s}$, and (c) $1500 \mathrm{rpm}, 10 \mathrm{~mm} / \mathrm{s}$ 38

Figure 4.2: Hooking defects in the friction stir lap welds and their relative sizes on the advancing side for the welding conditions of (a) $1000 \mathrm{rpm}$ at $20 \mathrm{~mm} / \mathrm{s}$ and (b) $1500 \mathrm{rpm}$ at $20 \mathrm{~mm} / \mathrm{s}$ 
Figure 4.3: Hooking defects observed on the advancing (left) and retreating (right) sides at varying tool rotational rates and welding speeds, namely, (a-b) $1500 \mathrm{rpm}$ and $10 \mathrm{~mm} / \mathrm{s}$, (c-d) $1500 \mathrm{rpm}$ and $20 \mathrm{~mm} / \mathrm{s}$, and (e-f) $1000 \mathrm{rpm}$ and $20 \mathrm{~mm} / \mathrm{s}$

Figure 4.4: (a) Low-magnification OJLwSPD defects present in-between the top and bottom sheets of a weld joined at a welding speed of $20 \mathrm{~mm} / \mathrm{s}$ and rotational rate of $1000 \mathrm{rpm}$ using a pin of $2.75 \mathrm{~mm}$ in length; high-magnification observations of the OJLwSPD defects that occurred at a rotational rate of (b) $1000 \mathrm{rpm}$ and (c) $1500 \mathrm{rpm}$.

Figure 4.5: (a) Overview of the FSLWed $\mathrm{Mg} / \mathrm{Mg}$ joint obtained at a tool rotational rate of $1000 \mathrm{rpm}$ and a welding speed of $20 \mathrm{~mm} / \mathrm{s}$ with (b) to (g) showing the microstructures in the different regions as indicated in (a) 44

Figure 4.6: Comparison of (a) the BM AZ31-H24 Mg alloy microstructure with the typical microstructures in the SZ of FSLWed AZ31-H24 Mg alloy at different tool rotational rates and welding speeds: (b) $1000 \mathrm{rpm}$ and $20 \mathrm{~mm} / \mathrm{s}$, (c) 1500 $\mathrm{rpm}$ and $20 \mathrm{~mm} / \mathrm{s}$, and (d) $1500 \mathrm{rpm}$ and $10 \mathrm{~mm} / \mathrm{s}$

Figure 4.7: Typical microhardness profiles across the FSLWed AZ31B-H24 Mg alloy welds joined at (a) $1000 \mathrm{rpm}$ and $20 \mathrm{~mm} / \mathrm{s}$, (b) $1500 \mathrm{rpm}$ and $20 \mathrm{~mm} / \mathrm{s}$, and (c) $1500 \mathrm{rpm}$ and $10 \mathrm{~mm} / \mathrm{s}$

Figure 4.8: Hall-Petch-type relationship between the average hardness and average grain size in the stir zone of the FSLWed AZ31B-H24 Mg alloy weld joined with different welding parameters, where the base metal grain size and hardness data are also plotted (The error bars on the plotted data represent the standard deviations for both hardness and grain size values). 50 
Figure 4.9: Fatigue life curves of the friction stir lap welds manufactured with various rotational rates and welding speeds and tested at room temperature, $\mathrm{R}=0.2$ and $50 \mathrm{~Hz}$ : (a) Semi-log scale plot of the maximum load vs. the number of cycles to failure (Nf) and (b) Double-log scale plot of the maximum stress vs. the number of reversals to failure (2Nf)

Figure 4.10: Fatigue failure locations (as indicated by F) in the FSLWed AZ31B-H24 Mg alloy weld joined at the various tool rotational and welding speeds: (a) 1000 rpm, $20 \mathrm{~mm} / \mathrm{s}$, (b) $1500 \mathrm{rpm}, 20 \mathrm{~mm} / \mathrm{s}$, and (c) $1500 \mathrm{rpm}, 10 \mathrm{~mm} / \mathrm{s}$

Figure 4.11: Typical SEM images of the fatigue fracture surface of a FSLWed AZ31B-H24 $\mathrm{Mg}$ alloy assembled at a rotational rate of $1000 \mathrm{rpm}$ and a welding speed of 20 $\mathrm{mm} / \mathrm{s}$ : (a) fatigue fracture surface at a lower $\operatorname{Pmax}=1 \mathrm{kN}$, (b) crack initiation site at a lower $P \max =1 \mathrm{kN}$, (c) crack propagation region at a lower $\mathrm{Pmax}=1$ $\mathrm{kN}$, (d) fatigue striations at a higher magnification at a lower $\operatorname{Pmax}=1 \mathrm{kN}$, (e) fatigue fracture surface and crack initiation site at a higher $P \max =5 \mathrm{kN}$, and (f) crack propagation region at a higher $P \max =5 \mathrm{kN}$. 56

Figure 4.12: Typical SEM images of the fatigue fracture surface of a FSLWed AZ31B-H24 $\mathrm{Mg}$ alloy assembled at a rotational rate of $1500 \mathrm{rpm}$ and a welding speed of 10 $\mathrm{mm} / \mathrm{s}$ : (a) fatigue fracture surface at a lower $\operatorname{Pmax}=0.5 \mathrm{kN}$, (b) crack initiation site at a lower $\operatorname{Pmax}=0.5 \mathrm{kN}$, (c) crack propagation region at a lower $P \max =0.5 \mathrm{kN}$, (d) fatigue fracture surface at a higher Pmax $=2 \mathrm{kN}$, (e) crack propagation region at a higher $\operatorname{Pmax}=2 \mathrm{kN}$, and (f) crack propagation region at a further higher magnification at a higher $\operatorname{Pmax}=2 \mathrm{kN}$ 
Figure 4.13: Typical SEM images of the fatigue fracture surface of a FSLWed AZ31B-H24 $\mathrm{Mg}$ alloy assembled at a rotational rate of $1500 \mathrm{rpm}$ and a welding speed of 20 $\mathrm{mm} / \mathrm{s}$ : (a) fatigue fracture surface at a lower $\operatorname{Pmax}=0.5 \mathrm{kN}$, (b) crack initiation site at a lower $\operatorname{Pmax}=0.5 \mathrm{kN}$, (c) crack propagation region at a lower Pmax $=0.5 \mathrm{kN}$, (d) fatigue fracture surface at a higher Pmax=2 kN, (e) crack initiation site at a higher $P \max =2 \mathrm{kN}$, and (f) crack propagation region at a further higher $\operatorname{Pmax}=2 \mathrm{kN}$

Figure 5.1: Typical microstructures of the FSLWed AZ31B-H24 Mg alloy at a tool rotational rate of $1000 \mathrm{rpm}$ and a welding speed of $20 \mathrm{~mm} / \mathrm{s}$ in (a) SZ, (b) TMAZ, (c) HAZ and (d) BM.

Figure 5.2: Typical microstructures of the FSLWed AZ31B-H24 Mg alloy at a tool rotational rate of $1500 \mathrm{rpm}$ and a welding speed of $20 \mathrm{~mm} / \mathrm{s}$ in (a) SZ, (b) TMAZ, (c) HAZ and (d) BM. 65

Figure 5.3: Typical microstructures of the FSLWed AZ31B-H24 Mg alloy at a tool rotational rate of $1500 \mathrm{rpm}$ and a welding speed of $10 \mathrm{~mm} / \mathrm{s}$ in (a) SZ, (b) TMAZ, (c) HAZ and (d) BM. 66

Figure 5.4: Secondary electron imaging and EDS point analysis of the Al-Mn and Al-Mg particles: (a) coarse Al8Mn5 particles as indicated by arrows in the BM; (b) coarse $\mathrm{Al}_{8} \mathrm{Mn}_{5}$ and fine $\mathrm{Al}_{12} \mathrm{Mg}_{17}$ particles as indicated by arrows in the $\mathrm{SZ}$; (c) EDS analysis of Al8Mn5 particles in the BM; (d) EDS analysis of Al12Mg17 particles in the SZ . 68

Figure 5.5: X-ray diffraction patterns obtained from the top surface of (a) BM; (b) SZ of the FSLWed AZ31B-H24 Mg alloy at $1000 \mathrm{rpm}$ and $20 \mathrm{~mm} / \mathrm{s}$; (c) SZ of the 
FSLWed AZ31B-H24 Mg alloy at $1500 \mathrm{rpm}$ and $20 \mathrm{~mm} / \mathrm{s}$; and (d) $\mathrm{SZ}$ of the FSLWed AZ31B-H24 Mg alloy at $1500 \mathrm{rpm}$ and $10 \mathrm{~mm} / \mathrm{s}$.

Figure 5.6: (0001) basal, $\left(10^{\overline{1}} 0\right)$ prismatic, and $(10 \overline{1} 1)$ pyramidal plane pole figures of the FSLWed AZ31B-H24 Mg alloy obtained from the SZ, TMAZ, HAZ and BM at (a) $1000 \mathrm{rpm}$ and $20 \mathrm{~mm} / \mathrm{s}$, (b) $1500 \mathrm{rpm}$ and $20 \mathrm{~mm} / \mathrm{s}$ and (c) $1500 \mathrm{rpm}$ and $10 \mathrm{~mm} / \mathrm{s}$.

Figure 5.7: Schematic illustration of the basal plane (0001) in a hcp unit cell, where the six prismatic planes $\left\{10 \overline{1}_{0}\right\}$ are perpendicular to the paper plane and indicated by $1,2, \ldots, 6$, showing the change of texture from $(0001)<11 \overline{2} 0>$ component (BM) into the $(0001)<10^{\overline{1}} 0>$ component (SZ), (a) BM, and (b-d) SZ with different angles of rotation after FSLW.

Figure 5.8: Typical microhardness profiles at the mid-thickness of the top sheet in the FSLWed AZ31B-H24 Mg alloy assembled at different tool rotational rates and welding speeds (where AS is the advancing side and RS is the retreating side)

Figure 5.9: Typical load versus displacement curves of the FSLWed AZ31B-H24 Mg alloy assembled at different tool rotational rates and welding speeds. 82

Figure 5.10: The fracture location, demarcated by the symbol "F", in the ruptured tensile samples of FSLWed AZ31B-H24 Mg alloy obtained at various combinations of tool rotational rate and welding speed: (a) $1000 \mathrm{rpm}-20 \mathrm{~mm} / \mathrm{s}$, (b) 1500 $\mathrm{rpm}-20 \mathrm{~mm} / \mathrm{s}$, and (c) $1500 \mathrm{rpm}-10 \mathrm{~mm} / \mathrm{s}$. .86

Figure 5.11: Typical SEM images of the tensile shear fracture surface of a FSLWed AZ31B-H24 Mg alloy assembled at a rotational rate of $1000 \mathrm{rpm}$ and a xvii 
welding speed of $20 \mathrm{~mm} / \mathrm{s}$ : (a) overall view of a fracture surface and crack initiation site, (b) crack initiation site at a higher magnification, (c) crack propagation region at a lower magnification and (d) crack propagation region at a higher magnification.

Figure 5.12: Typical SEM images of the tensile fracture surface of a FSLWed AZ31B-H24 Mg alloy assembled at a rotational rate of $1500 \mathrm{rpm}$ and a welding speed of 20 $\mathrm{mm} / \mathrm{s}$ : (a) overall view of a fracture surface, (b) crack initiation site, (c) crack propagation region at a lower magnification and (d) crack propagation region at a higher magnification

Figure 5.13: Typical SEM images of the tensile fracture surface of a FSLWed AZ31B-H24 $\mathrm{Mg}$ alloy assembled at a rotational rate of $1500 \mathrm{rpm}$ and a welding speed of 10 $\mathrm{mm} / \mathrm{s}$ : (a) overall view of a fracture surface, (b) crack initiation site, (c) crack propagation region at a lower magnification and (d) crack propagation region at a higher magnification

Figure 6.1: a) Schematic diagram of the experimental setup showing the corresponding locations for the residual stress measurements, b) Typical pre-scan XRD pattern, c) changes of typical XRD patterns, and d) $\sin 2 \psi$ diagram for the (105) diffraction plane of the $1000 \mathrm{rpm}-20 \mathrm{~mm} / \mathrm{s}$ joint determined at room temperature, where the solid line represents the linear least-squares fitting.

Figure 6.2: a) Longitudinal and b) transverse residual stress distributions of a FSLWed AZ31B-H24 Mg alloy in different welding conditions .96

Figure 6.3: a) Metallographic cross-sectional views of the welds showing the various features (hooking height $\mathrm{Hh}$ and effective sheet thickness te ), and (b-g) 
magnified views of the hooking defects on the advancing (left) and retreating (right) sides at different tool rotational rates and welding speeds, (b-c) 1000 rpm-20 mm/s, (d-e) $1500 \mathrm{rpm}-20 \mathrm{~mm} / \mathrm{s}$, and (f-g) $1500 \mathrm{rpm}-10 \mathrm{~mm} / \mathrm{s}$

Figure 6.4: Comparison of different load versus displacement curves for FSLWed AZ31B-H24 Mg alloy tested at different temperatures. Specimens welded at a) $1000 \mathrm{rpm}-20 \mathrm{~mm} / \mathrm{s}$, b) $1500 \mathrm{rpm}-20 \mathrm{~mm} / \mathrm{s}$, and c) $1500 \mathrm{rpm}-10 \mathrm{~mm} / \mathrm{s}$ 103

Figure 6.5: Tensile failure locations (as demarcated by the arrow labelled with F) in FSLWed AZ31B-H24 Mg alloy fabricated at various combinations of tool rotational rate and welding speed and tested at (a-c) LT $\left(-40^{\circ} \mathrm{C}\right)$, (d-f) RT $\left(25^{\circ} \mathrm{C}\right)$ and $(\mathrm{g}-\mathrm{i}) \mathrm{ET}\left(180^{\circ} \mathrm{C}\right)$.

Figure 6.6: Influence of the test temperature on the (a) tensile shear failure load and (b) energy absorption of the FSLWed AZ31B-H24 Mg alloy joined in different welding conditions. 106

Figure 6.7: Typical SEM images of the tensile shear fracture surfaces obtained at low temperature $\left(-40^{\circ} \mathrm{C}\right)$ for welding conditions of $(\mathrm{a}-\mathrm{b}) 1000 \mathrm{rpm}-20 \mathrm{~mm} / \mathrm{s}$, (c-d) $1500 \mathrm{rpm}-20 \mathrm{~mm} / \mathrm{s}$, and (e-f) $1500 \mathrm{rpm}-10 \mathrm{~mm} / \mathrm{s}$ 108

Figure 6.8: Typical SEM images of the tensile shear fracture surfaces obtained at room temperature $\left(25^{\circ} \mathrm{C}\right)$ for welding conditions of $(\mathrm{a}-\mathrm{b}) 1000 \mathrm{rpm}-20 \mathrm{~mm} / \mathrm{s}$, (c-d) $1500 \mathrm{rpm}-20 \mathrm{~mm} / \mathrm{s}$ and (e-f) $1500 \mathrm{rpm}-10 \mathrm{~mm} / \mathrm{s}$

Figure 6.9: Typical SEM images of the tensile shear fracture surfaces obtained at high temperature $\left(180^{\circ} \mathrm{C}\right)$ for welding conditions of $(\mathrm{a}-\mathrm{b}) 1000 \mathrm{rpm}-20 \mathrm{~mm} / \mathrm{s},(\mathrm{c}-\mathrm{d})$ $1500 \mathrm{rpm}-20 \mathrm{~mm} / \mathrm{s}$ and (e-f) $1500 \mathrm{rpm}-10 \mathrm{~mm} / \mathrm{s}$. 


\section{NOMENCLATURE}

\section{Acronym}

AS

$\mathrm{BM}$

CRSS

EST

ET

FSW

HAZ

HV

LD

LT

RD

RS

RT

SEM

SZ

TD

TMAZ

XRD

OJLwSPD

\section{Definition}

Advancing side

Base metal

Critical resolved shear stress

Effective sheet thickness

Elevated temperature

Friction stir welding

Heat-affected zone

Vickers hardness

Longitudinal direction

Low temperature

Rolling direction

Retreating side

Room temperature

Scanning electron microscope

Stir zone

Transverse direction

Thermomechanically-affected zone

X-ray diffraction

Original Joint Line with Severe Plastic Deformation 


\begin{tabular}{|c|c|c|}
\hline$\underline{\text { Symbol }}$ & Definition & $\underline{\text { Unit }}$ \\
\hline q & Heat input & Watt \\
\hline$\mu$ & Friction coefficient & \\
\hline$P$ & Pressure & $\mathrm{MPa}$ \\
\hline$\omega$ & Tool rotational rate & $\mathrm{rpm}$ \\
\hline $\mathrm{R}$ & Radius of the shoulder & $\mathrm{mm}$ \\
\hline$\alpha$ & Heat input efficiency & \\
\hline Q & Heat input per unit length & Watt $/ \mathrm{mm}$ \\
\hline $\mathrm{V}$ & Welding speed & $\mathrm{mm} / \mathrm{s}$ \\
\hline $\mathrm{F}$ & Tool plunge down force & $\mathrm{N}$ \\
\hline $\mathrm{a}$ & Weld pitch & $\mathrm{mm} / \mathrm{rev}$ \\
\hline $\mathrm{d}$ & Grain size & $\mu \mathrm{m}$ \\
\hline$\theta$ & Angle of rotation & Deg \\
\hline$\theta \mathrm{i}$ & Initial angle of rotation & Deg \\
\hline $\mathrm{n}$ & Integer & \\
\hline $\mathrm{N}$ & Fatigue life & \\
\hline $\mathrm{R}$ & Load ratio & \\
\hline $\mathrm{H}_{\mathrm{h}}$ & Hooking height & $\mathrm{mm}$ \\
\hline$t_{e}$ & Effective sheet thickness & $\mathrm{mm}$ \\
\hline$\psi$ & Angle between the sample normal and the normal & \\
\hline
\end{tabular}




\section{CHAPTER 1}

\section{INTRODUCTION}

\subsection{Background}

The growing environmental concern about global climate change in conjunction with highly volatile and rising energy prices has resulted in continuous and increasing pressure on the transportation industry to improve fuel efficiency and reduce anthropogenic environmentdamaging emissions [1-7]. Different strategies can be employed to address this challenge, including the use of alternative/renewable energy sources and the related powertrain improvements, aerodynamic (drag reducing) enhancements and vehicle light-weighting. Of these, reduction of vehicle weight has been the preferred approach in the global transportation industry. In principle, material selection strategies for vehicle components and assemblies are dependent on functionality, cost, light-weighting and recyclability considerations [1, 8-17]. Substitution of traditional materials, such as mild steels, for example, with advanced high-strength steels or aluminum alloys, has already allowed marked gains in weight reduction and there is further potential through a judicious application of ultra-lightweight magnesium $(\mathrm{Mg})$ alloys [18]. Of importance for realizing increased use of $\mathrm{Mg}$ alloys for light-weighting is the development of cost-effective joining technologies that render high mechanical performance of the assembly.

Mg alloys may be welded by using conventional arc and advanced fusion (e.g., laser) welding techniques. However, these processes tend to require a filler metal addition to mitigate weld cracking through modification of the molten weld pool composition as well as post-weld heat 
treatment to restore the fusion zone strength in hardened alloys $[19,20]$. Other challenges for fusion welding of $\mathrm{Mg}$ alloys stem from its relatively low viscosity and surface tension in the molten state, high oxidation potential [21], relatively high vapor pressure in the liquid phase and significantly high hydrogen solubility in the liquid phase relative to the solid phase [22, 23], which can result in an unstable weld pool, production of spatter, poor surface quality, porosity, solid inclusions, and evaporative losses (especially for the elements with high evaporative pressures and low boiling points such as zinc) [24]. Therefore, the applications of lightweight $\mathrm{Mg}$ alloys require the development and application of alternative advanced welding technologies, while guaranteeing the reliability and structural integrity of the welded joints.

Friction stir welding (FSW), an emerging "green" solid-state joining process that was invented at The Welding Institute (TWI) of UK in 1991 [8], can mitigate the above concerns linked to the melting and solidification of the weldment to render mechanical performance improvements for the assembly because the Mg alloy does not reach its melting temperature during FSW. In order to obtain a properly consolidated weld it is also necessary to have a shoulder much larger than the pin, typically 1.5-2 times the diameter of the pin, which rides along the surface of the work piece in an intimate contact, while the pin is submerged in to the work piece providing the stirring and heating. Utilization of FSW can be especially advantageous for Mg alloys as the process imparts a low heat input and has the flexibility to join cast, extruded and rolled materials without requiring complicated surface preparation or shielding gas protection $[25,26]$.

FSW can also assemble different joint configurations, such as lap-, butt- and T-joints, of which the lap joints are widely applied in vehicle and aircraft design and manufacturing. Of importance 
for friction stir lap welding (FSLW), however, is the greater diligence necessary in developing and optimizing tool designs and processing parameters to break the surface oxide layer on two planar surfaces and mitigate the three main defects, i.e., kissing bonds, hooking and top workpiece thinning [27]. Due to the advantages inherent to this process, FSW has been implemented by the automotive, aerospace, defense, and maritime industries. NASA has adopted FSW for use in the circumferential welds of the space shuttle's external fuel tanks. Other NASA applications of FSW include the Boeing Delta IV heavy rockets used to launch the Mars Phoenix Lander in July 2007. General Motors has funded research in FSW and has even started using FSW for some spot welding applications in production.

\subsection{Objective and scope of this dissertation}

Several papers have recently reported on the joining of similar alloys by FSW, especially for steel and Al alloys [28-37]. However, very limited studies have been reported for the friction stir welding of similar AZ31B-H24 Mg alloy in the lap configuration. Thus, substantial amount of information is still unknown in the open literatures, such as the optimum welding parameters, microstructural evolutions, mechanical properties like tensile and fatigue, thermal profiles, crystallographic texture, residual stress, etc. 
The specific objectives of the present research include the following:

- To evaluate the influence of processing parameters on the microstructure and crystallographic texture in a friction stir welded AZ31B-H24 $\mathrm{Mg}$ alloy in the lap configuration.

- To understand the effect of tool rotational rate and welding speed on the tensile and fatigue properties of a friction stir lap welded (FSLWed) AZ31B-H24 Mg alloy.

- To characterize the residual stress distributions and investigate the effect of the test temperature on the shear tensile properties of AZ31B-H24 Mg alloy lap welds obtained at different tool rotational rates and welding speeds.

\subsection{Structure of the dissertation}

This thesis has been structured as follows: A brief literature survey is presented in Chapter 2 on the fundamental principle of FSW, and some prior studies on the welding of similar lightweight Mg alloy materials. Chapter 3 gives the experimental procedures used in this study. Chapter 4 is on the friction stir lap welding (FSLW) of AZ31B-H24 Mg alloy, aimed to study the effect of the FSLW processing parameters on the weld integrity, microstructure, hardness and fatigue properties of AZ31B-H24 Mg alloy. Chapter 5 is about the effect of tool rotational rate and welding speed on the microstructure, texture and mechanical properties of a friction stir lap welded (FSLWed) AZ31B-H24 Mg alloy. As part of the microstructural analysis, the texture of the FSLWed AZ31B-H24 Mg alloy sheets was studied by pole figure measurements, and the crystallographic orientations of the basal, prismatic, and pyramidal planes are discussed. 
Chapter 6 is aimed at characterizing the residual stress distributions and investigating the effect of the test temperature on the shear tensile properties of FSLWed AZ31B-H24 Mg alloy lap welds obtained at different tool rotational rates and welding speeds. The shear tensile failure behavior of these lap joints is also discussed in terms of the welding conditions and correlated to the main welding defects (i.e. hooking) and the distributions of the residual stresses. Chapter 7 presents summary, contribution and future scope of the relevant work. 


\section{CHAPTER 2}

\section{LITERATURE REVIEW}

\subsection{Introduction}

With increasing demand of magnesium alloys in the automobile and aerospace sectors, and with the welding and joining of magnesium alloys still facing many challenges, the necessity of developing a reliable joining method for magnesium alloys remains vital to enhance their applications. Conventionally arc welding of magnesium alloys has been used mainly to repair structures with defects such as oxide films, cracks and cavities. Magnesium alloys can be joined using a wide range of welding processes, but conventional arc processes have exhibited some disadvantages such as a large heat affected zone, porosity, evaporative loss of the alloying elements and high residual stresses [38]. Friction stir welding (FSW) is one of the alternative methods, which could overcome the above limitations. As a solid-state joining process, it can thus avoid solidification-related defects and generate sound joints. In this section, a very brief literature review is presented to facilitate a concise overview of the FSW for lightweight alloys, and identify the areas where further research is needed. The motivation of this chapter is to provide a review of the published research relevant to the topic of friction stir welding of lightweight alloys, particularly magnesium alloys.

Although there are many investigations on the mechanical properties of magnesium alloys has been done, but only some limited studies on the properties of welded magnesium alloy joints are reported. Quan et al. [39] studied the effects of heat input on microstructure and tensile 
properties of a laser welded AZ31 Mg alloy. Liu and Dong [40] reported the effect of microstructural changes on the tensile properties of a non-autogenous gas tungsten arc welded AZ31 magnesium alloy. Zhu et al. [41] presented the effect of welding parameters on the welding defects and microstructural evolution in $\mathrm{CO} 2$ and diode laser welded AZ31 magnesium alloy. Tensile testing has also been conducted on friction stir welded (FSWed) AZ31, [42-45] FSWed wrought AZ61 [46] and a fine-grained laser welded Mg alloy [47]. Several authors have studied the strain hardening behavior of magnesium alloys with emphasis on the relationship between the grain size strengthening and dislocation strain hardening of the material [45, 48-50]. Chang et al. [51] studied the grain orientation of FSWed AZ31 and found that the tool rotational rate played an important role in the orientation of the basal plane (0002).

With regard to the fatigue properties, to the authors' knowledge, no such work on the behavior of FSLWed Mg alloy assemblies is available in the open literature. For Al alloys, the limited information on the lap welded joints has indicated that the welding defects, such as hooking and the redistribution of the un-welded lap oxide layers [52], can reduce the effective thickness of the top workpiece and orientate the un-welded lap as a pre-crack to a more preferred crack propagation direction, reducing significantly the fatigue properties [17,53,54]. Cao and Jahazi $[16,55]$ studied FSLW of AZ31B-H24 Mg alloy to identify the effect of welding speed and tool rotational rate on lap joint quality and determined a hardness trough in the weldment that diminished slightly at a low tool rotational rate and high welding speed. Yang et al. [56] investigated the effect of tool geometries (i.e., a concave shoulder with a cylindrical-, triangularor pie-shaped pin) and process conditions on the weld quality and static lap shear strength of the AZ31B-H24 Mg alloy where a strong dependence of the lap shear strength on the hook height 
was observed with a joint efficiency of the welds ranging between 68 and $76 \%$ of the tensile strength of base metal.

Furthermore to that it is very important to know during FSW process, severe plastic deformation in the material occurs at the elevated temperatures and preferential orientation or texture evolution is possible in the SZ and TMAZ of the welded joint. Since texture can strongly affect the mechanical properties of a material, the investigation of the crystallographic orientations arising from the FSW process is becoming an emerging research area of interest. The progressive developments in electron backscatter diffraction over the last decade or so have promoted research work on the microtexture of FSWed materials [57-59] A common phenomenon in these studies is the development of different micro-textures in various regions of the weldment. By analyzing X-ray diffraction (XRD) patterns, Park et al. [57] reported that the development of the

texture was due to the basal slip $(0002)<11 \overline{2} 0>$, which was favored over prismatic or pyramidal slip at the room temperature, and the strain rates during plastic deformation.

\subsection{Friction stir welding (FSW) process}

Friction stir welding is a solid-state joining technique [8] which was initially developed to join aluminium alloys such as highly alloyed $2 \mathrm{xxx}$ and $7 \mathrm{xxx}$ series. These alloys are usually considered to be "unweldable" using conventional arc processes because of their strong tendency to cracking and porosity in the fusion zone as well as significant degradation in the mechanical properties after welding. However, FSW can achieve metallic bonding below the material melting point, and thus substantially avoid metallurgical problems associated with the 
solidification process such as porosity and cracking. Sample preparation is less and absence of using shielding gas or consumable filler material. The basic principle of the FSW process is illustrated in Figure 2.1. A non-consumable, rotating tool, composed of a pin with a shoulder, is inserted into the edges of the plates to be joined, which are clamped to prevent the joint faces from being forced apart.

Due to the friction between shoulder the tool and the work-piece, the material is heated to a temperature below its melting point. The material around the pin eventually softens, allowing the tool to traverse along the weld line. The combination of tool rotation and its translation transfers the plasticized material from the front to the back of the pin and to be forged by the tool shoulder contact. The FSW process can achieve 0.8 to $65 \mathrm{~mm}$ thick welds for several materials including aluminium, copper, magnesium, lead, and zinc alloys [60, 61].

\subsubsection{Advantages of FSW process}

The FSW process has several advantages over conventional fusion welding processes as listed below [62-64].

- The process does not require use of consumable filler metal; instead, a tool, usually made of steel, is used for joining the aluminium alloys. The tool can weld up to 1000 meters of aluminum before replacement.

- Hot cracking and porosity defects, usually experienced in fusion welding processes are not associated with FSW process, due to the fact that the material within the stir zone is not melted. Hence, the liquid-to-solid transformation does not occur. 
- The weld produced by the FSW process has good mechanical properties compared with conventional fusion welded alloys. This is attributed to the reduced amount of heat generated during the joining process compared with fusion welding processes. Furthermore, the structure of the weld produced by the FSW process has fine, equiaxed and recrystallized grains.

- The FSW process is environmental friendly, for example it does not produce fumes or spatters and it does not require the use of shielding gas.

- Generally, the welds produced by the FSW process have a good appearance, and, hence, extra weld (capping) is not necessary. Thus, there is no requirement for grinding or machining after welding to remove the excess weld material, fluxes and sparks.

- The process causes less distortion to the component after welding.

- The process can operate in all welding positions (horizontal, vertical etc).

\subsubsection{Disadvantages of FSW process}

- The presence of a hole at the end of the weld from which the probe was withdrawn.

- Large down forces are required with heavy-duty clamping are necessary to hold the plates together.

- Less flexible than manual and arc processes (difficulties with thickness variations and non-linear welds).

- Absence of a filler wire means that the process cannot be easily used for making fillet welds. 
- Often slower welding speed than some fusion welding techniques, although this may be offset if fewer welding passes are required.

- Process economics are generally considered favorable, but specific published data are lacking.

\subsection{Friction stir welding terminology}

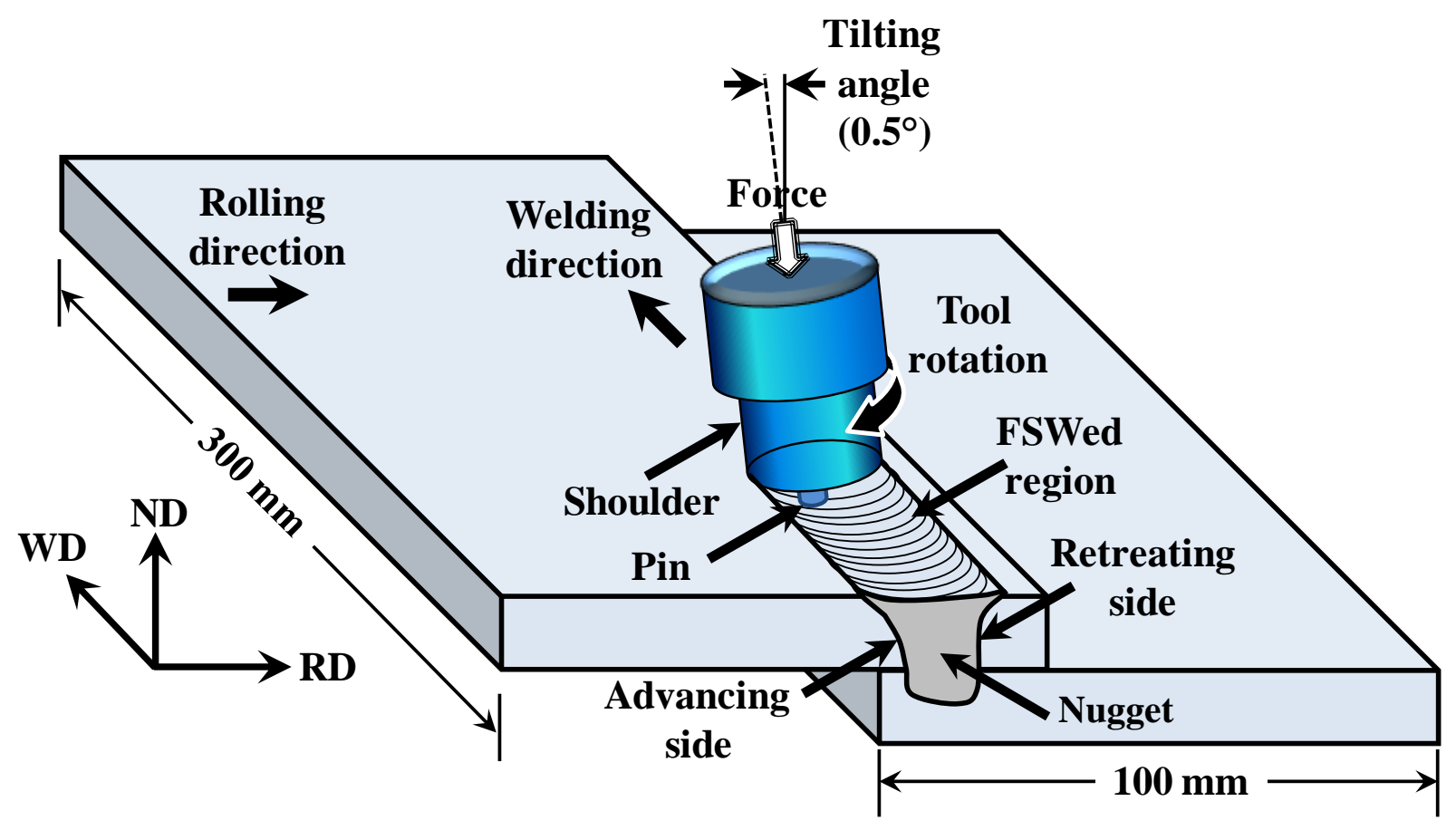

Figure 2.1: FSW schematic diagram for a typical lap weld configuration.

In FSW as shown in Figure 2.1 the tool can be usually defined as having two parts i.e., shoulder and pin. The pin is the most important part of the tool in that it is submerged into the work piece where material is to be welded. The pin provides the stirring and heating of the work piece by both frictional heating and shearing of the work piece. The shoulder is the other main part of the tool which is placed in intimate contact with the work piece and also provides significant 
frictional heat and contributes to the shearing of the work piece. Shoulder provides the necessary pressure to successfully join the welded material. The tool also has a larger shank that extends away from the work piece and allows for the friction stir welding machine to firmly grip and rotate the tool. The tool is typically kept at an angle with respect to the work piece (tilted $0^{\circ}-3^{\circ}$ ) such that the leading edge of the shoulder is slightly above the work piece, and the rear of the shoulder is slightly below the surface of the work piece. The depth of the lowest point of the shoulder below the surface of the welded plate [65] and it can also defined as the contact between the tool shoulder and the work piece [66] is known as plunge depth.

There are a number of terms used in FSW that help identify which part of the weld and tool are being discussed. When talking about the welding direction, this simply refers to the movement toward the un-welded material. The advancing and retreating sides of the weld can be distinct by placing a tangential vector on the tool. The side of the tool in which the vector is in the same direction as that of the welding direction is called the advancing side (AS); the side in which the vector is in the opposite direction is the retreating side (RS). The sheared material is the part of the weld that actually named as weld nugget. This is the zone that the tool affects mechanically and thermally. In some instances there are tools with more complicated designs including those with no shoulder tools (to eliminate the heat input by the shoulder), threads and/or flutes on the pin, non-axis symmetric pin design (Trivex) to increase the stirring. 


\subsection{FSW processing parameters}

In FSW, the feed rate is an important parameter. It is the ratio of welding speed $(V)$ to tool rotational speed $(\omega)$. The direction of the tool is defined using the terminology clockwise and anti-clockwise by looking down the tool towards the work-piece surface. The forces present in FSW are also an important parameter for the process. The force parallel with the axis of tool rotation is defined as the "down force" or forging force. The force acting in parallel with the welding direction is known as the "traversing force".

\subsubsection{Tool rotational rate and welding speed}

Several studies have been undertaken to investigate the effect of welding speed and tool rotational rate on the weldability of magnesium alloys. These two parameters are critical for generating sound welds since they directly influence the heat input and the flow of plasticized material. The heat input per unit length can be expressed by:

$$
\text { Heat input }=\mathrm{Q} / \mathrm{V}
$$

Where $\mathrm{Q}$ is the heat generated by friction and shear, and V is the welding speed. The heat generated by friction increases with increasing tool rotational rate, but not in a monotonic way since the coefficient of friction at the interface also varies with tool rotational rate. Therefore, increasing tool rotational rate or decreasing welding speed induces a higher temperature and heat input. This observation is consistent with all the studies carried out previously [67, 68]. 
M. Guerra et al. [69] reported that, for a constant welding speed, a low tool rotational rate leads to formation of inner voids since the frictional heat is not sufficient to promote material flow. These defects disappeared with increasing the tool rotational rate, but at very high tool rotational rates, inner voids, lack of bonding and surface cracks initiated due to excessive expulsion of the material were created [69]. Yang et al. [70] observed that a high welding speed could provide controlled dynamic recrystallization leading to a fine grained structure.

Gharacheh et al. [71] used $\omega / \mathrm{v}$ ratio as a processing parameter, and observed that increasing the ratio led to an increase in the heat input, an improved material flow and a wider and a deeper weld nugget. The hardness increased with increasing welding speed. Increasing welding speed over a critical value was observed to decrease the ultimate tensile strength while the yield strength was kept constant. Gharacheh et al. [71] also used the $\omega / \mathrm{v}$ ratio to study the influence of processing parameters on the mechanical properties. They observed that increasing the $\omega / \mathrm{v}$ ratio resulted in a decrease in the yield strength (YS), ultimate tensile strength (UTS), and elongation. Increasing the tool rotational rate resulted in an increase in the tensile strength $[72,73]$.

In the case of FSW of magnesium alloys, recent studies reported that the quality of the weld is highly sensitive to the tool rotational rate and the traversing speed [74-81]. Nakata et al. [74] reported that square butt FSW was conducted successfully using a narrow range of FSW parameters, i.e., high tool rotational rates and low traversing speeds. Higher tool traversing speeds and lower rotational rates than the optimum parameters caused formation of inner voids due to lack of bonding. Successful FSW of magnesium alloys has been reported in literature using of 800-1600 rpm tool rotational rates and 50-500 mm/min of welding speeds [74-81]. 


\subsubsection{Forge pressure}

Zhang et al. [82] studied the influence of welding pressure on AZ31 magnesium alloy at the same welding speed $(\mathrm{v}=200 \mathrm{~mm} / \mathrm{min}, \omega=1000 \mathrm{rpm})$. The welding pressure was observed to affect the temperature produced by friction. Increasing the welding pressure produced sound welds, while at low pressure pores were observed.

\subsubsection{Tilt angle}

A suitable tilt angle of the tool must be selected to ensure optimum efficiency of the tool. It mainly depends on the shoulder geometry. It is usually set up to $3^{\circ}$ for a plain shoulder $[67,83]$, and varied to $1.5^{\circ}$ for a concave shoulder and between 0 and $1^{\circ}$ for a scroll shoulder [84].

\subsubsection{Tool plunge depth}

The tool plunge depth has to be controlled, mainly for any tool shoulders. If it is too deep, a large amount of flash is produced, leading to local thinning of the welded plates because the shoulder penetrates through the material. When the plunge depth is too shallow, there is no contact between the shoulder and the work piece surface, which prevents complete stirring and induces surface groove formation. 


\subsubsection{Preheating or cooling}

It could be necessary to preheat materials with high melting points or thermal conductivities, prior to FSW, since the heat produced by this process may not be sufficient for high melting point materials such as steel and titanium or high conductivity such as copper. Cooling can also be used to prevent grain growth and precipitate dissolution for the welding materials of low melting point materials such as aluminium and magnesium or low conductivity materials.

\subsection{Microstructure in friction stir welds}

Threadgill et al. [61] studied the friction stir weld microstructure in different materials, including 2xxx, 5xxx, 6xxx and 7xxx and cast aluminium alloys, titanium alloys, ferritic steels, pure copper, magnesium alloys and pure zinc. FSW processed alloys possess a distinct variation in the alloy microstructure in various regions, which are accordingly termed the weld nugget, thermomechanically affected zone (TMAZ), heat affected zone (HAZ) and the parent metal as shown in Figure 2.2. Similar to FSW of aluminium alloys, these zones are also formed in FSW of magnesium alloys $[74,78,79]$.

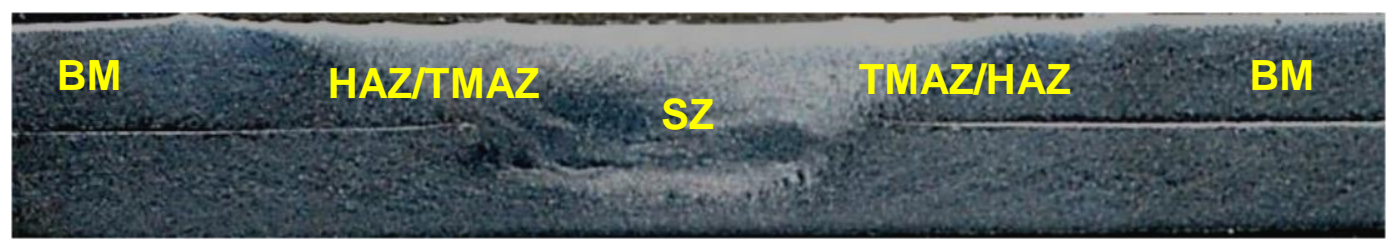

Figure 2.2: Cross section of a FSLWed AZ31B-H24 Mg alloy indicating the 'welding zones' of FSW [74, 78, 79]. 


\subsubsection{Weld zone}

The weld zone or nugget is characterized by a fine and equiaxed structure for aluminium alloys resulting from the effect of dynamic recrystallization that takes place in this zone, which is further characterized by formation of circular rings, also known as an onion ring structure. Several theories are suggested for the formation of onion rings, namely variation in second phase particle-rich bands, grain sizes and variations in texture, etc. The hardness in the nugget is usually higher than that of the heat affected zone $[85,86]$.

The weld nugget zone in the FSW of magnesium alloys is with a basin or elliptical shape, characterized by fine recrystallized grains. However, Lee et al. [77] reported that the weld nugget can be divided into two zones, zone I, located on the upper side of the weld nugget showed partially recrystallized, with deformation layers throughout the grains and zone II, showing full recrystallization with no deformation layers such as twins, etc, for the welding of AZ91D and hot-rolled AZ31B-H24.

Generally, FSW resulted in generation of fine recrystallized grains in the weld nugget in AZ91D magnesium alloys $[74,78,79]$. In as-cast magnesium alloys, the coarse $\alpha-\mathrm{Mg}$ phase and $\beta$ $\mathrm{Al}_{12} \mathrm{Mg}_{17}$ second phase disappeared after FSW [74-78]. Lee et al. [78] and Park et al. [79] reported that the grain size in the weld nugget became larger with increase in the tool rotational rate and lower traversing speed due to increasing heat input which promoted growth in recrystallized grains. 


\subsubsection{Thermomechanically affected zone (TMAZ)}

TMAZ is located on the advancing and retreating sides of the weld nugget. The microstructure is significantly deformed and rotated due to mechanical shearing and thermal heating. On the advancing side, TMAZ is characterized by the presence of material flow on the upper surface of the weld. This material flow consists of material that is dragged by the shoulder from the retreating side of the weld around the rear of the tool and deposited on the advancing side [85].

\subsubsection{Heat affected zone (HAZ)}

HAZ is a common weld zone that is present in many welding processes. It is clearly seen in the fusion welds than in the friction welds due to the higher heat implemented in fusion welding compared with that of the FSW process. The HAZ in FSW is not subjected to the mechanical deformation during welding, but it undergoes a thermal cycling. The temperature gradient in HAZ is lower than that in TMAZ and thus has a reduced effect on the microstructure and the mechanical properties compared with the fusion welding. Usually, in heat treatable aluminium alloys, the HAZ exhibits a reduction in hardness, which is attributed to the coarsening of dominant constituent phases $[87,88]$.

\subsection{Different types of weld joint configuration}

The most common weld configurations can be seen in Figure 3. For FSW, the simple geometry of the butt joint (Figure 3a) and lap joint (Figure 3d) make them the most commonly used 
configurations. For the lap joint, the two work pieces to be joined are placed on top of one another (the work pieces could be different thicknesses for this geometry.)

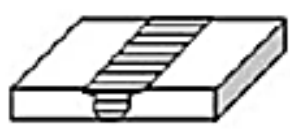

(a)

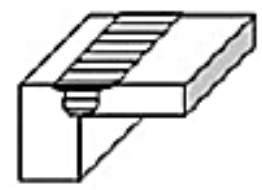

(b)

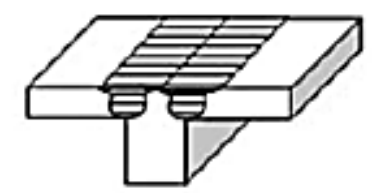

(c)

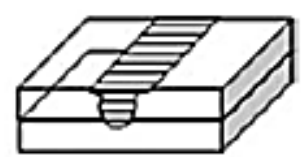

(d)

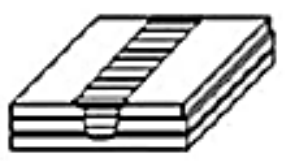

(e)

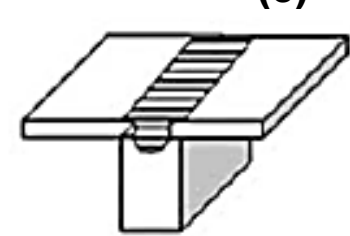

(f)

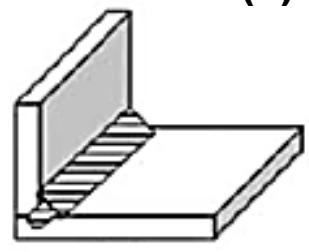

(g)

Figure 2.3: Standard weld configurations. a) square butt, b) edge butt, c) T joint butt, d) lap joint, e) multiple lap joint, f) $\mathrm{T}$ lap joint, and g) fillet joint [26]

In the lap joints the rotating tool is plunged through the top plate (completely) so that some percentage of the length of the pin of the tool plunges into the bottom plate. The tool is then traversed through the material, resulting in the joining of the top plate to the bottom plate along the weld path.

\subsection{Weld tool design}

One of the most important aspects of FSW is the design of the welding tool. The FSW tool affects the heat generation, material flow, power input, and weld quality. In the basic form, the shoulder provides the heating and restrains the material from leaving the weld zone, while both the pin and the shoulder contribute to the flow, or stirring of the material. The design of the tool can range from a smooth cylindrical pin with a flat shoulder to threads, flutes, flats, scrolls, etc., 
appearing on both the pin and shoulder. The pin can also have an asymmetrical shape. Tool design is driven by the application, such as reduced wear, reduced force, increased stirring, increased heating, etc. Table 2.1 gives some popular tool designs and their applications.

Table 2.1: Various tool designs from The Welding Institute [89].

\begin{tabular}{|c|c|c|c|c|c|c|}
\hline Tool & Cylindrical & Whorl $^{\mathrm{TM}}$ & $\begin{array}{c}\text { MX } \\
\text { triflute }^{\mathrm{TM}}\end{array}$ & $\begin{array}{c}\text { Flared } \\
\text { triflute }^{\mathrm{TM}}\end{array}$ & A-skew ${ }^{\mathrm{TM}}$ & Re-stir ${ }^{\mathrm{TM}}$ \\
\hline Schematics & & & & & & \\
\hline Tool pin shape & $\begin{array}{l}\text { Cylindrical } \\
\text { with threads }\end{array}$ & $\begin{array}{l}\text { Tapered } \\
\text { with threads }\end{array}$ & $\begin{array}{l}\text { Threaded, } \\
\text { tapered with } \\
\text { three flutes }\end{array}$ & $\begin{array}{l}\text { Tri-flute with } \\
\text { flute ends } \\
\text { flared out }\end{array}$ & $\begin{array}{l}\text { Inclined } \\
\text { cylindrical } \\
\text { with threads }\end{array}$ & $\begin{array}{l}\text { Tapered with } \\
\text { threads }\end{array}$ \\
\hline $\begin{array}{l}\text { Ratio of pin volume to } \\
\text { cylindrical pin volume }\end{array}$ & 1 & 0.4 & 0.3 & 0.3 & 1 & 0.4 \\
\hline $\begin{array}{l}\text { Swept volume to pin } \\
\text { volume ratio }\end{array}$ & 1.1 & 1.8 & 2.6 & 2.6 & $\begin{array}{l}\text { depends on } \\
\text { pin angle }\end{array}$ & 1.8 \\
\hline Rotary reversal & No & No & No & No & No & Yes \\
\hline Application & $\begin{array}{l}\text { Butt } \\
\text { welding; } \\
\text { fails in lap } \\
\text { welding }\end{array}$ & $\begin{array}{l}\text { Butt welding } \\
\text { with lower } \\
\text { welding } \\
\text { torque }\end{array}$ & $\begin{array}{l}\text { Butt welding } \\
\text { with further } \\
\text { lower } \\
\text { welding } \\
\text { torque }\end{array}$ & $\begin{array}{l}\text { Lap welding } \\
\text { with lower } \\
\text { thinning of } \\
\text { upper plate }\end{array}$ & $\begin{array}{l}\text { Lap welding } \\
\text { with lower } \\
\text { thinning of } \\
\text { upper plate }\end{array}$ & $\begin{array}{l}\text { When } \\
\text { minimum } \\
\text { asymmetry } \\
\text { in weld } \\
\text { property is } \\
\text { desired }\end{array}$ \\
\hline
\end{tabular}

\subsection{Weld defects in FSW}

Weld quality inspection is aimed to detect imperfections, flaws and defects. A defect is defined as a flaw of prescribed shape, size, orientation, location or properties as to be rejected. Volumetric flaws arise from a lack of material in friction stir welds. This defect is often referred to as porosity, but since the lack of material is not attributed to the formation of gas bubbles in the friction stir welds. Therefore, porosity is a misnomer, and the term void is preferred. The 
void can be described as being buried, surface breaking, continuous (such as a wormhole), etc. Voids are caused by insufficient material flow and can occur in various sizes and locations. Another volumetric flaw is weld flash, occurring along the edges of the weld (most commonly on the retreating side), which results in material being extruded at the top of the weld region rather than remaining within the weld.

The appearance of excessive flash on a weld can be an indication of the formation of a void or worm hole. Weld line flaws occur along the once planar interface between the two joined pieces. The appearance of sections of the joint line within the welded region is referred to as joint line remnant. The most serious type of this flaw occurs at the weld root. Flaws in the weld root can result from inadequate probe length, poor control of position/force, variations in work piece thickness, and local cooling. Weld imperfections, flaws, and defects can generally be eliminated (or at least significantly reduced) by insuring adequate flow, with proper processing parameters for the material being welded, and tool geometry.

\subsubsection{Voids}

This type of defect is generated within the weld if a high traversing speed and slow rotational rate $[90,91]$, inadequate welding pressure [92], as well as non-adequate joint gap [92, 93] arise. The use of a small shoulder also leads to the lack of material consolidation. Void formation is usually observed on the advancing side of the weld [82]. If the welding pressure is inadequate, the weld receives insufficient forging action from the tool shoulder to achieve full consolidation [92]. During FSW at high traversing speeds and slow tool rotational rates, the material receives 
less work per unit of weld length, i.e. fewer tool rotations per mm. Under such conditions, the plasticized material may not reach a sufficiently high temperature [91].

\subsubsection{Joint line remnants}

The friction stir welds may contain discontinuities, which form as a result of improper material deformation due to absence of the sufficient pressure required to deform the material. The result of improper dispersion of the oxides that comes from the component surface due to poor surface cleaning, prior to joining, leads to improper bonding [94]. This discontinuity is usually formed at either the root of the weld and/or at the interface of the material to be joined. Joint line remnants, also referred to as kissing bond, lazy S, zigzag line can be easily detected during metallographic examination, destructive testing using bend test and/or in severe conditions, and even can be observed in the weld root by visual examinations.

Joint line remnant defect can also form as a result of oxide accumulation within the weld line interface. Metallographic examination has revealed semi-continuous oxide particles distributed around the original joint-line. The extent of the oxide particles determines the severity of this imperfection and the effectiveness on the structural integrity [92, 95, 96]. Using high welding speed and a large shoulder diameter, as well as improper tool alignment with the joint line, can lead to formation of such defects. Proper control of the welding parameters and removal of the oxides from the surface by machining, prior to welding can eliminate such flaws. 


\subsubsection{Lack of penetration}

The use of a short, bad profiled or a damaged probe, incorrect plunge depth, poor joint alignment or a variation in thickness of the work pieces may lead to formation of joint line features called root flaws also referred as the lack of penetration. In the butt welds, the most serious joint line flaws are usually those located at the weld root. The correct depth of penetration of the tool is essential to ensure that mixing occurs over the full plate thickness. Lack of precision in any of the above discussed parameters leads to the root flaw formation, indicating lack of bonding [97].

\subsection{Material properties and characteristics of an AZ31B H24 Mg alloy}

Magnesium is the sixth most abundant element in the earth's crust (about $2 \%$ by mass) and the ninth most abundant in the Universe [98]. By appearance, $\mathrm{Mg}$ is a silver/white metal and is typically coated with a thin oxide layer which reduces the metals reactivity giving it a dull and darkened appearance. The oxide layer also prevents corrosion, though $\mathrm{Mg}$ is readily corroded by chlorides and sulfates. The chemical composition of AZ31B-H24 Mg alloy can be seen in Table 2.2. The mechanical properties can be seen in Table 2.3.

Table 2.2: Chemical composition of AZ31B-H24 Mg alloy [99].

\begin{tabular}{|c|c|c|c|c|c|c|c|c|}
\hline Material & \%Al & \% Cu & \% Fe & \% Mn & \% Ni & \% Si & \%Zn & \% Mg \\
\hline AZ31B & $2.5-3.5$ & 0.05 Max & 0.005 & 0.2 Min & 0.005 Max & 0.1 & $0.6-1.4$ & Balance \\
\hline
\end{tabular}


Table 2.3: Material properties of AZ31B-H24 Mg alloy [100].

\begin{tabular}{|c|c|c|c|c|c|}
\hline Material & Density & $\begin{array}{c}\text { Tensile } \\
\text { Strength }\end{array}$ & $\begin{array}{c}\text { Yield } \\
\text { Strength }\end{array}$ & $\begin{array}{c}\text { Elastic } \\
\text { Modulus }\end{array}$ & $\begin{array}{c}\text { Poisson's } \\
\text { Ratio }\end{array}$ \\
\hline $\mathrm{AZ} 31 \mathrm{~B}$ & $1.77 \mathrm{Kg} / \mathrm{m}^{3}$ & $260 \mathrm{MPa}$ & $200 \mathrm{MPa}$ & $44.8 \mathrm{GPa}$ & 0.35 \\
\hline
\end{tabular}

$\mathrm{Mg}$ is also a highly reactive metal, reacting with water at room temperature. Placing $\mathrm{Mg}$ in water at room temperature will result in the formation of hydrogen bubbles on its. $\mathrm{Mg}$ is also highly flammable when it is powdered or shaved into thin strips (such as flash resulting from a weld). Once ignited, $\mathrm{Mg}$ can continue to burn in an oxygen environment, a nitrogen environment, and in water. $\mathrm{Mg}$ is difficult to ignite in a bulk state. Special considerations for safety should be taken when working with and around $\mathrm{Mg}$. AZ31B Mg is said to have good machinability. Given the proper tooling geometry $\mathrm{Mg}$ can be cut quickly, machined to a good finish, and machined with less power than needed for aluminum or steel. The tool geometry plays an important role in chip formation and flow, heat generation, and material build up on the tool. Proper geometry can reduce the amount of wear on the tool and allow for higher feed rates. The tool should always be kept sharp when cutting/drilling because dull tools can result in excessive heat buildup, problems with dimensional tolerances, and sparking along the tools edge. The power required to machine magnesium is $56 \%$ less than the power required to machine aluminum. This alloy is also suitable for welding using conventional welding techniques (gas shielded arc) [101]. The melting point of $\mathrm{Mg}$ is $650^{\circ} \mathrm{C}$ [102]. The $\mathrm{Mg}$ alloy used for this research (AZ31B H24) has a slightly lower melting point of $630^{\circ} \mathrm{C}$. As the temperature of the metal rises the material undergoes a linear decrease in density. Using the experiments of Mc Gonigal et al. [103] this linear change in the solid state $\left(\rho(T)=-2.05 \mathrm{e}^{-4} \mathrm{~T}+1.77\right)$ has been calculated and reported in Table 2.4. 
Table 2.4: Temperature dependent density of a pure Mg.

\begin{tabular}{|c|c|}
\hline $\mathbf{T}\left({ }^{\circ} \mathbf{C}\right)$ & Density $\left(\mathbf{g} / \mathbf{c m}^{3}\right)$ \\
\hline 25 & 1.76 \\
\hline 50 & 1.76 \\
\hline 100 & 1.75 \\
\hline 150 & 1.74 \\
\hline 200 & 1.73 \\
\hline 250 & 1.72 \\
\hline 300 & 1.71 \\
\hline 350 & 1.70 \\
\hline 400 & 1.69 \\
\hline 450 & 1.68 \\
\hline 500 & 1.67 \\
\hline 550 & 1.66 \\
\hline 600 & 1.65 \\
\hline 650 & 1.64 \\
\hline
\end{tabular}

\subsection{Applications of Mg AZ31B-H24}

AZ31B in a sheet or plate has good applications in medium strength situations at temperatures at or below $300^{\circ} \mathrm{F}$. Since the alloy is non-magnetic, it also finds application in the electronic industry as electromagnetic interference and radio-frequency interference shielding. $\mathrm{Mg}$ is also the third most commonly used structural metal (following steel and aluminum). High grade car wheels made from Mg alloy are called "MAG Wheels" which are significantly lighter than their steel or aluminum counterparts. Chevrolet and Mercedes-Benz made race cars in the 1950's with 
$\mathrm{Mg}$ alloy body panels which resulted in very light (and faster) automobiles. Porsche made the frame of their 917/053 automobile with a Mg alloy which won the 1971 Le Mans and still holds the absolute distance record for this event. Volkswagen and Porsche both used $\mathrm{Mg}$ to make engine components including the engine block. More recently $\mathrm{BMW}$ used $\mathrm{Mg}$ in the engine blocks for their 1, 3, 5, 6, 7, Z4, Z5, X3 series automobiles in 2006 selling 300,000 units [104]. The 2006 Z06 Corvette engine cradle was made using Mg and in the process advanced the technology for manufacturing automotive parts from $\mathrm{Mg}$ [105]. 


\section{CHAPTER 3}

\section{EXPERIMENTAL DETAILS}

The focus of this chapter is to provide details about the materials, experiments and procedures used in this research. Specifically, details are presented for the equipment and methods that are used for the initial characterization of the FSLWed joints.

\subsection{Experimental materials and procedures.}

The base metal selected in this study was $2 \mathrm{~mm}$ thick AZ31B-H24 Mg alloy in the sheet form with dimensions of $1200 \mathrm{~mm} \times 500 \mathrm{~mm}$ and a nominal composition (wt.\%) of 2.5-3.5 Al, 0.7-1.3 $\mathrm{Zn}, 0.2-1.0 \mathrm{Mn}$ and the balance Mg. Test coupons, $300 \mathrm{~mm}$ (length) $\times 100 \mathrm{~mm}$ (width), were sectioned from the as-received sheets followed by milling of the edges along the length. Surface preparation of the sheets prior to FSLW consisted of cleaning the faying surfaces and the surrounding areas with ethanol, followed by scouring with an abrasive pad to remove the oxides and final cleaning in ethanol. The workpieces were then overlapped with a width of approximately $28 \mathrm{~mm}$, as indicated in Figure 3.1(a), and tightly clamped using spacers within a welding fixture that was secured to the backing anvil/worktable of an ISTIR MTS FSW system. FSLW was conducted in position control mode using a H13 steel tool (46.6 - 50 HRC) that consisted of a scrolled shoulder with a diameter of $19.05 \mathrm{~mm}$ and an adjustable $1 / 4-20$ left-hand threaded pin having a diameter of $6.35 \mathrm{~mm}$, a threaded length of $4.45 \mathrm{~mm}$, a thread spacing of $1.27 \mathrm{~mm}$ and a pitch of $0.8 \mathrm{thread} / \mathrm{mm}$. The tool-to-workpiece angle was maintained at $0.5^{\circ}$ with a shoulder heel plunge depth (the portion of the shoulder under the top surface of the workpiece) 
of approximately $0.25 \mathrm{~mm}$ for all the welding experiments. The welding direction was perpendicular to the rolling direction of the workpiece (Figure 3.1(b)) and all the joints were FSLWed at a speed of $10 \mathrm{~mm} / \mathrm{s}$ or $20 \mathrm{~mm} / \mathrm{s}$. The tool rotational rates were $1000 \mathrm{rpm}$ and 1500 rpm at a pin length of $2.75 \mathrm{~mm}$. It is noteworthy that relative to the welding and tool rotational directions indicated in Figure 2.1, the welds were manufactured with the retreating side near the edge of the top workpiece, abbreviated as RNE. There were total 44 samples used for both tensile and fatigue tests for this research work, out of that 18 samples were used for tensile shear test (6 samples for room temperature, 6 samples for low temperature and 6 samples for high temperature tensile test) and 26 samples were used for high cycle fatigue test for all three welding conditioned mentioned above. The weld integrity was characterized in terms of the welding defects, microstructure, hardness and fatigue properties. All the processing work was done at National Research Council Canada (NRC).

\subsection{Metallography}

The FSLWed assemblies were sectioned in the direction perpendicular to the welding direction (WD) to examine the microstructures in the weld cross-sections. The cold mounted samples were manually ground with $\mathrm{SiC}$ papers up to a grit of \#1200 with water as the lubricant and then polished using 6, 3 and $1 \mu \mathrm{m}$ diamond paste followed by the 0.05 MASTERPREP solutions. The polishing lubricant for the diamond paste was a mixture of rust inhibiting solution and distilled water (10\% solution by volume). Due to the reactive nature of magnesium in the presence of water, ethanol was used as a cleaning agent during the polishing stages. Subsequent etching was 
done using a solution of ethanol $(10 \mathrm{ml})$, picric acid $(5 \mathrm{~g})$, acetic acid $(5 \mathrm{ml})$ and water $(10 \mathrm{ml})$ to reveal the grain structure.

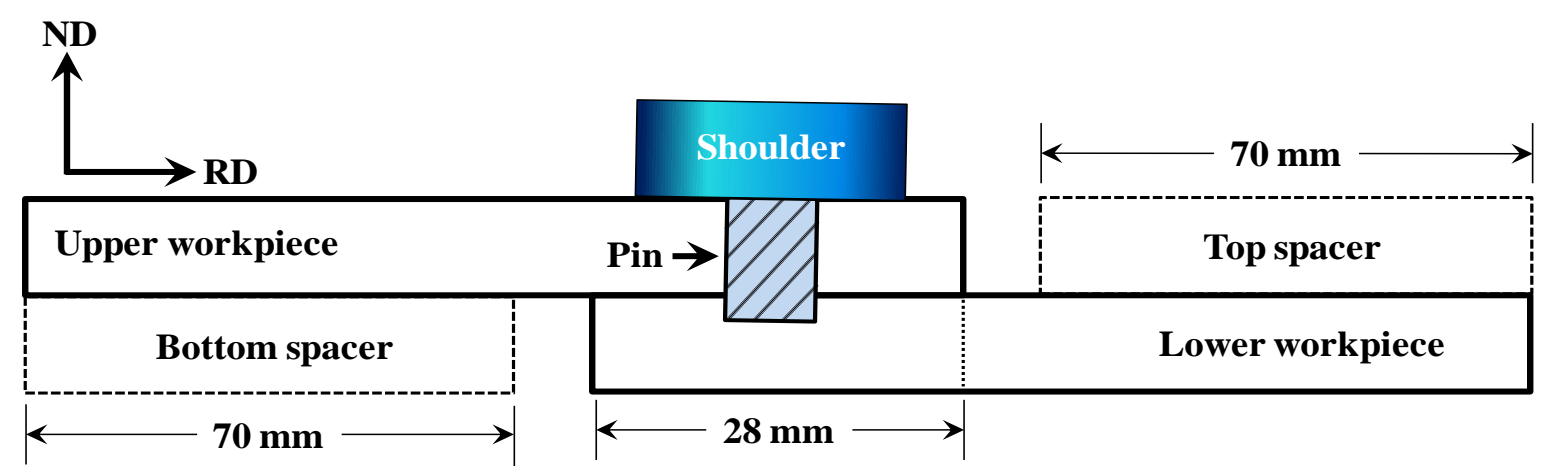

(a)

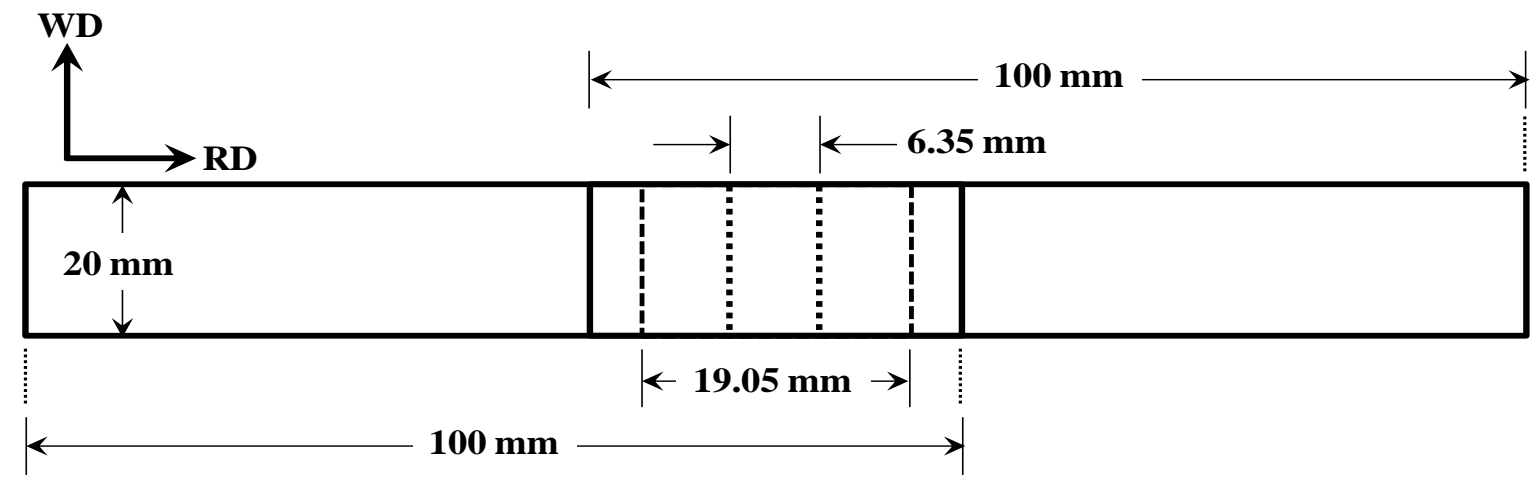

(b)

Figure 3.1: Schematic diagrams of the experimental setup showing (a) the side view of the overlapped $\mathrm{Mg} / \mathrm{Mg}$ joint, (b) the top view of the welded coupon.

\subsection{Quantitative Image Analysis}

Microscopic images were taken using an optical microscope (OM) and JSM-6380LV SEM as shown in Figure 3.2. Image analysis was performed using routine Clemex software to obtain the 
grain size. The Clemex image analysis system was composed of Clemex CMT software adaptable to ASTM standards, a Nikon EPIPHOT 200 optical microscope (10x eye piece, five different object lenses with magnifications of $5 \times, 10 \times, 20 \times, 40 \times$, and 100×), a high-resolution digital camera, and a high performance computer to carry out the detailed analysis. Five images were taken at the center of the weld to calculate the average grain size of each welded sample. Point and line analysis was conducted on the welded joint using Oxford EDS, equipped with SEM, with 3D fractographic analysis.

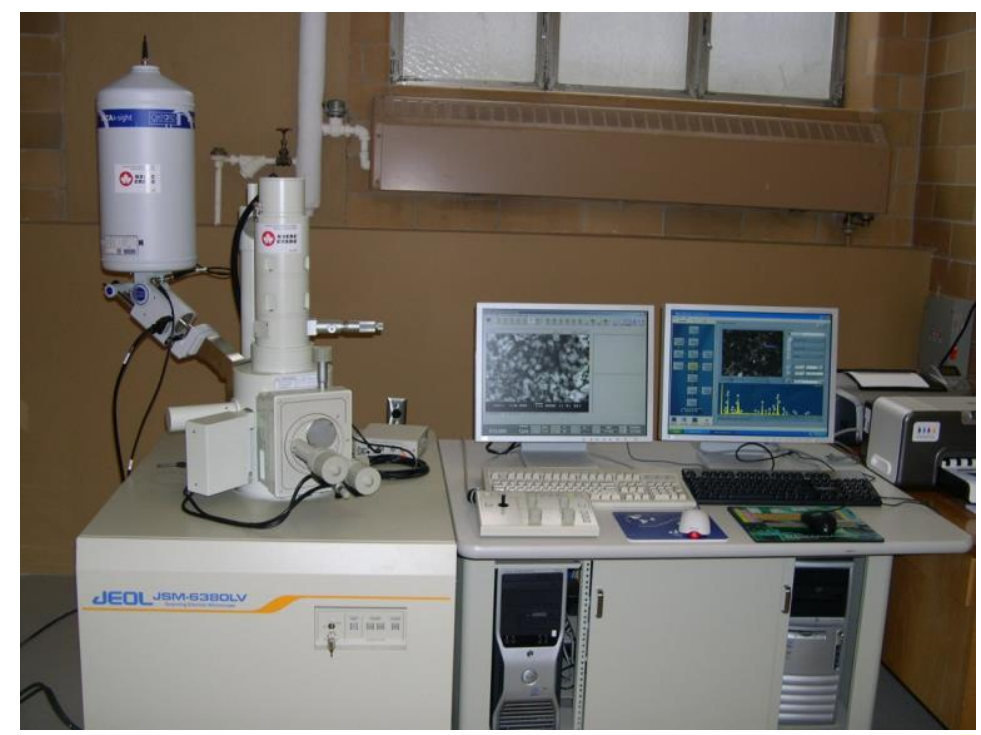

Figure 3.2: The JSM-6380LV SEM system with EDS.

\subsection{X-ray diffraction for phase identification}

X-ray diffraction (XRD) patterns were determined using $\mathrm{CuK}_{\alpha}$ radiation at $45 \mathrm{kV}$ and $40 \mathrm{~mA}$.

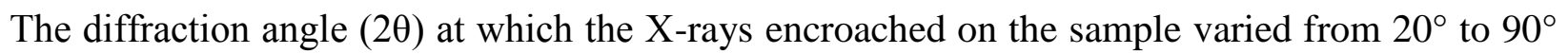
with a step size of $0.05^{\circ}$ and 3 seconds in each step. 


\subsection{Crystallographic texture measurement}

The crystallographic texture distribution on the FSLWed specimens at different weld locations as shown in the Figure 3.3 was measured by a Panalytical X'Pert PRO X-ray diffractometer (XRD) using $\mathrm{CuK}_{\alpha}$ radiation (wavelength $\lambda=0.15406 \mathrm{~nm}$ ) at $45 \mathrm{kV}$ and $40 \mathrm{~mA}$ with a sample tilt angle ranging from 0 to $70^{\circ}$. The samples on the XRD sample stage were mounted in such a way that the RD of the sheet was oriented parallel to the X-axis of the sample stage, with the X-ray incident beam being impinged on the top surface of the lap welds. The results will be represented as (0002), (10ī0), and (10i1) color-scale intensity pole figures. Coordinate axes selected for the pole figures were the rolling direction (RD), transverse direction (TD), and normal direction (ND) of the plate.

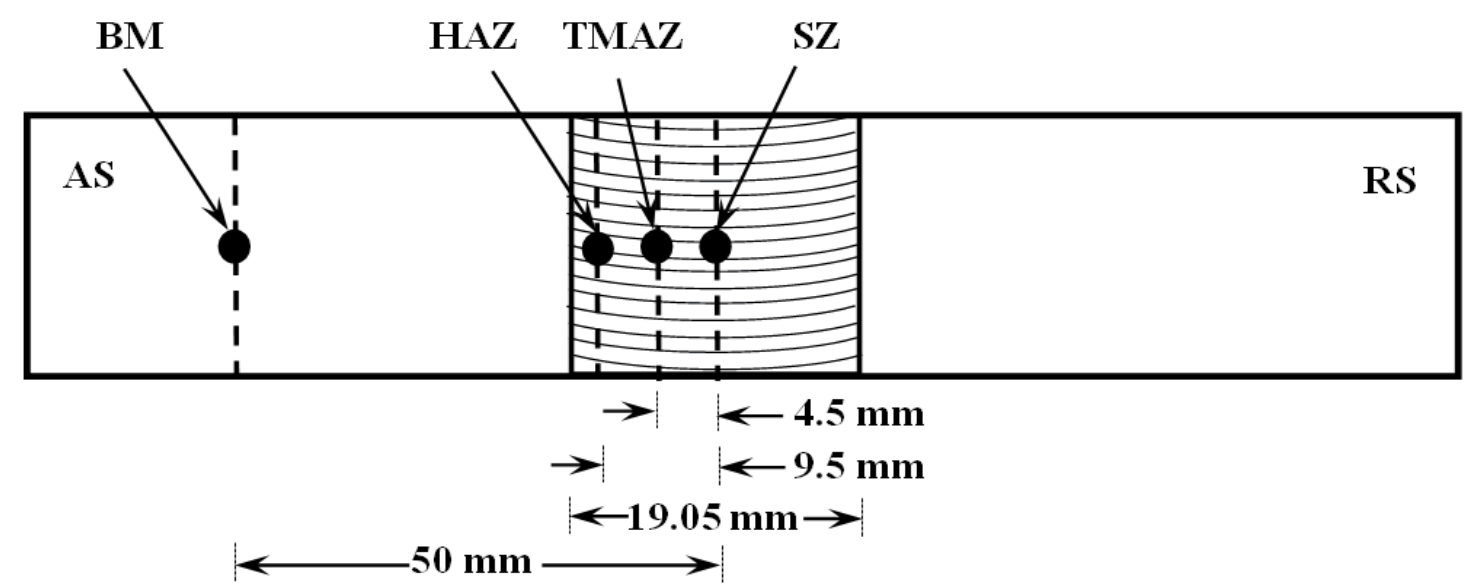

Figure 3.3: Schematic diagram of the texture measurement at different welding zones.

\subsection{Microhardness test}

A computerized Buehler microhardness testing machine as shown in the Figure 3.4 was used for the microindentation hardness tests at the center of the welded joint, using a load of $100 \mathrm{~g}$ for 15 
$\mathrm{s}$ and an indent interval of $0.3 \mathrm{~mm}$ (i.e., at least three times the diagonal length of the indentation to prevent any potential effect of the strain fields caused by adjacent indentations).

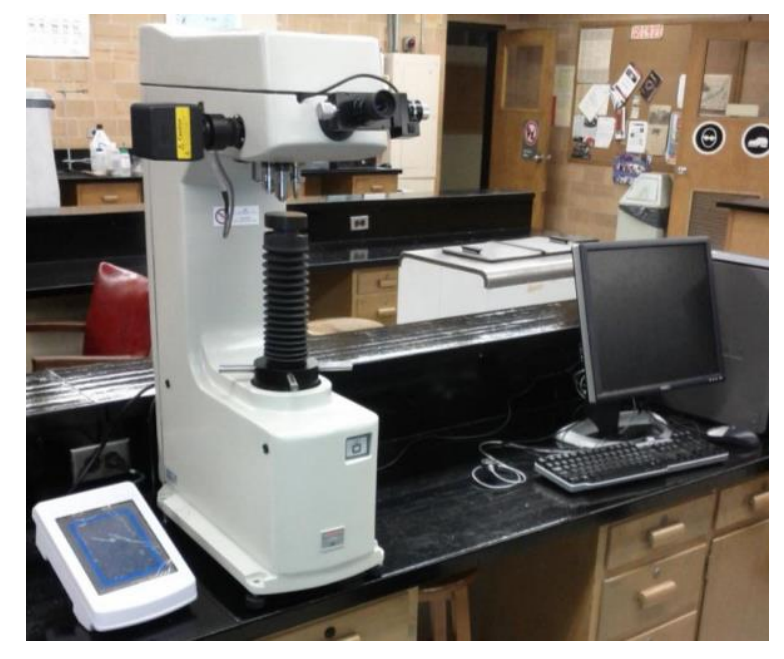

Figure 3.4: A Buehler Micromet-5100 Vickers microhardness tester.

\subsection{Lap shear tensile test}

To evaluate the shear tensile strength of the joints and establish the optimum welding conditions, the tensile shear tests were conducted at $\mathrm{LT}\left(-40^{\circ} \mathrm{C}\right)$, RT $\left(25^{\circ} \mathrm{C}\right)$ and ET $\left(180^{\circ} \mathrm{C}\right)$ to obtain the lap-shear failure load using a fully computerized universal testing machine at a constant crosshead speed of $1 \mathrm{~mm} / \mathrm{min}$. To balance the offset axes of the lap members and minimize bending effects, two spacers having the same thickness as the work-piece (i.e. $2 \mathrm{~mm}$ ) were used during the tensile shear tests.

\subsection{Fatigue Test}

Fatigue tests were performed using a fully computerized Instron 8801 servo-hydraulic testing system under load control. Before fatigue testing, all the lateral edges of the fatigue specimens 
were slightly ground using abrasive papers up to a grit number of 600 , so as to avoid the influence of local surface stress concentration. A load ratio $\mathrm{R}\left(=\mathrm{P}_{\min } / \mathrm{P}_{\max }\right)$ set at 0.2 , a sinusoidal waveform, and a frequency of $50 \mathrm{~Hz}$ were applied during the fatigue tests. Two samples will be tested at each load level chosen. The fracture surfaces of the welded joints after fatigue tests were examined using a JEOL6380LV scanning electron microscope (SEM) equipped with an Oxford energy dispersive X-ray spectroscopy (EDS) and a three-dimensional fractographic imaging and analysis tool.

\subsection{Residual stress}

The residual stress distributions in the FSWed AZ31B-H24 Mg alloy lap joints were measured using a non-destructive X-ray diffraction $(\mathrm{XRD})$ technique. The welds, $300 \mathrm{~mm}$ in length $\times 172$ $\mathrm{mm}$ in width, were then sectioned using an abrasive waterjet micromachining system into smaller samples with dimensions of $100 \mathrm{~mm}$ in length $\times 100 \mathrm{~mm}$ in width, in order to fit into the sample stage of the high-temperature XRD machine. XRD is one of the most widely used residual stress measurement techniques. X-ray stress analysis is derived from two fundamental theories: the theory of elasticity, which defines the relationship between stresses and strains, and X-ray diffraction theory, which give the relationship between the atomic arrangement in a solid and its diffraction pattern. The Bragg law is the basis of stress analysis by X-ray diffraction. Figure 3-5 illustrates the relationship between strain and diffraction angle. The gray spots represent the atomic positions in a strain-free crystal. The light horizontal lines represent the crystal planes in the strain-free crystal. For the strain-free crystal, the Bragg law is given by,

$$
n \lambda=2 d \sin \theta
$$


where $n$ is an integer for a radiation wavelength of $\lambda, d$ is inter planer spacing and $\theta$ is half of a diffraction angle.

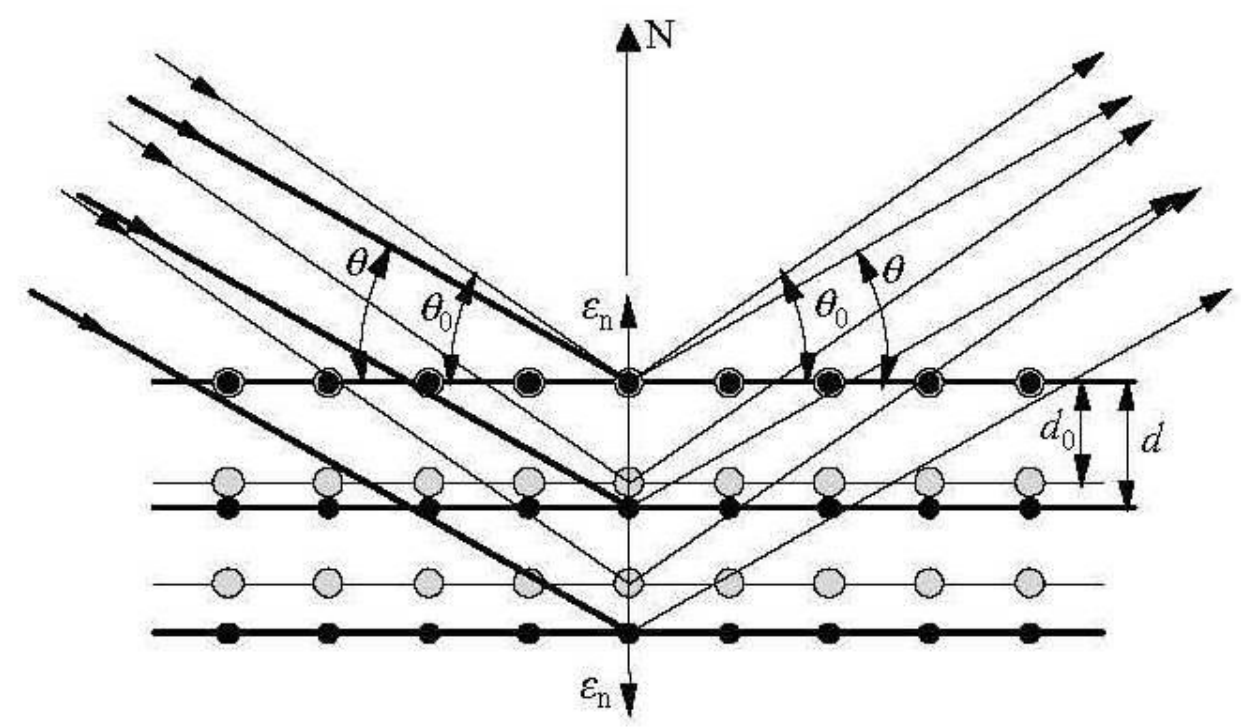

Figure 3.5: Strain measurement based on Bragg's law [106].

It has been shown that there is a clear relationship between the diffraction pattern that is observed when X-rays are diffracted through crystal lattices and the distance between atomic planes (the inter-planar spacing) within the material. By altering the inter-planar spacing different diffraction patterns will be obtained. Changing the wavelength of the X-ray beam will also result in a different diffraction pattern. The inter-planar spacing of a material that is free from strain will produce a characteristic diffraction pattern for that material. When a material is strained, elongations and contractions are produced within the crystal lattice, which change the inter-planar spacing of the $\{h k l\}$ planes. This induces a change in $d$, which in turn causes a shift in the diffraction pattern. By a precise measurement of this shift, the change in the inter-planar spacing can be evaluated and thus the strain within the material can be obtained. To determine 
this, it is important to establish mathematical relationships between the inter-planar spacing and the strain.

With the aim of measure a single acting stress $\sigma_{\phi}$ in a chosen direction, i.e., at an angle $\emptyset$ to $\sigma_{l}$, elasticity theory for an isotropic solid show that the strain along an inclined line is,

$$
\varepsilon_{\phi \psi}=\frac{1+v}{\mathrm{E}} \sigma_{\phi} \sin ^{2} \psi-\frac{v}{\mathrm{E}}\left(\sigma_{1}+\sigma_{2}\right)
$$

where $v$ and $E$ are the Poisson ratio and Young's modulus of the material, $\sigma_{1}$ and $\sigma_{2}$ are principal stresses parallel to sample surface [54]. Eq. (2.4) forms the basis of the $\sin ^{2} \psi$ method. It suggests that a plot of strain $\varepsilon \varnothing_{\psi}$ versus $\sin ^{2} \psi$ yield a straight line whose slope is represented by $\sigma_{\varphi}(1+v) / E$, therefore,

$$
\sigma_{\phi}=\frac{\mathrm{E}}{1+v} m \text {, }
$$

where $\mathrm{m}$ is the slope of $\varepsilon_{\varnothing \psi}$ versus $\sin ^{2} \psi$ curve. This is the basis of stress determination using Xray diffraction. The commonly-used $\sin ^{2} \psi$ method as detailed elsewhere [107] was adopted in the present study for the determination of the surface residual stresses. Residual stress analysis was performed using a Panalytical X'Pert PRO MRD (Panalytical B.V., Almelo, Netherlands) high-resolution X-ray diffractometer. Figure 3.6 shows the positions that corresponded to the residual stress measurements in different regions (i.e. BM, HAZ, TMAZ and SZ as defined at the mid-thickness) on both advancing side (AS) and retreating side (RS) of the welds in which both longitudinal (LD) and transverse (TD) directions are also indicated (welding is along the LD). The residual stress measurements for the BM, HAZ and TMAZ occurred at $35 \mathrm{~mm}, 9.5 \mathrm{~mm}$ and $4.5 \mathrm{~mm}$ from the center of the SZ, respectively. The measured area is $3.5 \mathrm{~mm} \times 10 \mathrm{~mm}$ (i.e., slit width $\times$ mask size). An initial scan was performed with a diffraction angle $2 \theta$ ranging from 10 to 
$150^{\circ}$ to identify the diffraction peaks. The diffraction peak at $2 \theta=105^{\circ}$ was selected for the determination of the residual stresses based on the pre-scan diffraction pattern. The XRD spectra surrounding this peak were scanned from $\psi=+45^{\circ}$ in 7 steps.

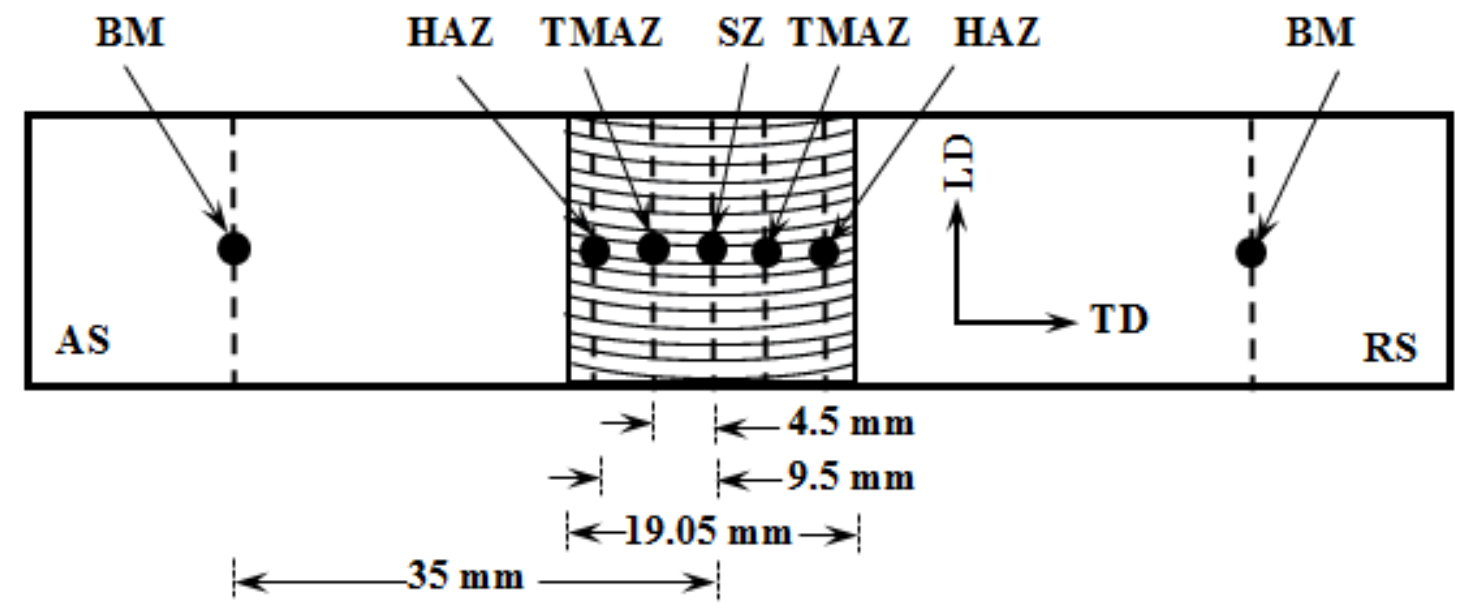

Figure 3.6: Schematic diagrams of the residual stress measurement at different welding zones on both advancing and retreating sides. 


\section{CHAPTER 4}

\section{MICROSTRUCTURE AND FATIGUE PROPERTIES OF A FRICTION STIR LAP WELDED MAGNESIUM ALLOY}

In this investigation, friction stir lap welded (FSLWed) joints of AZ31B-H24 magnesium alloy were characterized in terms of welding defects, microstructural changes, microhardness and fatigue properties at various combinations of tool rotational rates and welding speeds were systematically studied.

\subsection{Welding defects}

Figure 4.1 shows macroscopic overviews of the lap welds obtained at various tool rotational rates and welding speeds with a pin length of $2.75 \mathrm{~mm}$. According to the relationship between the tool rotational direction and welding direction, two sides can be identified: the advancing side (AS) and the retreating side (RS) that correspond to the left- and right-hand sides in Figure 4.1. On both AS and RS, defects such as hooking and kissing bonds were observed. Overall, the hooking defect, which was normally observed at a lower magnification, was most evident at the TMAZ of the AS in the AZ31B-H24 Mg alloy lap welds, where the interface of the workpieces was pulled up into the top workpiece. Also, the hook was inclined upwards towards the weld surface and terminated at the border of the SZ. In the AZ31B-H24 Mg alloy lap welds, the kissing bond defects (to be discussed below) were a result of insufficient mixing at the interface of the workpieces that led to the presence of separated interfaces with entrained oxide layers. 

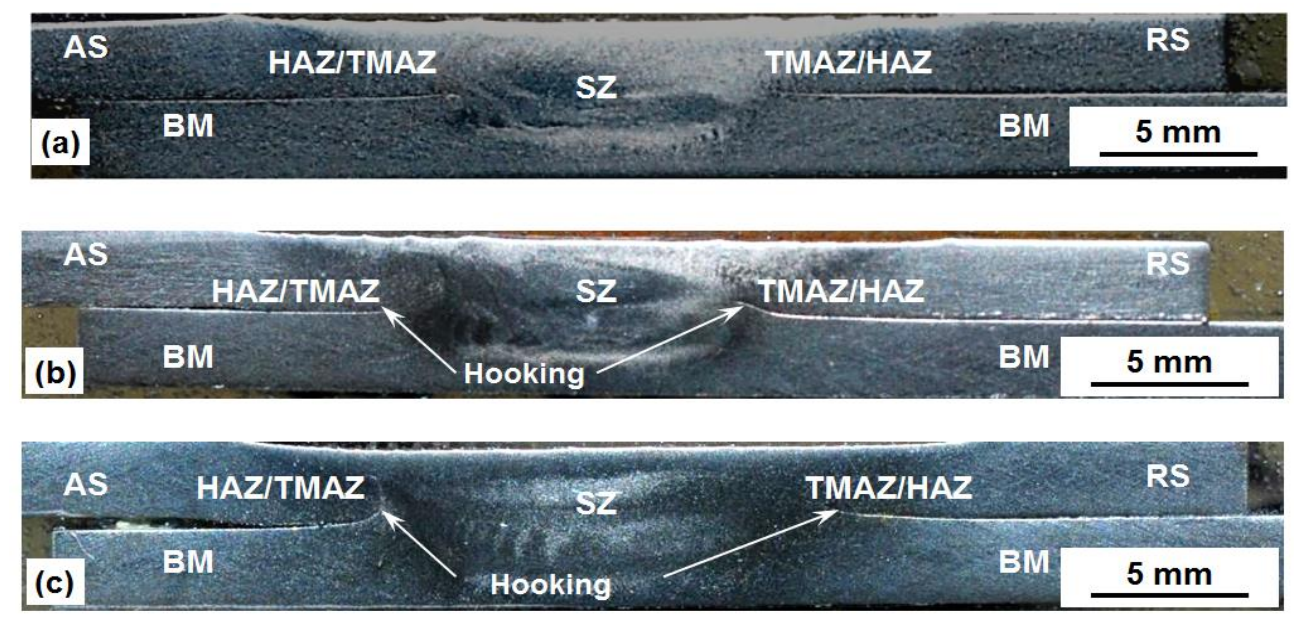

Figure 4.1: Macroscopic images of the lap joints obtained at various combinations of rotational rate and welding speed of (a) $1000 \mathrm{rpm}, 20 \mathrm{~mm} / \mathrm{s}$, (b) $1500 \mathrm{rpm}, 20 \mathrm{~mm} / \mathrm{s}$, and (c) $1500 \mathrm{rpm}, 10$ $\mathrm{mm} / \mathrm{s}$.

It is noteworthy that the kissing bonds have recently been deliberated to be more suitably referred to as the "Original Joint Line with Severe Plastic Deformation (OJLwSPD)" [108]. As the hooking defect causes the local thinning of the effective sheet thickness (EST) for the top or bottom workpiece and subsequently decreases the load-bearing capacity or strength of the joint, understanding the effect of the tool rotational rate and welding speed on the relative size of the hook defects is important. In particular, the tool rotational rate was observed to have a significant influence on the formation of hooking defects, as indicated in Figure 4.2, with a decrease from $1500 \mathrm{rpm}$ to $1000 \mathrm{rpm}$ resulting in a considerable reduction in the hook height from $\sim 1.4 \mathrm{~mm}$ to $\sim 0.14 \mathrm{~mm}$ on the AS. The welding speed was observed to have a secondary effect on the hook size, as illustrated in the SEM images of the hooking defects on the AS and RS of the lap welds depicted in Figure 4.3. In general, the hook height on the AS decreased from $\sim 1.4 \mathrm{~mm}$ to $\sim 1.3$ $\mathrm{mm}$ with increasing welding speed from $10 \mathrm{~mm} / \mathrm{s}$ to $20 \mathrm{~mm} / \mathrm{s}$. A similar result for the FSLWed AZ31 Mg alloy was reported by Yang et al. [56]. 

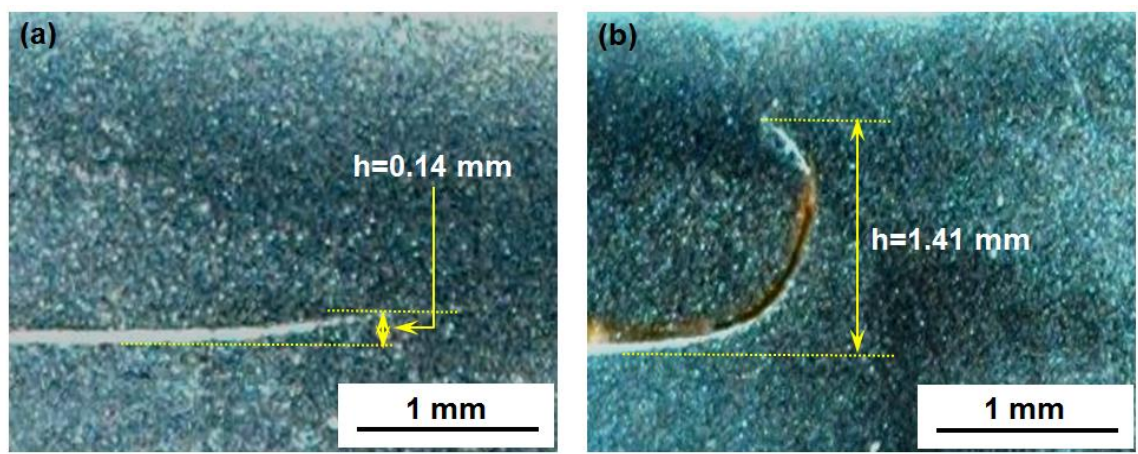

Figure 4.2: Hooking defects in the friction stir lap welds and their relative sizes on the advancing side for the welding conditions of (a) $1000 \mathrm{rpm}$ at $20 \mathrm{~mm} / \mathrm{s}$ and (b) $1500 \mathrm{rpm}$ at 20 $\mathrm{mm} / \mathrm{s}$.

These findings indicate that the material flow in the SZ, near either the AS or RS, influences the characteristics of the hooking defect that appears in the TMAZ, i.e., the region surrounding the SZ, as observed in Figure 4. Specifically, with decreasing tool rotational rate or increasing welding speed, the heat input during FSW is reduced (to be discussed later). Also, within the weldment, severe deformation caused by the passage of the tool results in strain and heat gradients; the TMAZ experiences much lower plastic strain and temperature than the SZ. With due consideration of the results presented in Figures 4.2 and 4.3, the "cold" welding (low heat input) conditions were conducive to much small hooking defects. It should be pointed out that the flow of the plasticized material during FSW is quite complicated, as it is influenced by a variety of factors including tool thread orientation, rotational direction, processing parameters, etc. Based on the analysis detailed in [109], a left-hand threaded pin rotating clockwise would result in a downward flow of the material adjoining the pin surface and mitigate the formation of cavity defects at the bottom. This, however, would be further related to the combination of the rotational rate with the welding speed. 
A disproportionately high rotational rate or slow welding speed would push or drive an excessive amount of plasticized material towards the bottom, which then has to be squeezed out in the upward direction at a small distance from the pin surface, inevitably due to the constant volume process conditions during FSW. That is, the interfaces between the top and bottom workpieces, on both the AS and RS, would extend along the border between the SZ and TMAZ towards the upper tool shoulder. Similar observations that indicated material flow from the bottom into the top workpiece were reported [53]. Increasing the tool rotational rate increases turbulent flow in the SZ and thereby exacerbates the hook size through a greater upward flow of the material in the TMAZ during FSLW. Similarly, decreasing the welding speed allows a more intense stirring action of the pin which promotes material movement upwards. As the welding speed increases, the hooking defects may become progressively smaller, be completely eliminated, or even change their orientations as shown in Figure 4.3(e) and (f) for the AZ31B-H24 Mg alloy lap welds. Depending on the combination of rotational and welding speeds applied, the orientation of the hook on the AS may change significantly (sharply inclined upwards to a slightly downward deflection (Figure 4.3(e)), whilst on the RS, the evolution is relatively gradual and remains inclined upwards. Nonetheless, for each weld condition examined in the present study, the hook on the AS was not observed to interconnect to that from the RS or extend to the outer surface of the top/bottom work-piece.

Compared with the distinguishable hooking defects observed in the TMAZ, the kissing bonds or OJLwSPD defects usually appear as film-like, faint dark lines in the SZ (Figure 4.4). For the welding conditions in the present study, OJLwSPD defects with irregular morphologies, such as 
zigzag lines and wavy patterns, were observed in the SZ of each lap joint examined at a higher magnification and, in some cases, noted to extend throughout the entire SZ width (Figure 4.4).
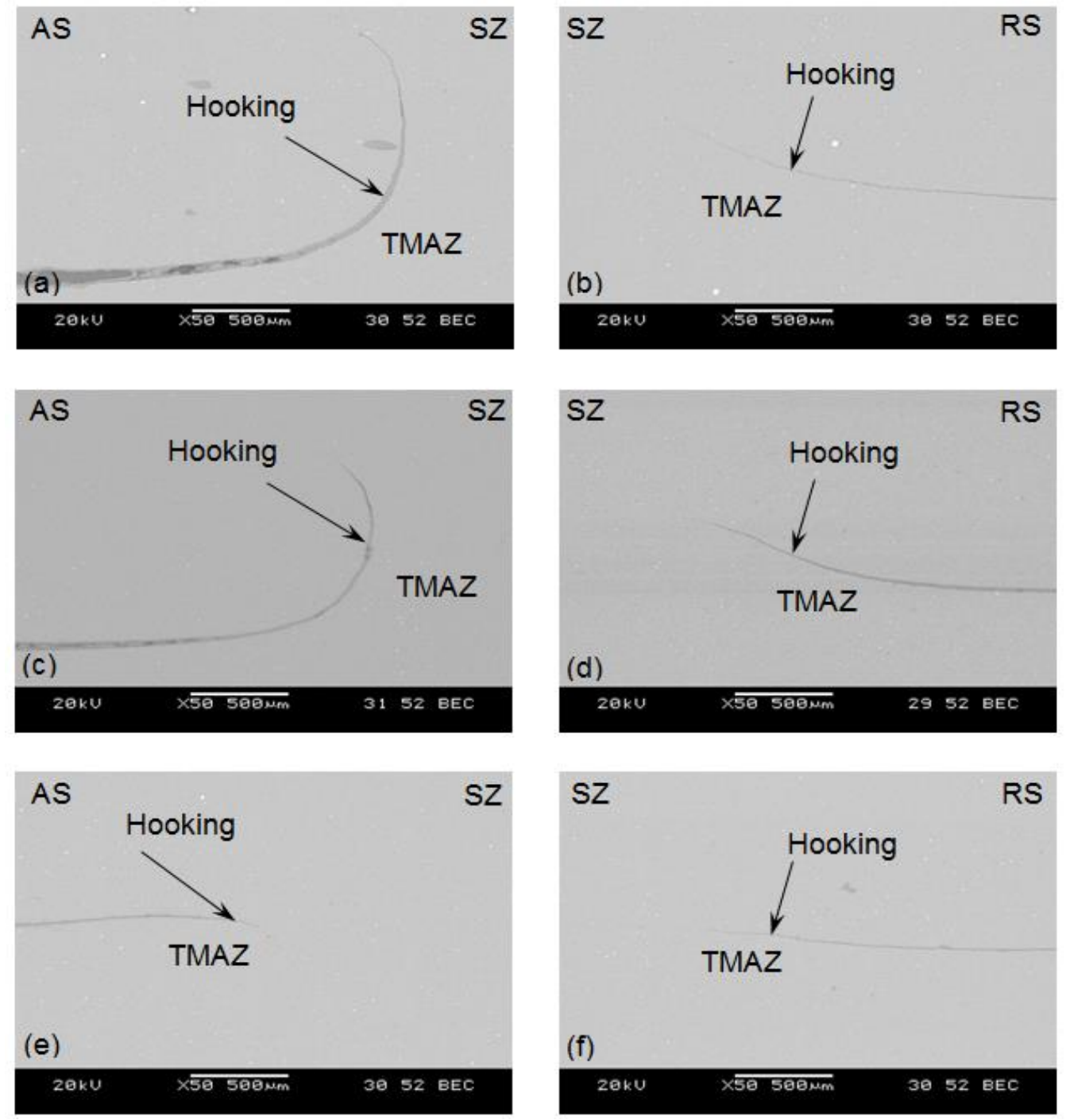

Figure 4.3: Hooking defects observed on the advancing (left) and retreating (right) sides at varying tool rotational rates and welding speeds, namely, (a-b) $1500 \mathrm{rpm}$ and $10 \mathrm{~mm} / \mathrm{s}$, (c-d) $1500 \mathrm{rpm}$ and $20 \mathrm{~mm} / \mathrm{s}$, and (e-f) $1000 \mathrm{rpm}$ and $20 \mathrm{~mm} / \mathrm{s}$.

The recurrent oscillating traces of OJLwSPD, as shown in Figure 4.4(b) and (c), were associated with the formation of oxide bands $[110,111]$. Also, the OJLwSPD defects appearing in the SZ near the SZ/TMAZ interface may be an extension of the hooking defect in the TMAZ. However, 
the OJLwSPD defect width in the SZ was much narrower than that of the hooking defect in the TMAZ.

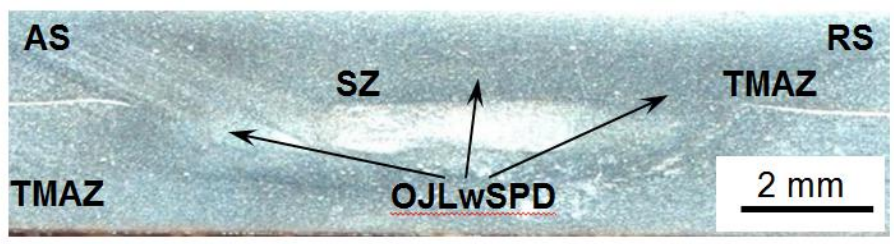

(a)
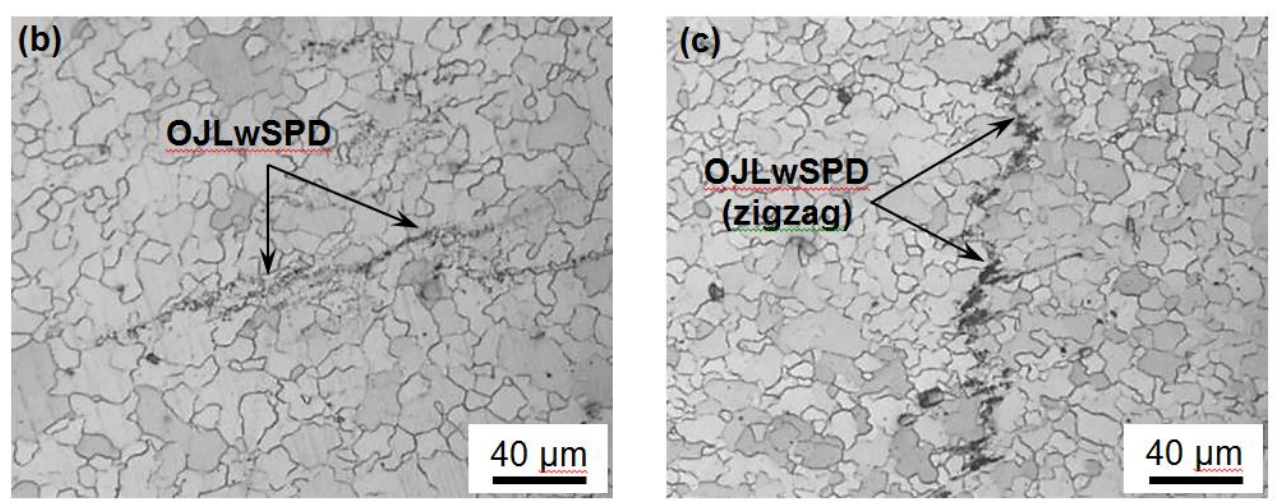

Figure 4.4: (a) Low-magnification OJLwSPD defects present in-between the top and bottom sheets of a weld joined at a welding speed of $20 \mathrm{~mm} / \mathrm{s}$ and rotational rate of $1000 \mathrm{rpm}$ using a pin of $2.75 \mathrm{~mm}$ in length; high-magnification observations of the OJLwSPD defects that occurred at a rotational rate of (b)1000 rpm and (c) $1500 \mathrm{rpm}$.

\subsection{Microstructure}

The thermomechanical conditions during FSLW of AZ31B-H24 Mg alloy resulted in the formation of distinct regions in the weldment, namely, the SZ or weld nugget around the weld centerline, the TMAZ on both sides of the SZ, and the HAZ surrounding the TMAZ and in turn delimited by the BM, as shown in Figure 4.5, where the typical microstructures were observed across a weld made at a welding speed of $20 \mathrm{~mm} / \mathrm{s}$ and a rotational rate of $1000 \mathrm{rpm}$. The asreceived microstructure of the $\mathrm{BM}$ consisted of mainly elongated/deformed grains in conjunction 
with fine equiaxed and recrystallized grains, as shown in Figure 4.5(g). This heterogeneous grain structure and size of the BM may originate from the incomplete dynamic recrystallization (partial annealing) during the warm rolling process as noted in [55]. At a higher resolution, mechanical twinning in the BM was also observed. In the SZ and TMAZ (Figure 4.5(c)-(e)), the severe plastic deformation and the elevated temperature resulted in dynamic recrystallization of the AZ31B-H24 Mg alloy, and the grains became predominately equiaxed in both regions. However, relative to the $\mathrm{BM}$, the grains in the $\mathrm{SZ}$ and TMAZ were larger in size, indicating the concomitant occurrence of grain coarsening under the welding conditions in the present study. The HAZ microstructure lay in-between those of TMAZ and BM. In comparison with the BM, the HAZ contained a greater fraction of equiaxed grains and a slightly coarser grain size due to the dominating effect of frictional heating, which resulted in the partial recrystallization of the elongated/deformed grains and the coarsening of the original equiaxed recrystallized grains in the $\mathrm{BM}$ microstructure in the $\mathrm{H} 24$ temper. This microstructural evolution observed in the different regions of the current friction stir lap welds of AZ31B-H24 Mg alloy is consistent with that appearing in the friction stir butt welds of AZ31B-H24 Mg alloy [111-115].

The effect of the welding speed and tool rotational rate on the microstructure in the SZ is shown in Figure 4.6(b)-(d) relative to the BM structure given in Figure 4.6(a). It is clear that the microstructure in the SZ was significantly different from that of the BM. At a constant welding speed of $20 \mathrm{~mm} / \mathrm{s}$, increasing the tool rotational rate from $1000 \mathrm{rpm}$ to $1500 \mathrm{rpm}$ was observed to increase the average grain size in the SZ from $7.4 \mu \mathrm{m}$ to $8.6 \mu \mathrm{m}$. For the welding speed, a decrease from $20 \mathrm{~mm} / \mathrm{s}$ to $10 \mathrm{~mm} / \mathrm{s}$ at $1500 \mathrm{rpm}$ resulted in a slight increase in the average grain size from $8.6 \mu \mathrm{m}$ to $9.5 \mu \mathrm{m}$. 

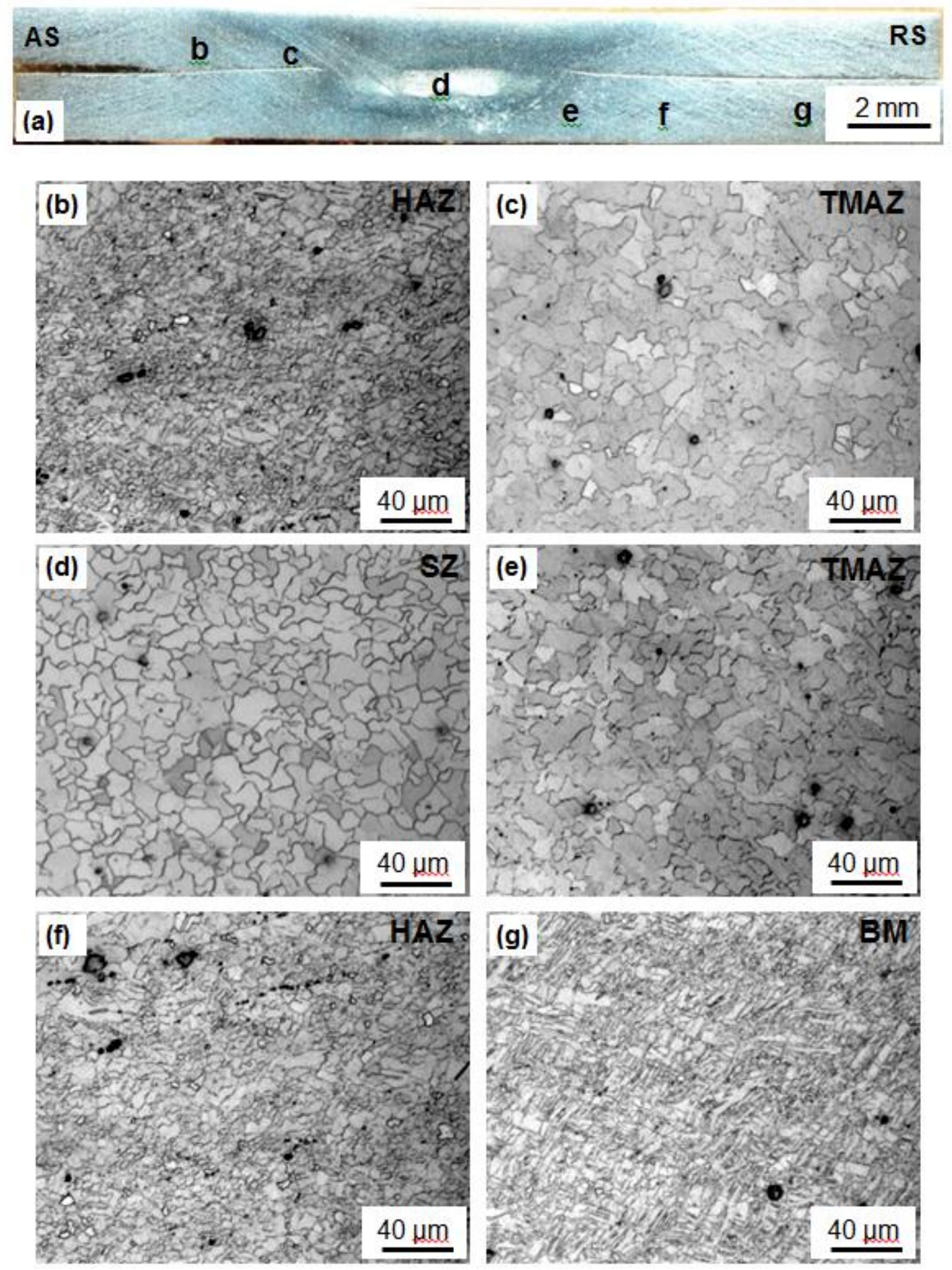

Figure 4.5: (a) Overview of the FSLWed $\mathrm{Mg} / \mathrm{Mg}$ joint obtained at a tool rotational rate of 1000 $\mathrm{rpm}$ and a welding speed of $20 \mathrm{~mm} / \mathrm{s}$ with (b) to (g) showing the microstructures in the different regions as indicated in (a). 

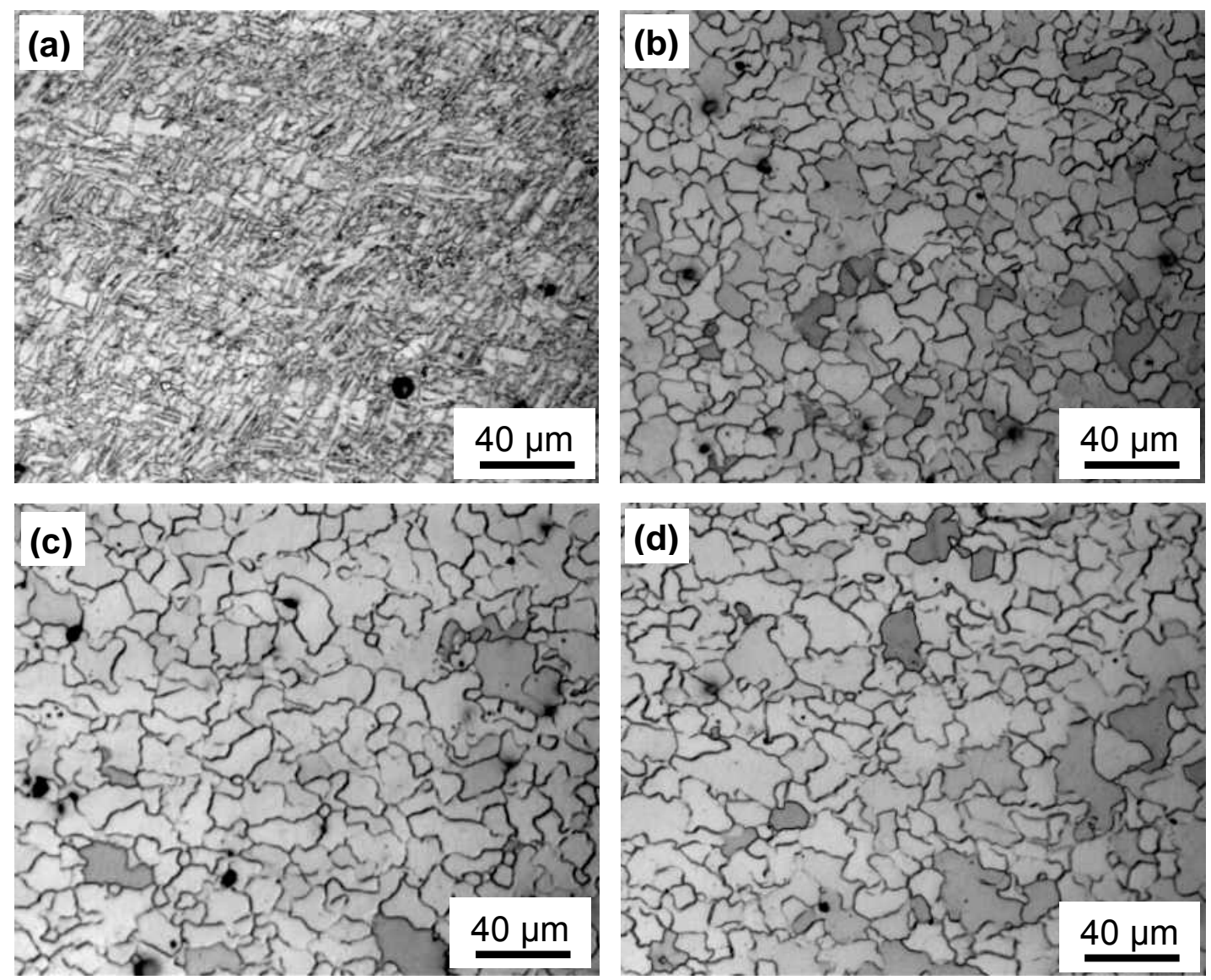

Figure 4.6: Comparison of (a) the BM AZ31-H24Mg alloy microstructure with the typical microstructures in the SZ of FSLWed AZ31-H24 Mg alloy at different tool rotational rates and welding speeds: (b) $1000 \mathrm{rpm}$ and $20 \mathrm{~mm} / \mathrm{s}$, (c) $1500 \mathrm{rpm}$ and $20 \mathrm{~mm} / \mathrm{s}$, and (d) $1500 \mathrm{rpm}$ and 10 $\mathrm{mm} / \mathrm{s}$.

The increase in the average grain size observed with increasing tool rotational rate and decreasing welding speed is a result of the heat input that can be deliberated through the weld pitch (a ratio of the tool welding speed to the tool rotational rate). Specifically, a low weld pitch value of $0.4 \mathrm{~mm} /$ revolution for the combination of $1500 \mathrm{rpm}$ with $10 \mathrm{~mm} / \mathrm{s}$, which represents a "hot" welding condition, would render a coarse grain structure relative to a high weld pitch value of $1.2 \mathrm{~mm} /$ revolution or a "cold" welding condition at $1000 \mathrm{rpm}$ and $20 \mathrm{~mm} / \mathrm{s}$. Alternatively, the 
effect of the welding parameters may be related to the heat input during FSW that has been given by Frigaard et al. [116] as follows,

$$
q=\frac{4}{3} \pi^{2} \mu P \omega R^{3}
$$

where $\mathrm{q}$ is the heat input, $\mu$ is the friction coefficient, $\mathrm{P}$ is the pressure, $\omega$ is the tool rotational rate and $\mathrm{R}$ is the radius of the shoulder. For a moving welding source, the heat input per unit length, Q, has been re-written by Kim et al. [117] based on eq. (4.1) as,

$$
Q \propto \frac{\alpha q}{v}=\frac{4}{3} \pi^{2} \frac{\alpha \mu P \omega R^{3}}{v}
$$

where $\alpha$ is a heat input efficiency, and $\mathrm{v}$ is the welding speed. When $\alpha, \mu$ and $\mathrm{R}$ are assumed to be constant, eq. (4.2) can be simplified as,

$$
Q \propto \frac{P \omega}{v}=P a \propto F a
$$

where a is the ratio of the tool rotational rate to the welding speed (or the inverse of the weld pitch) and $\mathrm{F}$ is the tool plunge-down force. According to eq. (4.3), at a constant welding speed $(\mathrm{v})$, the heat input per unit length $(\mathrm{Q})$ increases linearly with increasing tool rotational rate $(\omega)$. Thus a higher temperature in the SZ is expected at $1500 \mathrm{rpm}$ than at the $1000 \mathrm{rpm}$ condition, which explains the grain coarsening in the microstructure of the former (Figure 4.6(c)) with respect to the latter (Figure 4.6(b)) at a given welding speed of $20 \mathrm{~mm} / \mathrm{s}$. In contrast, at a constant rotational rate $(\omega)$, the heat input per unit length increases linearly with the inverse of the welding speed (v) and thus higher temperatures in the $\mathrm{SZ}$ are expected at $10 \mathrm{~mm} / \mathrm{s}$ than at the $20 \mathrm{~mm} / \mathrm{s}$ condition, which accounts for the coarser grain structure in the former (Figure 4.6(d)) microstructure relative to the latter (Figure 4.6(c)) at $1500 \mathrm{rpm}$. 


\subsection{Microhardness}

Vickers microhardness profiles, measured at the mid-thickness in each workpiece across the AZ31B-H24 Mg alloy weldments assembled at different tool rotational rates and welding speeds, are given in Figure 4.7(a)-(c). For each welding condition, a hardness trough was observed with higher values in the BM relative to that in the TMAZ and SZ. The hardness decreased gradually from about 70-75 $\mathrm{HV}$ in the BM to approximately 55-62 $\mathrm{HV}$ at the center of the SZ of the welds, representing a decrease of up to $\sim 25 \%$. This hardness change was attributed to the effect of the welding parameters on the heat input during FSW and the resulting microstructural evolution (i.e., average grain size) in the HAZ, TMAZ and SZ, as depicted previously in Figure 4.5(b)-(d). Specifically, at a constant welding speed of $20 \mathrm{~mm} / \mathrm{s}$, an increase in the rotational rate from 1000 rpm to $1500 \mathrm{rpm}$ was observed to decrease the average value of the hardness in the SZ from about $64 \mathrm{HV}$ to about $54 \mathrm{HV}$ (Figure 4.7(a) and (b)). As expected, this was due to the greater heat input and coarser SZ grain size in the latter welding condition, as seen in Figure 4.6(c) versus Figure 4.6(b). At a constant rotational rate of $1500 \mathrm{rpm}$, a decrease in the welding speed from $20 \mathrm{~mm} / \mathrm{s}$ to $10 \mathrm{~mm} / \mathrm{s}$ was observed to reduce the average hardness in SZ slightly further to roughly $52 \mathrm{HV}$ (Figure 4.7(b) and (c)). At the lower welding speed of $10 \mathrm{~mm} / \mathrm{s}$, more heat may also be transported via conduction further into the weldment, as evidenced by the widening of the hardness trough (Figure 4.7(c) versus 4.7(b)). 

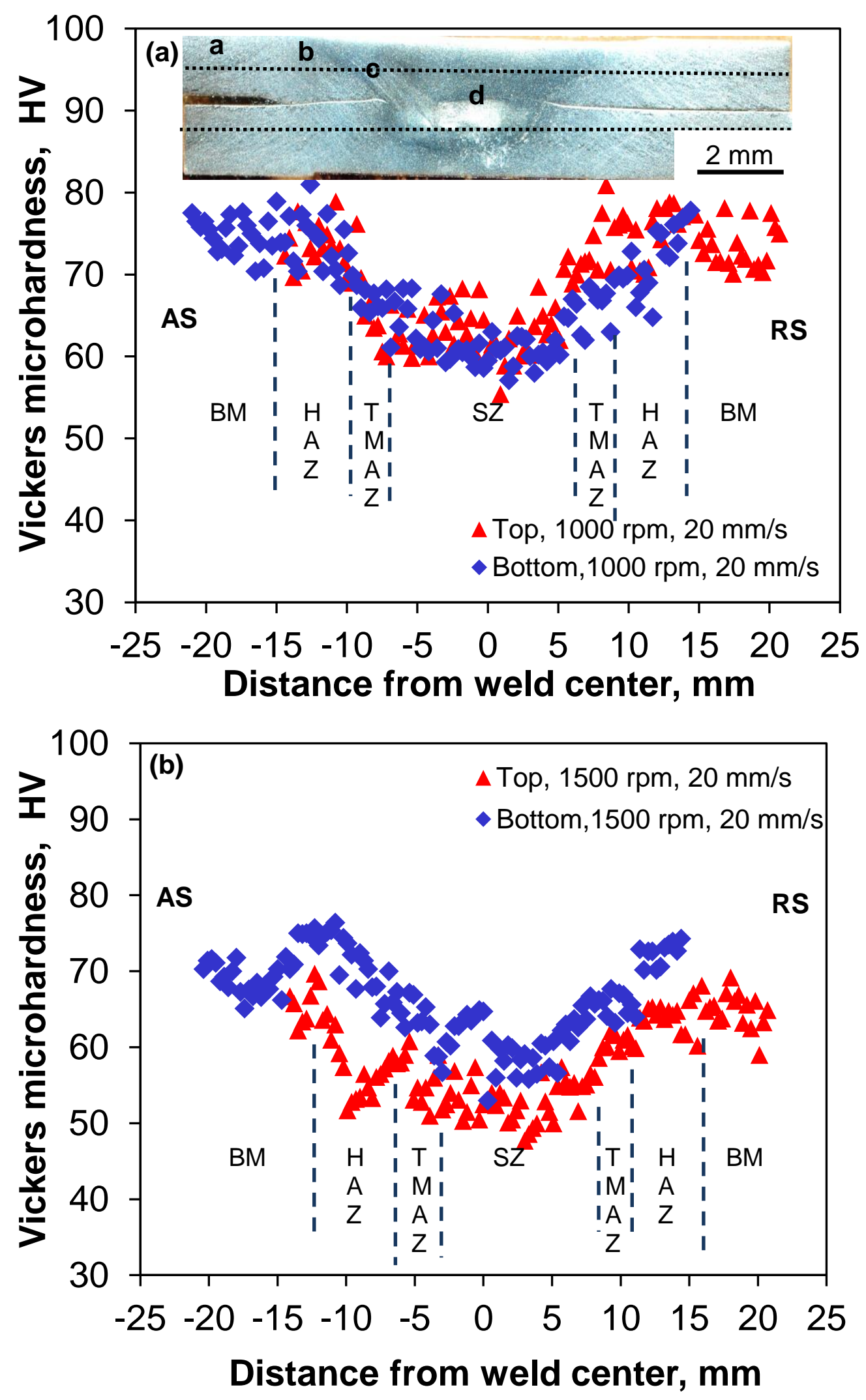


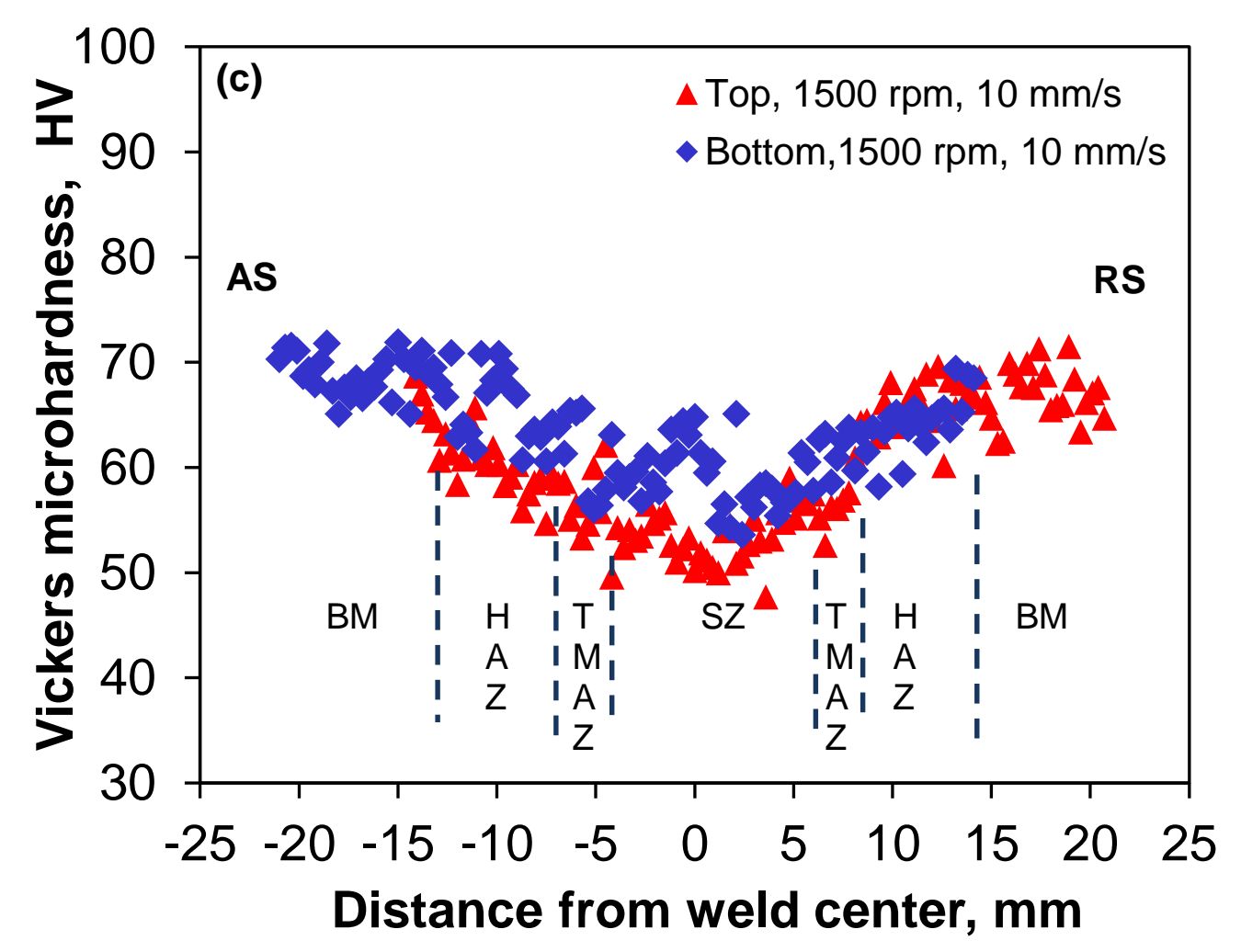

Figure 4.7: Typical microhardness profiles across the FSLWed AZ31B-H24 Mg alloy welds joined at (a) $1000 \mathrm{rpm}$ and $20 \mathrm{~mm} / \mathrm{s}$, (b) $1500 \mathrm{rpm}$ and $20 \mathrm{~mm} / \mathrm{s}$, and (c) $1500 \mathrm{rpm}$ and $10 \mathrm{~mm} / \mathrm{s}$.

Moreover, the general microhardness profile along the top sheet of the lap welds was observed to have consistently lower hardness values than those along the bottom sheet, naturally due to the higher temperatures (and concomitantly a coarser grain structure) experienced locally in the upper workpiece during FSW, as corroborated previously [26, 27].

The effect of grain size on the hardness or strength of the AZ31B-H24 Mg alloy can be rationalized through a Hall-Petch type relationship. Specifically, the finer grain size of the BM microstructure would exhibit a higher hardness value as compared to the progressively coarsened grain structure from the HAZ (across the TMAZ) to the center of the SZ, since the grain boundaries are the major barrier to the slip of dislocations. Hence the processes/welding 
conditions that result in coarser grains would have a lower resistance to localized plastic deformation (i.e., fewer grain boundaries) and render a decrease in the hardness or strength. Figure 4.8 shows the relationship between the average hardness values measured in the SZ, and the average grain size determined in the SZ for the different welding conditions examined in the present work. It should be noted that the average grain size was assessed from approximately 4,000 grains in the SZ in each welding condition and about 10,000 grains in the BM. The HallPetch-type relationship obtained between the hardness and the grain size (d) in the SZ of the FSLWed AZ31B-H24 Mg alloy (Figure 9) could be expressed as,

$$
H V=1420 d^{-\frac{1}{2}}+6.3
$$

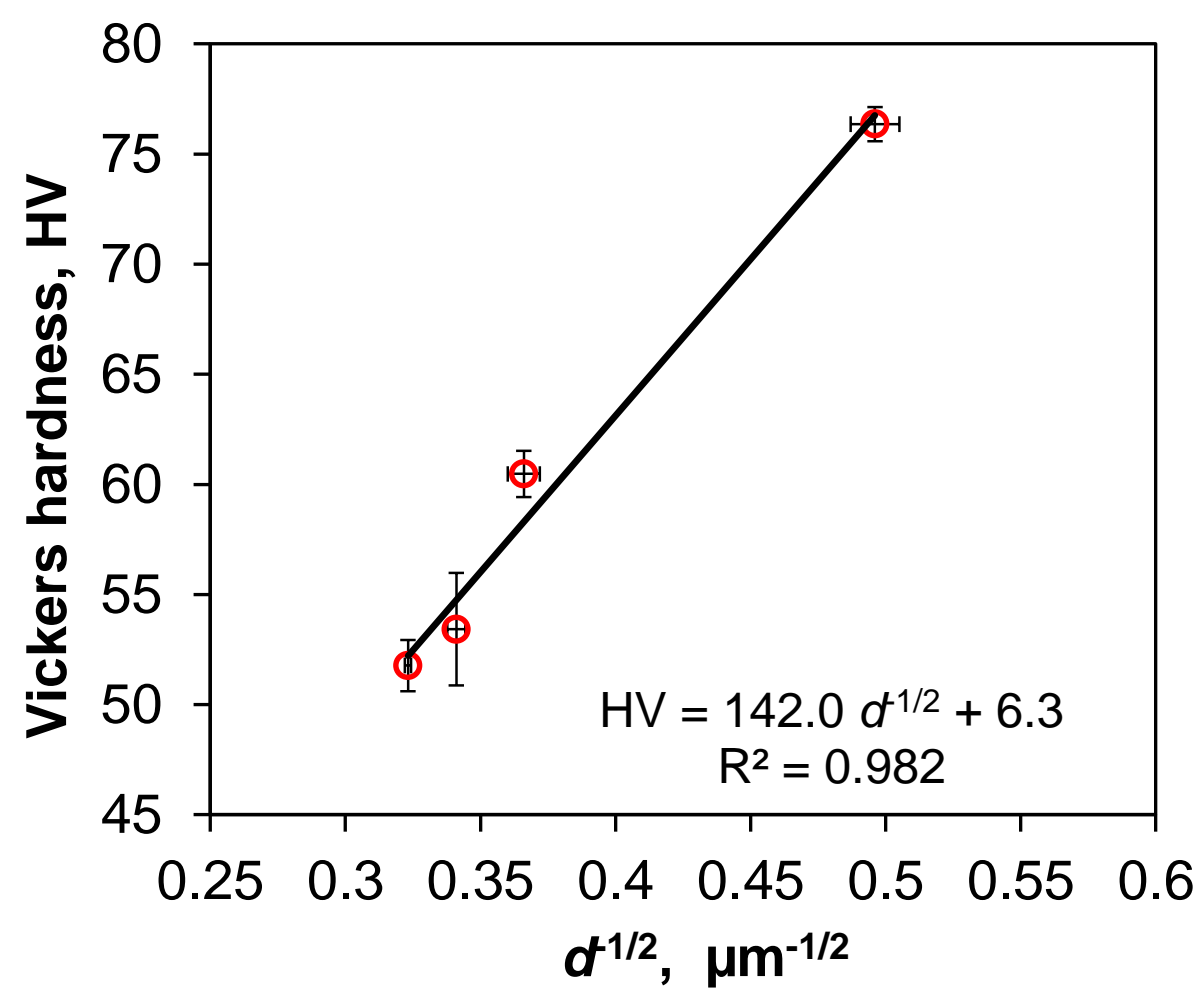

Figure 4.8: Hall-Petch-type relationship between the average hardness and average grain size in the stir zone of the FSLWed AZ31B-H24 Mg alloy weld joined with different welding parameters, where the base metal grain size and hardness data are also plotted (The error bars on the plotted data represent the standard deviations for both hardness and grain size values). 


\subsection{Fatigue properties}

Fatigue tests were performed to evaluate the strength of the FSLWed AZ31B-H24 Mg alloy in the tensile-shear configuration under cyclic loading (Fig. 1(d)). The fatigue experimental data obtained at room temperature $(\mathrm{RT})$, loading ratio $(\mathrm{R})=0.2$ and $50 \mathrm{~Hz}$ are plotted in Fig. 10 in the form of the maximum load as a function of number of cycles to failure for the lap welds assembled using various welding parameters, i.e., tool rotational and welding speeds (1000 rpm and $20 \mathrm{~mm} / \mathrm{s}, 1500 \mathrm{rpm}$ and $20 \mathrm{~mm} / \mathrm{s}$, as well as $1500 \mathrm{rpm}$ and $10 \mathrm{~mm} / \mathrm{s}$ ). It is seen from Figure 4.9(a) that at all load levels applied, the FSLWed AZ31B-H24 Mg alloy joints made with a welding condition of $1000 \mathrm{rpm}$ and $20 \mathrm{~mm} / \mathrm{s}$ had a much longer fatigue life than that of the other two welding conditions, namely, $1500 \mathrm{rpm}-10 \mathrm{~mm} / \mathrm{s}$ and $1500 \mathrm{rpm}-20 \mathrm{~mm} / \mathrm{s}$. Also, increasing the welding speed from $10 \mathrm{~mm} / \mathrm{s}$ to $20 \mathrm{~mm} / \mathrm{s}$ at a constant tool rotational rate of $1500 \mathrm{rpm}$ gave a visibly longer fatigue life for the maximum cyclic load ranging from 0.5 to $2 \mathrm{kN}$. This can be better observed from Figure 4.9(b) where the fatigue data are presented in a double-log scale of the maximum stress versus the number of reversals to failure $\left(2 \mathrm{~N}_{\mathrm{f}}\right)$ for the FSLWed AZ31B-H24 $\mathrm{Mg}$ alloy joints assembled with the different welding conditions. It is clear that the fatigue life over the entire range from $1 \mathrm{kN}$ to $5 \mathrm{kN}$ was the longest for the welds joined at $1000 \mathrm{rpm}$ and 20 $\mathrm{mm} / \mathrm{s}$, and the shortest for the welds joined at $1500 \mathrm{rpm}$ and $10 \mathrm{~mm} / \mathrm{s}$, with the welds joined at $1500 \mathrm{rpm}$ and $20 \mathrm{~mm} / \mathrm{s}$ positioned in-between those two lines. This was primarily attributed to the severity of welding defects (Figures 4.2-4.4) in conjunction with the microstructural changes (Figures 4.5 and 4.6). 

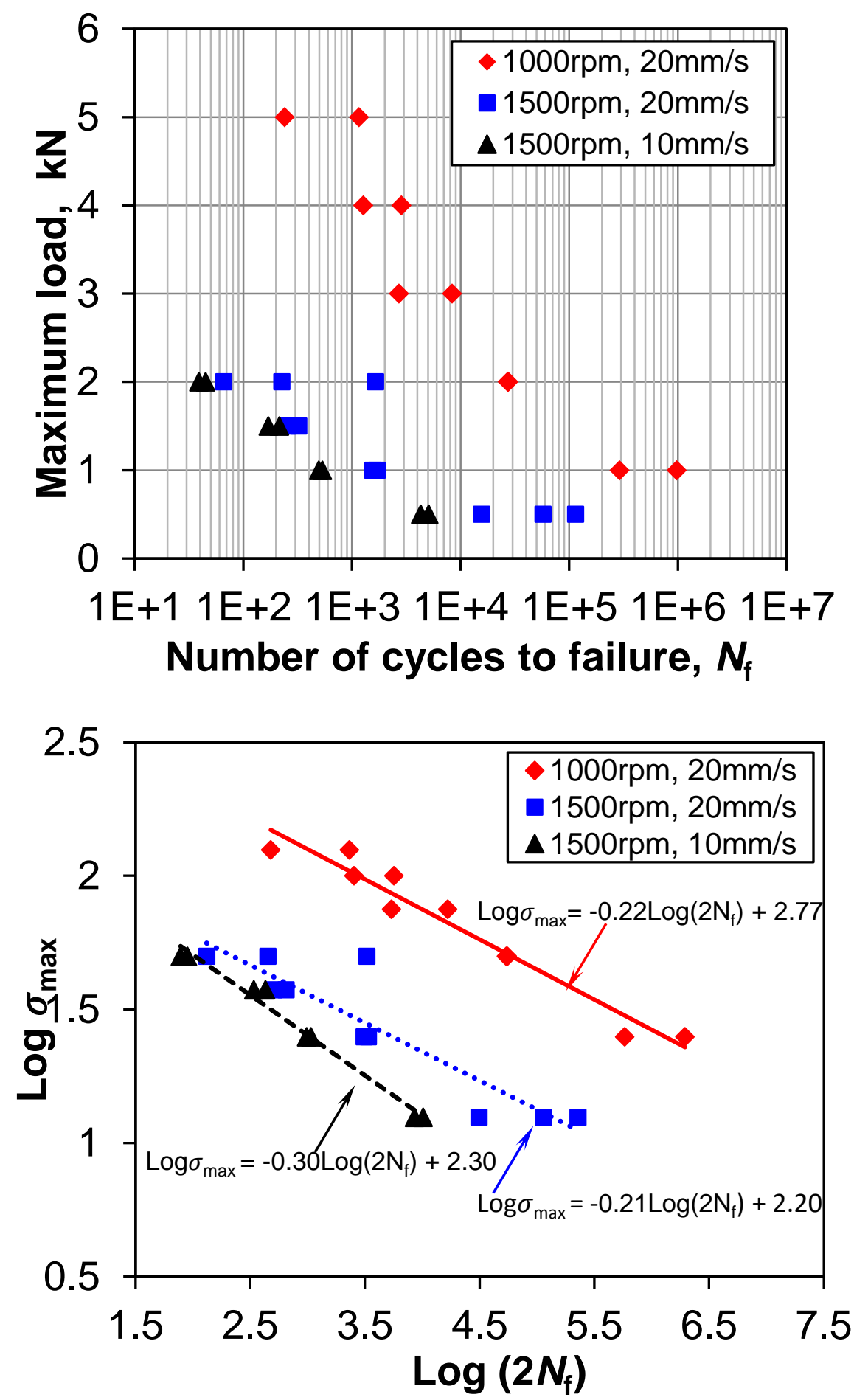

Figure 4.9: Fatigue life curves of the friction stir lap welds manufactured with various rotational rates and welding speeds and tested at room temperature, $\mathrm{R}=0.2$ and $50 \mathrm{~Hz}$ : (a) Semi-log scale plot of the maximum load vs. the number of cycles to failure $\left(\mathrm{N}_{\mathrm{f}}\right)$ and (b) Double-log scale plot of the maximum stress vs. the number of reversals to failure $\left(2 \mathrm{~N}_{\mathrm{f}}\right)$. 
For the lap joint configuration shown in Figure 1(d) used in the present study, the maximum stress occurs in the top workpiece $\mathrm{n}$ the AS and in the bottom workpiece on the RS, due to the stress distribution and the bending stresses present during fatigue testing, thereby representing the critical locations for fatigue crack initiation. In addition, the re-orientation of the interface extends the hook into either the top or bottom workpiece, causing a net reduction in the EST of the material. The EST is defined as the minimum sheet thickness by measuring the smallest distance from any un-bonded interface tip either to the top surface of the upper workpiece or to the bottom surface of the lower workpiece, whichever is smaller [53, 118]. This parameter, introduced by Cederqvist and Reynolds [119], may be used to measure the extent of how much of the original sheet thickness remains effectively capable of carrying the load after welding. Therefore, the thinning of the overlap sheets, caused by the hooking defect, is the primary cause for the reduction of fatigue life in FSLWed Al alloys [17, 53, 120].

The fracture of the AZ31B-H24 Mg alloy lap welds was observed to occur predominantly in or near the interface of the SZ/TMAZ on the AS of the top workpiece (Figure 4.10), where the severe stress concentration arising from the presence of the hooking defect caused the crack to propagate directly into the top workpiece. In contrast, OJLwSPDs (Figure 4.4) were less damaging due to the fact that there were no sharp corners/edges for stress concentration. Additionally, there existed some mechanical bonding between the interfaces for OJLwSPD defects, which was not the case for the hooking defects. Therefore, hooking was the most damaging defect in the FSLWed joints. As mentioned earlier and shown in Figure 4.3(a), the welded joints made with the "hot" welding condition of $1500 \mathrm{rpm}$ and $10 \mathrm{~mm} / \mathrm{s}$ had the largest hooking height, resulting in the smallest EST or load-carrying capacity, and thus the shortest 
fatigue life (Figure 4.9). In contrast, the "cold" welding condition of $1000 \mathrm{rpm}$ and $20 \mathrm{~mm} / \mathrm{s}$ considerably suppressed the occurrence of the hook (Figure 4.3(e) and (f)), giving rise to the longest fatigue life (Figure 4.9).

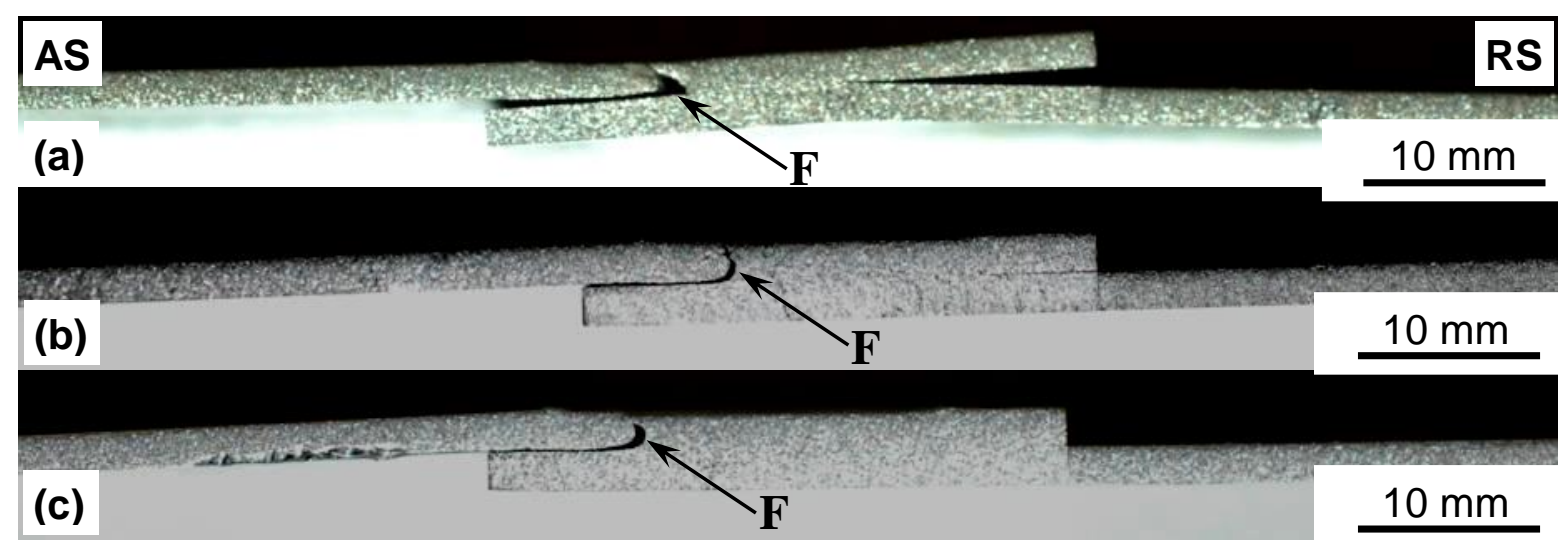

Figure 4.10: Fatigue failure locations (as indicated by F) in the FSLWed AZ31B-H24 Mg alloy weld joined at the with various tool rotational rates and welding speeds: (a) $1000 \mathrm{rpm}, 20 \mathrm{~mm} / \mathrm{s}$, (b) $1500 \mathrm{rpm}, 20 \mathrm{~mm} / \mathrm{s}$, and (c) $1500 \mathrm{rpm}, 10 \mathrm{~mm} / \mathrm{s}$.

\subsection{Fractography}

The fatigue tests showed that all the FSLWed specimens fractured near the interface of the SZ/TMAZ on the AS of the top workpiece. These fracture locations corresponded to the more critical hooking defects that resulted from excessive upward flow of the material and the occurrence of upper workpiece thinning during FSW (Figure 4.3). In particular, fatigue fracture was observed to initiate from the tip of the hooking defect lines, due to the presence of severe stress concentration, and crack propagation occurred within the weld region, as indicated in Figure 4.10. Figures 4.11-4.13 show the SEM images of the fatigue fracture surface of the 
FSLWed AZ31B-H24 Mg alloy joints made with different welding parameters and tested at varying cyclic load levels. These fractographic images displayed several different zones, including fatigue crack initiation, propagation and final rapid fracture. It can be observed that the fracture exhibited multiple crack initiations from the interior of the upper workpiece corresponding to the tip/root of the hooking defect, as shown in Figure 4.11(a) and (b). At a lower cyclic load level, fatigue cracking originated from the hook opening through the TMAZ and then propagating into the SZ, as indicated by arrows in Figure 4.11(b), Figure 4.12(b) and Figure 4.13(b). Fatigue crack propagation was mainly characterized by fatigue striations (Figure 4.11(c) and (d), Figure 4.12(c) and Figure 4.13(c)) along with secondary cracks, which appeared usually perpendicular to the fatigue crack propagation direction.

The fatigue striations, clearly observed at the higher magnifications, formed mainly by the repeated plastic blunting-sharpening process in the plastic zone ahead of a propagating crack arising from the twinning-detwinning process, which is reasonable considering the hexagonal closed packed crystal structure of the AZ31B-H24 Mg alloy in which there is a limited number of slip systems at room temperature [121-123]. At a higher cyclic load level, the crack also initiated in the region near the root of the hooking defects, indicated by the arrows in Figure 4.11(e), Figure 4.12(d) and Figure 4.13(e), and the propagation exhibited a mix of some dimples and cleavage type fracture. The final fracture surface appeared relatively coarser with the presence of plastic deformation and tearing ridge features. 

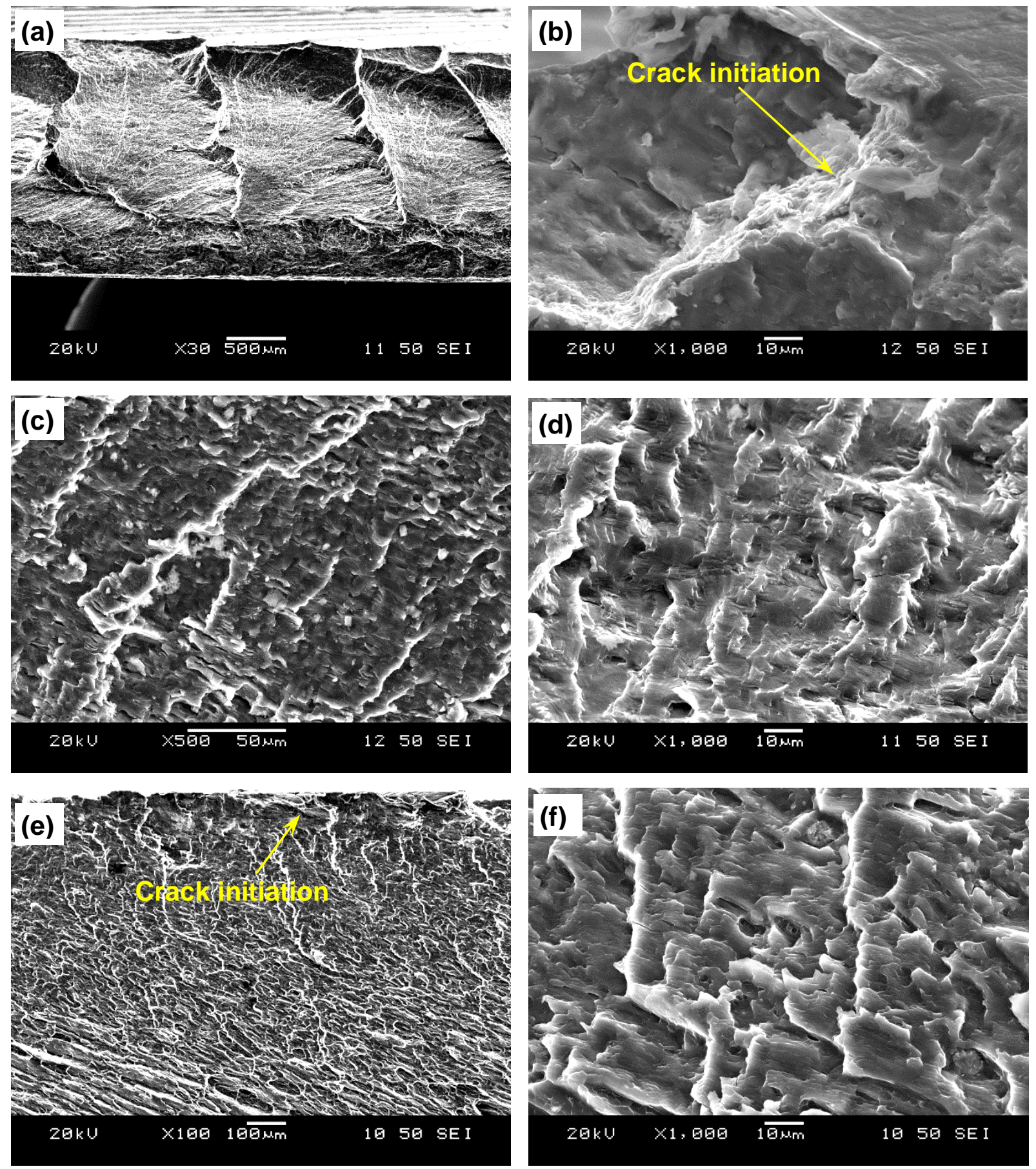

Figure 4.11: Typical SEM images of the fatigue fracture surface of a FSLWed AZ31B-H24 Mg alloy assembled at a rotational rate of $1000 \mathrm{rpm}$ and a welding speed of $20 \mathrm{~mm} / \mathrm{s}$ : (a) fatigue fracture surface at a lower $\mathrm{P}_{\max }=1 \mathrm{kN}$, (b) crack initiation site at a lower $\mathrm{P}_{\max }=1 \mathrm{kN}$, (c) crack propagation region at a lower $\mathrm{P}_{\max }=1 \mathrm{kN},(\mathrm{d})$ fatigue striations at a higher magnification at a lower $P_{\max }=1 \mathrm{kN}$, (e) fatigue fracture surface and crack initiation site at a higher $\mathrm{P}_{\max }=5 \mathrm{kN}$, and (f) crack propagation region at a higher $\mathrm{P}_{\max }=5 \mathrm{kN}$. 

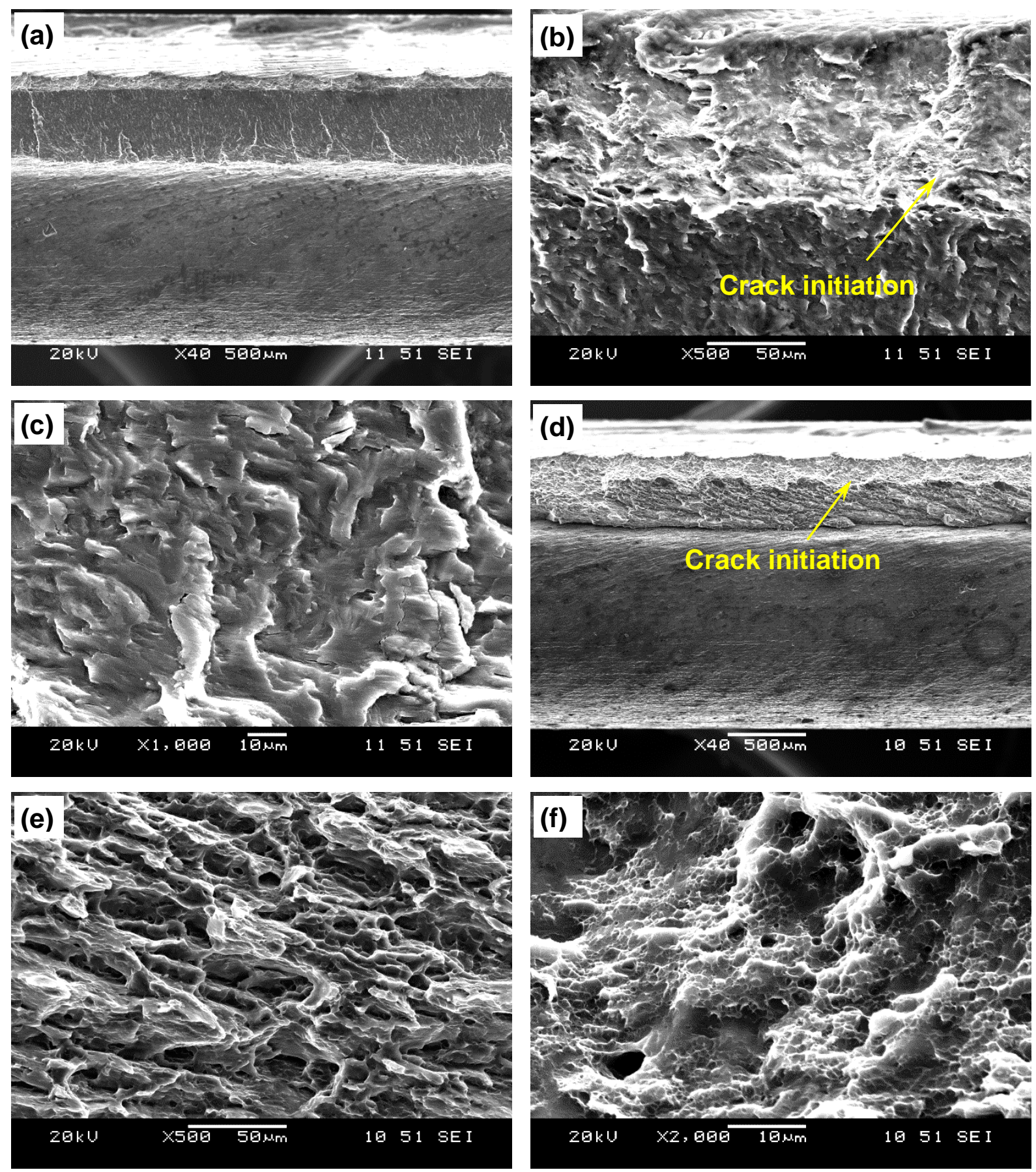

Figure 4.12: Typical SEM images of the fatigue fracture surface of a FSLWed AZ31B-H24 Mg alloy assembled at a rotational rate of $1500 \mathrm{rpm}$ and a welding speed of $10 \mathrm{~mm} / \mathrm{s}$ : (a) fatigue fracture surface at a lower $P_{\max }=0.5 \mathrm{kN}$, (b) crack initiation site at a lower $\mathrm{P}_{\max }=0.5 \mathrm{kN}$, (c) crack propagation region at a lower $P_{\max }=0.5 \mathrm{kN}$, (d) fatigue fracture surface at a higher $\mathrm{P}_{\max }=2 \mathrm{kN}$, (e) crack propagation region at a higher $\mathrm{P}_{\max }=2 \mathrm{kN}$, and (f) crack propagation region at a further higher magnification at a higher $\mathrm{P}_{\max }=2 \mathrm{kN}$. 

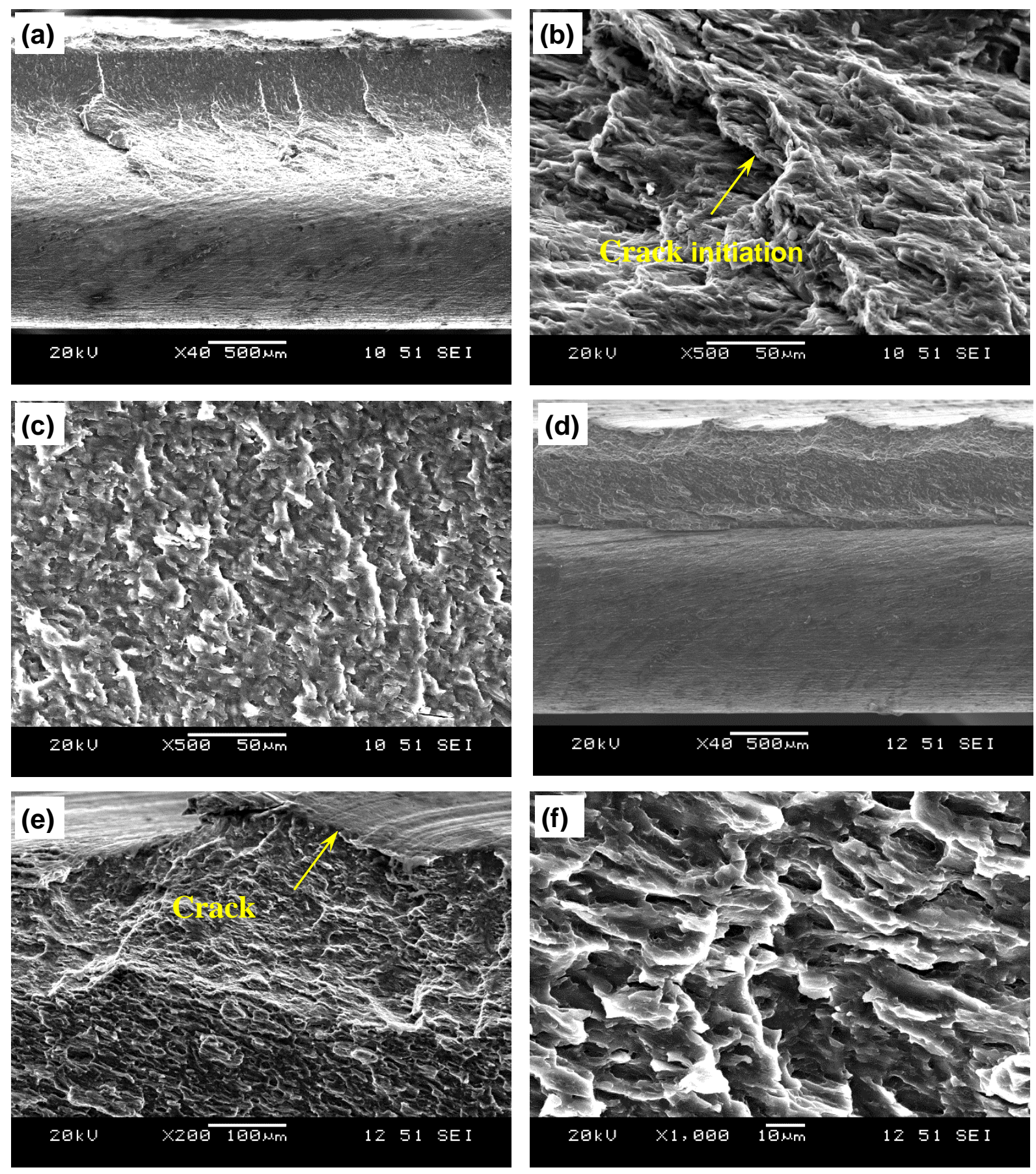

Figure 4.13: Typical SEM images of the fatigue fracture surface of a FSLWed AZ31B-H24 Mg alloy assembled at a rotational rate of $1500 \mathrm{rpm}$ and a welding speed of $20 \mathrm{~mm} / \mathrm{s}$ : (a) fatigue fracture surface at a lower $\mathrm{P}_{\max }=0.5 \mathrm{kN}$, (b) crack initiation site at a lower $\mathrm{P}_{\max }=0.5 \mathrm{kN}$, (c) crack propagation region at a lower $P_{\max }=0.5 \mathrm{kN}$, (d) fatigue fracture surface at a higher $\mathrm{P}_{\max }=2 \mathrm{kN}$, (e) crack initiation site at a higher $\mathrm{P}_{\max }=2 \mathrm{kN}$, and (f) crack propagation region at a further higher $\mathrm{P}_{\max }=2 \mathrm{kN}$. 


\subsection{Summary of the results}

The influence of welding parameters, i.e., tool rotational rate and welding speed, on the weld integrity of FSLWed AZ31B-H24 Mg alloy having a sheet thickness of $2 \mathrm{~mm}$ was examined. The following important conclusions could be drawn from this study:

1. The stir zone and thermo-mechanically affected zone (TMAZ) experienced full dynamic recrystallization and thus consisted predominantly of equiaxed grains. The grain size in the stir zone increased with increasing heat input (i.e., increasing tool rotational rate and decreasing welding speed).

2. The hardness decreased gradually from the base metal through the HAZ, to the TMAZ and then to the stir zone where the lowest hardness was obtained. The overall hardness across the stir zone was slightly higher at a lower heat input (i.e., at a lower tool rotational rate and/or a higher welding speed).

3. The existence of hooking defects in friction stir lap welds was the key factor that significantly reduced the fatigue strength or life due to (i) the sharp tips causing severe stress concentration and (ii) the reduced effective sheet thickness (i.e., large hooking height) or reduced load-bearing capacity. Specifically, the fatigue cracks usually initiated at the tip of the hooking defect on the advancing side of the top sheet due to the more severe stress concentration caused by the presence of a larger hook height. The fatigue crack then propagated into the stir zone by the formation of fatigue striations perpendicular to the propagation direction, followed by the final rapid shear failure.

4. The welding parameters were observed to have a significant effect on the hook height and the subsequent fatigue life. A relatively "cold" weld conducted at a rotational rate of 1000 
rpm and welding speed of $20 \mathrm{~mm} / \mathrm{s}$ led to almost complete elimination of the hooking defect, thus considerably (over two orders of magnitude) improving the fatigue life.

5. Fractographic analysis revealed that the fracture surface exhibited multiple crack initiation sites originating from the tip of the hooking defect located in the upper work-piece. The crack propagation exhibited some more obvious brittle fracture features and was also differentiated by the characteristic fatigue striations. 


\section{CHAPTER 5}

\section{TEXTURE DEVELOPMENT IN A FRICTION STIR LAP WELDED AZ31B MAGNESIUM ALLOY}

In this chapter the task was aimed to characterize the microstructure, microtexture, and tensile properties of an AZ31B-H24 Mg alloy at different tool rotational and welding speeds. The Microstructural observations were done on optical and scanning electron microscope to identify the intermetallic second phase particles and to further confirmation of the intermetallic particles XRD is also performed. During the FSW the texture changes occurred due to the shear plastic flow near the pin surface that occurred from the intense local stirring which could possibly changes the mechanical properties of a material. Therefore it is necessary to understand the microtexture changes and the its effects on the tensile failure load.

\subsection{Microstructure}

Based on the microstructural characterization, three distinct zones, namely the SZ, TMAZ and HAZ could be identified in the friction stir lap welds of the AZ31B-H24 Mg alloy. The typical microstructures of the three zones are shown in Figures 5.1, 5.2 and 5.3 for tool rotational rates of $1000 \mathrm{rpm}$ and $1500 \mathrm{rpm}$ at a welding speed of $20 \mathrm{~mm} / \mathrm{s}$ and $10 \mathrm{~mm} / \mathrm{s}$, respectively. It is clear that the SZ, TMAZ and HAZ exhibited different grain structural features, which were attributed to the difference in the frictional heat and material flow characteristics caused by the FSW process. The as-received microstructure of the $\mathrm{BM}$ consisted of fine equiaxed and recrystallized grains as well as elongated/deformed pancake-like grains, as shown in Figures 5.1(d), 5.2(d) and 
5.3(d). The heterogeneous grain structure and size in the BM originated from the incomplete dynamic recrystallization (partial annealing) during the warm rolling process as noted in [55]. The severe plastic deformation (from the mechanical stirring) and high temperature (from the frictional heating) during FSLW led to near-complete dynamic recrystallization as evidenced by the equiaxed morphology for all the grains in the SZ (Figures 5.1(a), 5.2(a) and 5.3(a)) and TMAZ (Figures 5.1(b), 5.2(b) and 5.3(b)). However, the simultaneous increase in the average grain size of the SZ and TMAZ (Table 5.1) relative to the BM suggests the occurrence of both recrystallization and grain coarsening under the welding conditions applied in this study. The HAZ microstructure (Figures 5.1(c), 5.2(c) and 5.3(c)) was more similar to that of the BM but with a greater fraction of equiaxed grains and a slightly coarser grain size (Table 5.1). This was attributed to the dominating effect of frictional heating that caused partial recrystallization of some elongated/deformed grains and the coarsening of the recrystallized grains. The microstructural evolution observed in the different regions of the FSLWed AZ31B-H24 Mg alloy was consistent with that which occurred in the friction stir butt welds of the AZ31B-H24 Mg alloy [113-115, 124-125].

Comparing Figure 5.1 with Figure 5.2, it is apparent that grain coarsening occurred in the SZ with increasing tool rotational rate at a constant welding speed of $20 \mathrm{~mm} / \mathrm{s}$. Similarly, decreasing the welding speed at a fixed tool rotational rate of $1500 \mathrm{rpm}$ was observed to result in grain coarsening, as illustrated in Figures 5.2 and 5.3 and tabulated in Table 1. The grain coarsening is attributed to the increasing heat input during FSW that can be deliberated through the weld pitch (defined as a ratio of the welding speed to the tool rotational rate). Specifically a low weld pitch value $(0.4 \mathrm{~mm} /$ revolution) for the $1500 \mathrm{rpm}$ and $10 \mathrm{~mm} / \mathrm{s}$, which indicates a "hot" welding 
condition, would render a coarse grain structure relative to the higher weld pitch value $(0.8$ $\mathrm{mm} /$ revolution and $1.2 \mathrm{~mm} /$ revolution) or "colder" welding conditions at $1500 \mathrm{rpm}, 20 \mathrm{~mm} / \mathrm{s}$ and $1000 \mathrm{rpm}, 20 \mathrm{~mm} / \mathrm{s}$.

Table 5.1: Effect of tool rotational rate and welding speed on the grain size (mean value \pm SD) and failure load of FSLWed AZ31B-H24 Mg alloy.

\begin{tabular}{|c|c|c|c|c|c|c|c|}
\hline \multirow{2}{*}{$\begin{array}{c}\text { Tool } \\
\text { rotational } \\
\text { rate, } \mathrm{rpm}\end{array}$} & \multirow{2}{*}{$\begin{array}{c}\text { Welding } \\
\text { speed, } \\
\mathrm{mm} / \mathrm{s}\end{array}$} & $\begin{array}{c}\text { Weld } \\
\text { pitch, } \\
\mathrm{mm} / \mathrm{rev}\end{array}$ & \multicolumn{4}{|c|}{ Grain size (d), $\mu \mathrm{m}$} & $\begin{array}{c}\text { Failure } \\
\text { load, } \mathrm{kN}\end{array}$ \\
\hline 1000 & 20 & 1.2 & $4.25 \pm 0.10^{*}$ & $4.63 \pm 0.25$ & $6.16 \pm 0.14$ & $7.46 \pm 0.24$ & 6.52 \\
\hline 1500 & 20 & 0.8 & - & $5.31 \pm 0.23$ & $6.48 \pm 0.19$ & $8.59 \pm 0.16$ & 2.16 \\
\hline 1500 & 10 & 0.4 & - & $6.15 \pm 0.22$ & $8.20 \pm 0.06$ & $9.57 \pm 0.06$ & 2.22 \\
\hline
\end{tabular}

* The mean value and standard deviation (SD) for the BM were taken from all the values measured for the BM in different welding conditions. 

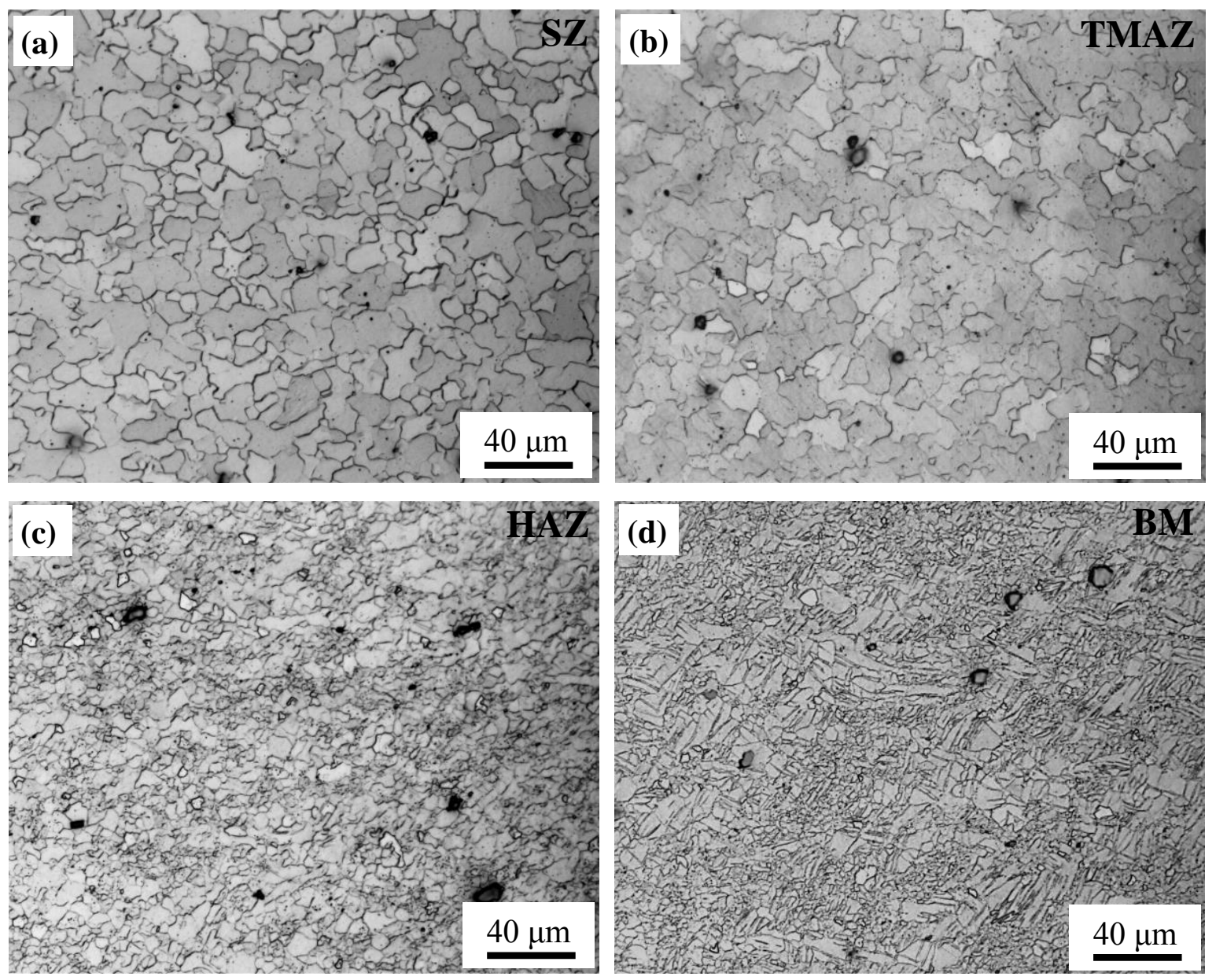

Figure 5.1: Typical microstructures of the FSLWed AZ31B-H24 Mg alloy at a tool rotational rate of $1000 \mathrm{rpm}$ and a welding speed of $20 \mathrm{~mm} / \mathrm{s}$ in (a) SZ, (b) TMAZ, (c) HAZ and (d) BM. 

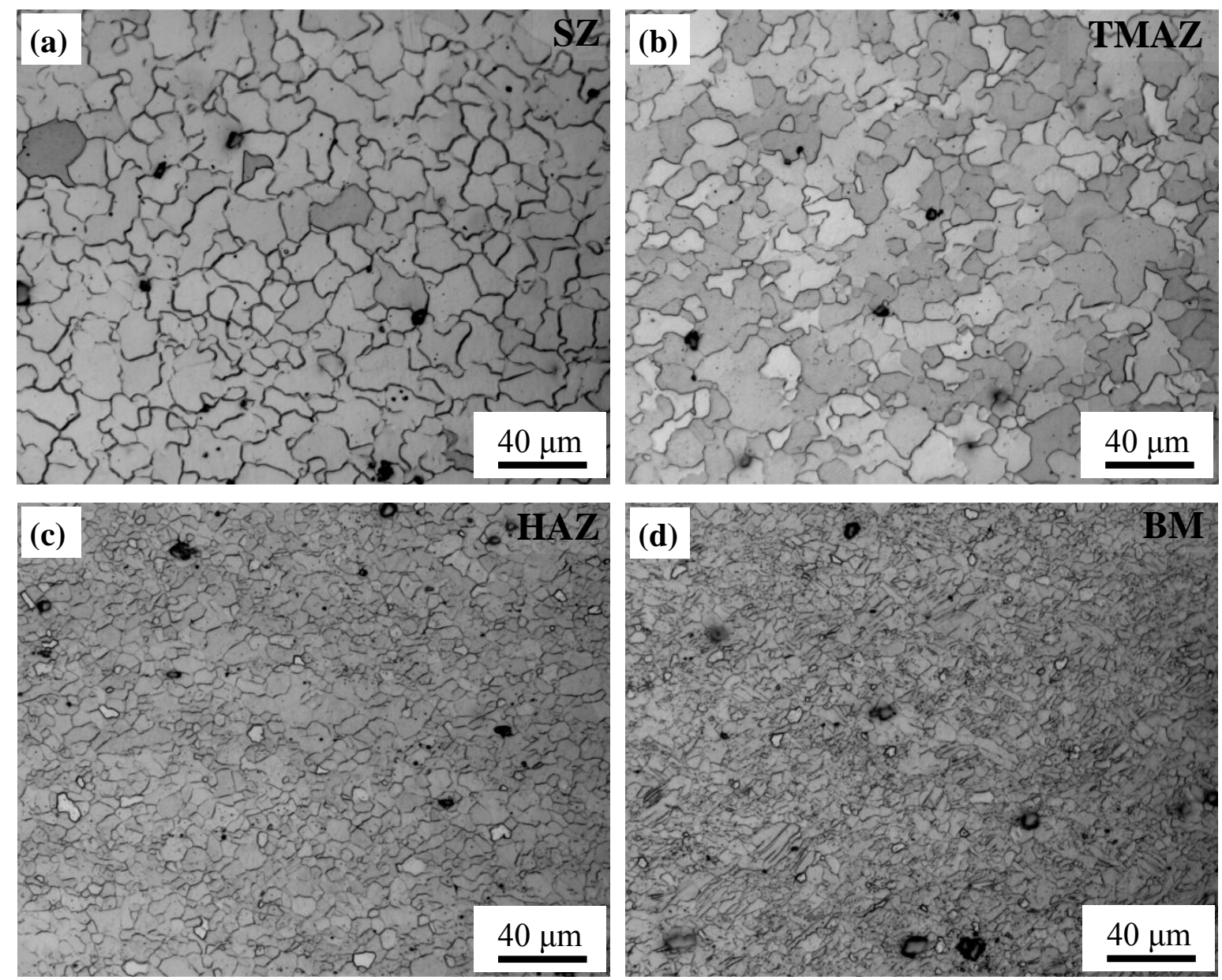

Figure 5.2: Typical microstructures of the FSLWed AZ31B-H24 Mg alloy at a tool rotational rate of $1500 \mathrm{rpm}$ and a welding speed of $20 \mathrm{~mm} / \mathrm{s}$ in (a) SZ, (b) TMAZ, (c) HAZ and (d) BM. 

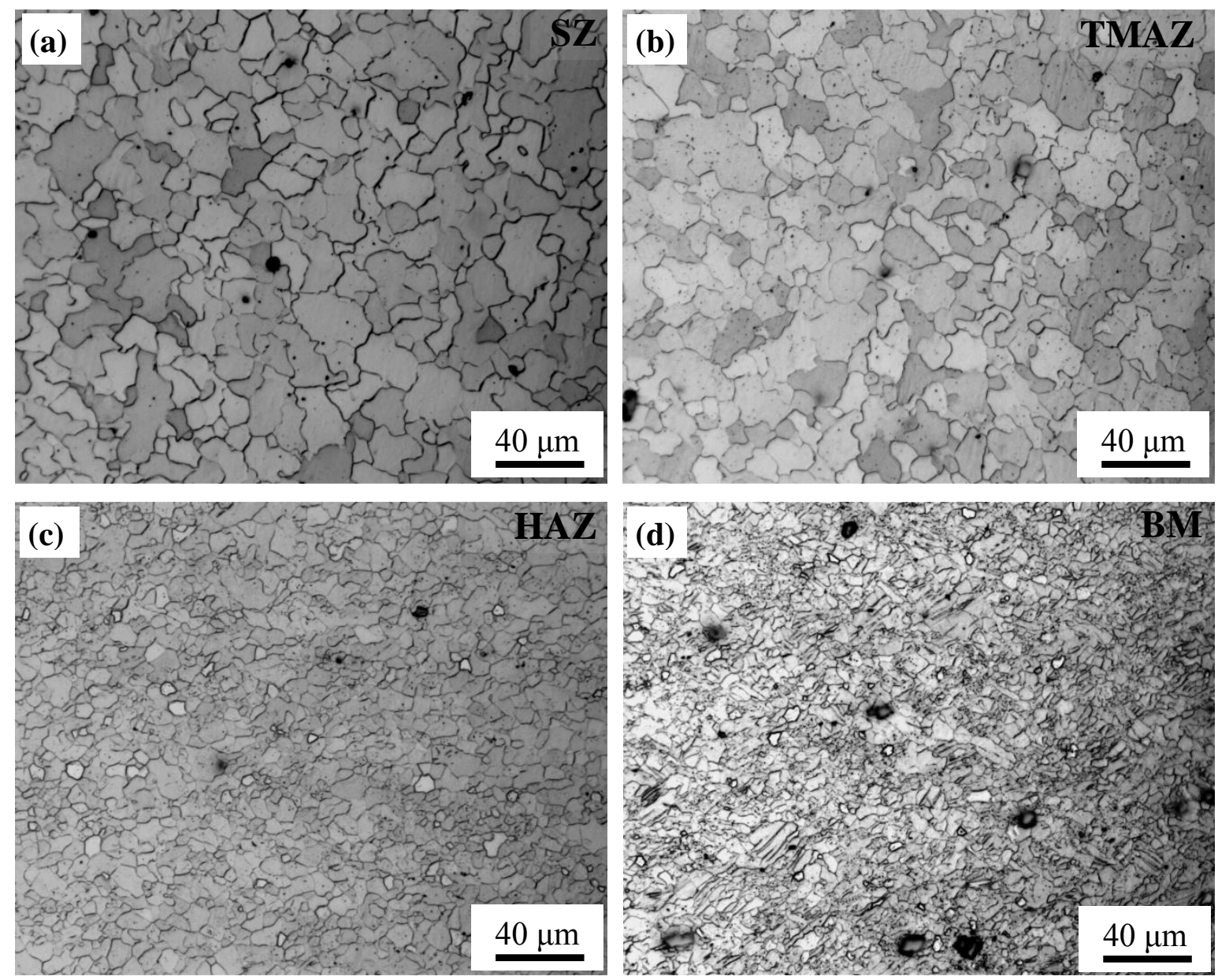

Figure 5.3: Typical microstructures of the FSLWed AZ31B-H24 Mg alloy at a tool rotational rate of $1500 \mathrm{rpm}$ and a welding speed of $10 \mathrm{~mm} / \mathrm{s}$ in (a) SZ, (b) TMAZ, (c) HAZ and (d) BM.

SEM examinations of the BM microstructure revealed a relatively homogeneous $\alpha-\mathrm{Mg}$ matrix and the presence of relatively fine $\left(\sim 30 \mu \mathrm{m}^{2}\right)$ particles, as indicated by arrows in Figure 5.4(a). EDS analysis (Figure 5.4)) indicated that these particles were on average 61.4 at. \% $\mathrm{Al}$ and 38.6 at. \% Mn (Table 5.2). Taking into consideration the binary phase diagram of Al-Mn [126], these particles are likely to be $\mathrm{Al}_{8} \mathrm{Mn}_{5}$, which has a $\mathrm{Mn}$ content between 37 and 50 at. \%. In the SZ, two types of particles were present (Table 5.2). Specifically, the slightly larger particles in the SZ (Figure 5.4(b) were identified as $\mathrm{Al}_{8} \mathrm{Mn}_{5}$ based on the EDS analysis. The finer $\left(\sim 15 \mu \mathrm{m}^{2}\right)$ 
particles (Figure 5.4(b)) were approximately on average 34.4 at. \% $\mathrm{Al}$ and 55.9 at. \% Mg (Table 5.2, Figure 5.4(d)) and appeared to correspond to the $\beta-\mathrm{Al}_{12} \mathrm{Mg}_{17}$, based on the Al-Mg binary phase diagram [127].

Table 5.2: EDS analysis results on the particles observed in the BM and SZ of FSLWed AZ31B$\mathrm{H} 24 \mathrm{Mg}$ alloy.

\begin{tabular}{|c|c|c|c|}
\hline \multirow{2}{*}{ Element } & \multirow{2}{*}{$\begin{array}{c}\text { BM } \\
\text { particles }\end{array}$} & $\begin{array}{c}\text { Large } \\
\text { particles }\end{array}$ & $\begin{array}{c}\text { Small } \\
\text { particles }\end{array}$ \\
\hline $\mathrm{Al}, \mathrm{K}_{\alpha}$ (at.\%) & 61.4 & 34.4 & 63.5 \\
\hline $\mathrm{Mn}, \mathrm{K}_{\alpha}$ (at.\%) & 38.6 & 9.6 & 36.5 \\
\hline $\mathrm{Mg}, \mathrm{K}_{\alpha}$ (at.\%) & - & 56.0 & - \\
\hline
\end{tabular}

The nature of the intermetallic phases present in the BM and SZ was also investigated by XRD. Figure 5.5 shows the results of the XRD analysis for the BM and $\mathrm{SZ}$ in the samples assembled with different tool rotational rates and welding speeds. Specifically for the BM prior to FSW, the XRD analysis revealed distinct peaks of the $\mathrm{Al}_{8} \mathrm{Mn}_{5}$ and $\beta-\mathrm{Al}_{12} \mathrm{Mg}_{17}$ phases, along with some peaks that overlapped with the Mg peaks, as illustrated in Figure 5.5(a). XRD characterization of the FSLWed joint (Figure 5.5(b) - 5.5(d)) also showed independent peaks for the $\mathrm{Al}_{8} \mathrm{Mn}_{5}$ and $\beta$ $\mathrm{Al}_{12} \mathrm{Mg}_{17}$ phases, along with some peaks that coincided with $\mathrm{Mg}$. It is noteworthy that intermetallic phases, such as $\beta-\mathrm{Al}_{12} \mathrm{Mg}_{17}$ particles, when present in AZ31B-H24 Mg alloy, are known to be brittle [128]; however, these $\beta-\mathrm{Al}_{12} \mathrm{Mg}_{17}$ particles are also present in the $\mathrm{BM}$, so the likelihood of crack formation in the SZ of the friction stir lap welds may remain similar. Similar 
intermetallic phases have been identified by Xiao et al. [129] in a resistance spot welded AZ31$\mathrm{H} 24 \mathrm{Mg}$ alloy.
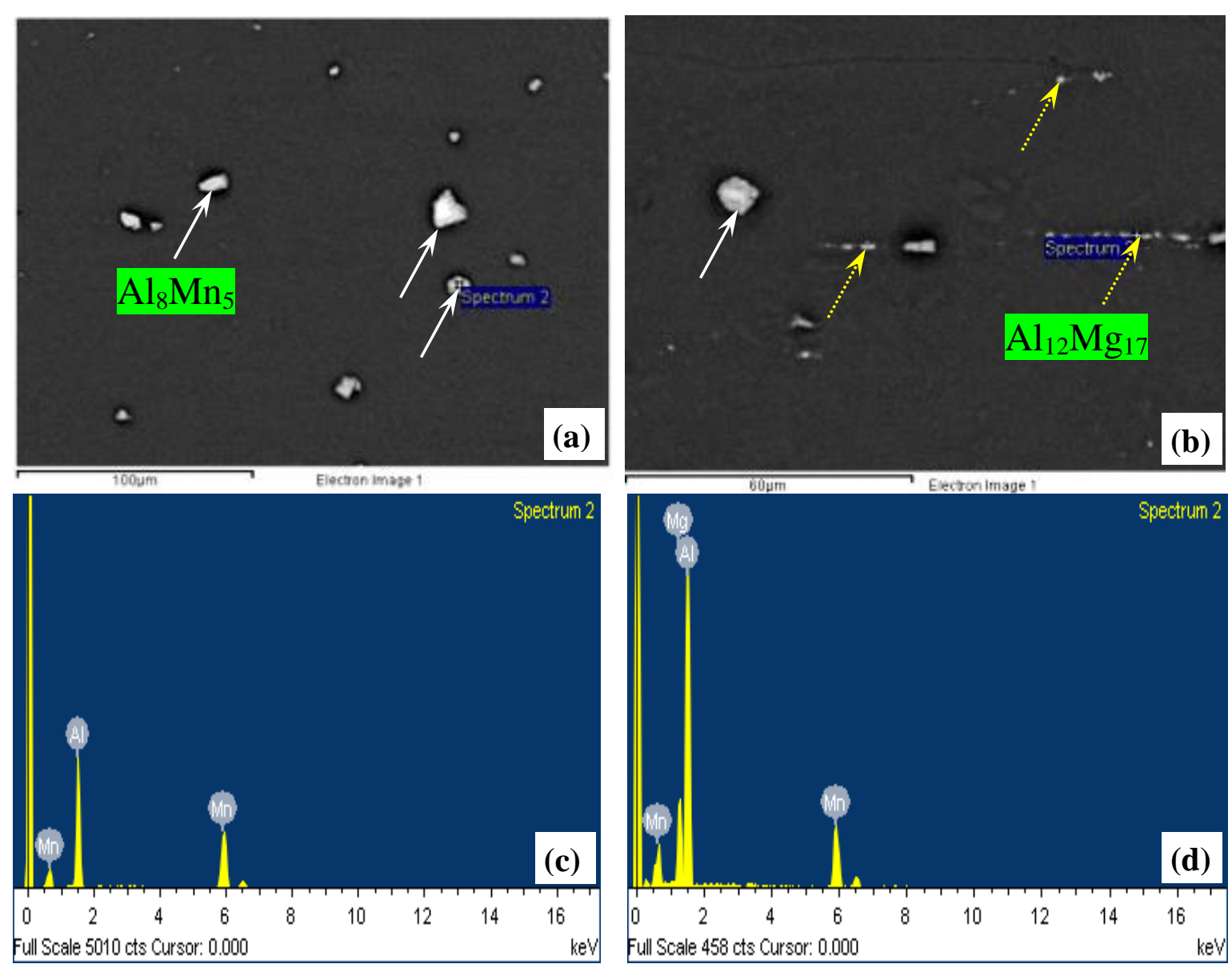

Figure 5.4: Secondary electron imaging and EDS point analysis of the Al-Mn and Al-Mg particles: (a) coarse $\mathrm{Al}_{8} \mathrm{Mn}_{5}$ particles as indicated by arrows in the $\mathrm{BM}$; (b) coarse $\mathrm{Al}_{8} \mathrm{Mn}_{5}$ and fine $\mathrm{Al}_{12} \mathrm{Mg}_{17}$ particles as indicated by arrows in the SZ; (c) EDS analysis of $\mathrm{Al}_{8} \mathrm{Mn}_{5}$ particles in the BM; (d) EDS analysis of $\mathrm{Al}_{12} \mathrm{Mg}_{17}$ particles in the $\mathrm{SZ}$. 

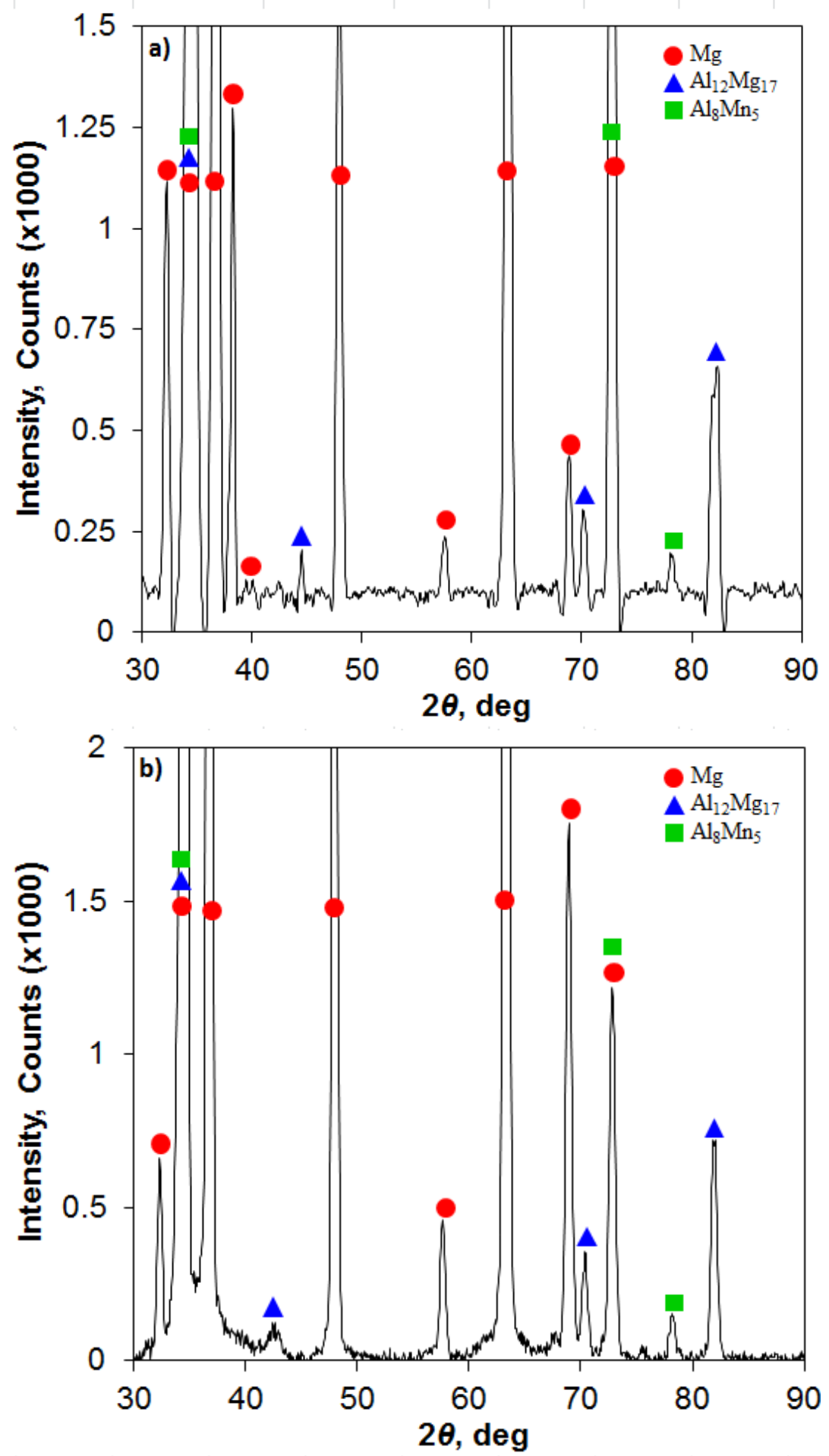

Figure 5.5: X-ray diffraction patterns obtained from the top surface of (a) BM; (b) SZ of the FSLWed AZ31B-H24 Mg alloy at $1000 \mathrm{rpm}$ and $20 \mathrm{~mm} / \mathrm{s}$; (c) SZ of the FSLWed AZ31B-H24 Mg alloy at $1500 \mathrm{rpm}$ and $20 \mathrm{~mm} / \mathrm{s}$; and (d) SZ of the FSLWed AZ31B-H24 Mg alloy at 1500 $\mathrm{rpm}$ and $10 \mathrm{~mm} / \mathrm{s}$. 

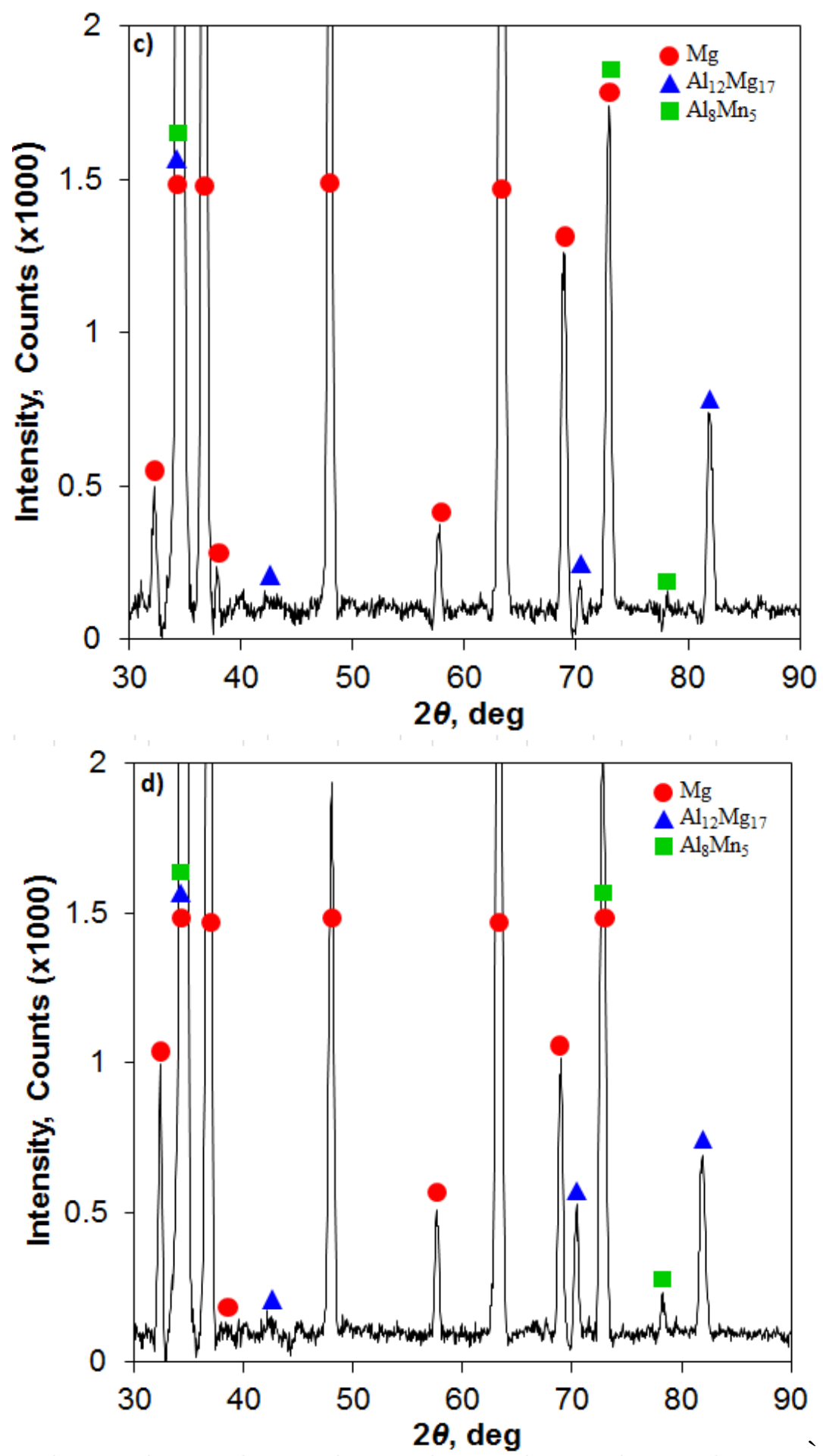

Figure 5.5: X-ray diffraction patterns obtained from the top surface of (a) BM; (b) SZ of the FSLWed AZ31B-H24 Mg alloy at $1000 \mathrm{rpm}$ and $20 \mathrm{~mm} / \mathrm{s}$; (c) SZ of the FSLWed AZ31B-H24 Mg alloy at $1500 \mathrm{rpm}$ and $20 \mathrm{~mm} / \mathrm{s}$; and (d) SZ of the FSLWed AZ31B-H24 Mg alloy at 1500 $\mathrm{rpm}$ and $10 \mathrm{~mm} / \mathrm{s}$. [Repeated] 


\subsection{Crystallographic texture}

The (0001), (10 $\overline{1} 0)$ and (10 $\overline{1} 1)$ pole figures determined from the FSLW joints at tool rotational rates of $1000 \mathrm{rpm}$ and $1500 \mathrm{rpm}$, and at welding speeds of $10 \mathrm{~mm} / \mathrm{s}$ and $20 \mathrm{~mm} / \mathrm{s}$ are shown in Figure 5.6 for the different locations. The BM shows a strong basal texture, where the basal plane (0001) normal was largely parallel to the normal direction (ND) with some grains tilted slightly towards the RD and the $\langle 10 \overline{1} 0\rangle$ and $\langle 10 \overline{1} 1\rangle$ directions were aligned or tilted in the TD (Figure 5.6(a-c)). It suggests that $(0001)<11 \overline{2} 0>$ texture component was mainly present in the current AZ31B-H24 BM. It has been reported that two major types of basal texture components, $(0001)<11 \overline{2} 0>$ and $(0001)<10 \overline{10}>$, are available, depending on the activation of the slip systems in the basal plane (either $\langle 11 \overline{2} 0\rangle$ single slip or $\langle 10 \overline{10}\rangle$ double slip oriented in the RD) in the Mg alloys [130-132]. Similarly, the $(0001)<11 \overline{2} 0>$ texture component in the AZ31 Mg alloy has also been reported in [133-138].

After FSLW the basal plane (0001) normal in the SZ became tilted slightly towards the TD, which was in direct contrast to the basal plane (0001) normal in the BM that was tilted slightly towards the RD (Figure 5.6(a-c)). This means that the relatively strong basal texture in the SZ resulted from the basal plane (0001) normal being largely parallel to the ND with only some grains slightly tilted in the TD. The occurrence of such a texture change in the SZ was attributed to the intense localized shear plastic flow near the top sheet surface that is a result of the material flow generated by the rotating tool on the AS of the weld during FSW. Since the preferential slip plane of the AZ31-H24 Mg alloy with an hcp structure is known to be the basal plane (0001) for 
plastic deformation at room temperature [139], the change in the texture may affect the tensile properties of the FSWed AZ31B-H24 Mg alloy as discussed later.

In the $\mathrm{BM}$, the prismatic planes (10i0) were oriented towards the TD in a concentric circular pattern at $90^{\circ}$ from the center of the pole figure, indicating the formation of a partially basal fiber texture (c-axis in the normal direction), which is also known as crystallographic fibering produced by crystallographic reorientation of the grains during deformation [140-142]. The partially crystallographic fibering in the BM could also be seen from the pyramidal planes (10 $\overline{1} 1)$ that formed an incomplete ring at approximately $45^{\circ}$ from the center of the pole figure towards the TD, as shown in (Figure 5.6(a-c). On the other hand, in the SZ most of the prismatic planes (10i10) and pyramidal planes (10i1) were oriented towards the RD, irrespective of the welding conditions (Figure 5.6(a-c). These changes reflect a $30^{\circ}$ rotation of the hcp unit cell with respect to the rolled sheet normal (or ND). It indeed suggests a texture transformation from the $(0001)<11 \overline{2} 0>$ texture component existing in the BM into the $(0001)<10 \overline{1} 0>$ texture component newly formed in the SZ after FSLW. Similar phenomena of texture change during compressive deformation of an extruded AM30 magnesium alloy were reported by Sarker and Chen [132], where the two initial types of basal textures $\{0001\}<21 \overline{1} 0>$ and $\{0001\}<10 \overline{1} 0>$ were transformed into two new types of textures $\{12 i 0\}<0001>$ and $\{01 \overline{1} 0\}<0001>$ during the compression, indicating that the c-axes of the hcp unit cells were always rotated towards the anti-compression direction due to the occurrence of extension twinning at room temperature. 


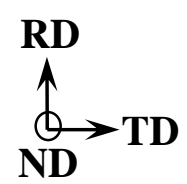

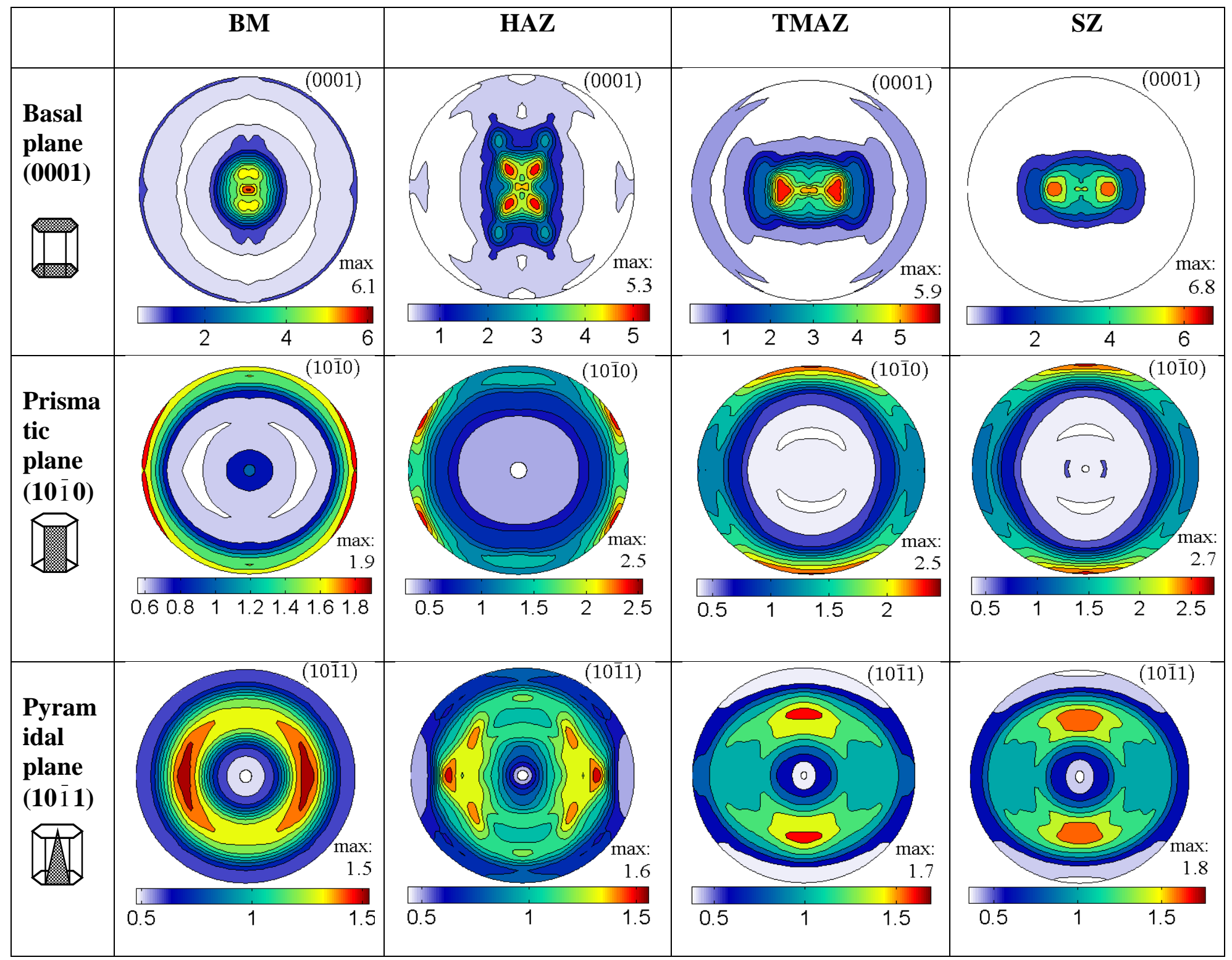

(a)

\section{ADVANCING SIDE}

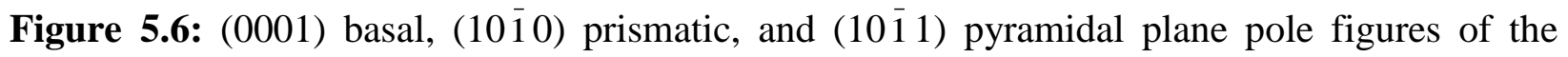
FSLWed AZ31B-H24 Mg alloy obtained from the SZ, TMAZ, HAZ and BM at (a) $1000 \mathrm{rpm}$ and $20 \mathrm{~mm} / \mathrm{s}$, (b) $1500 \mathrm{rpm}$ and $20 \mathrm{~mm} / \mathrm{s}$ and (c) $1500 \mathrm{rpm}$ and $10 \mathrm{~mm} / \mathrm{s}$. 


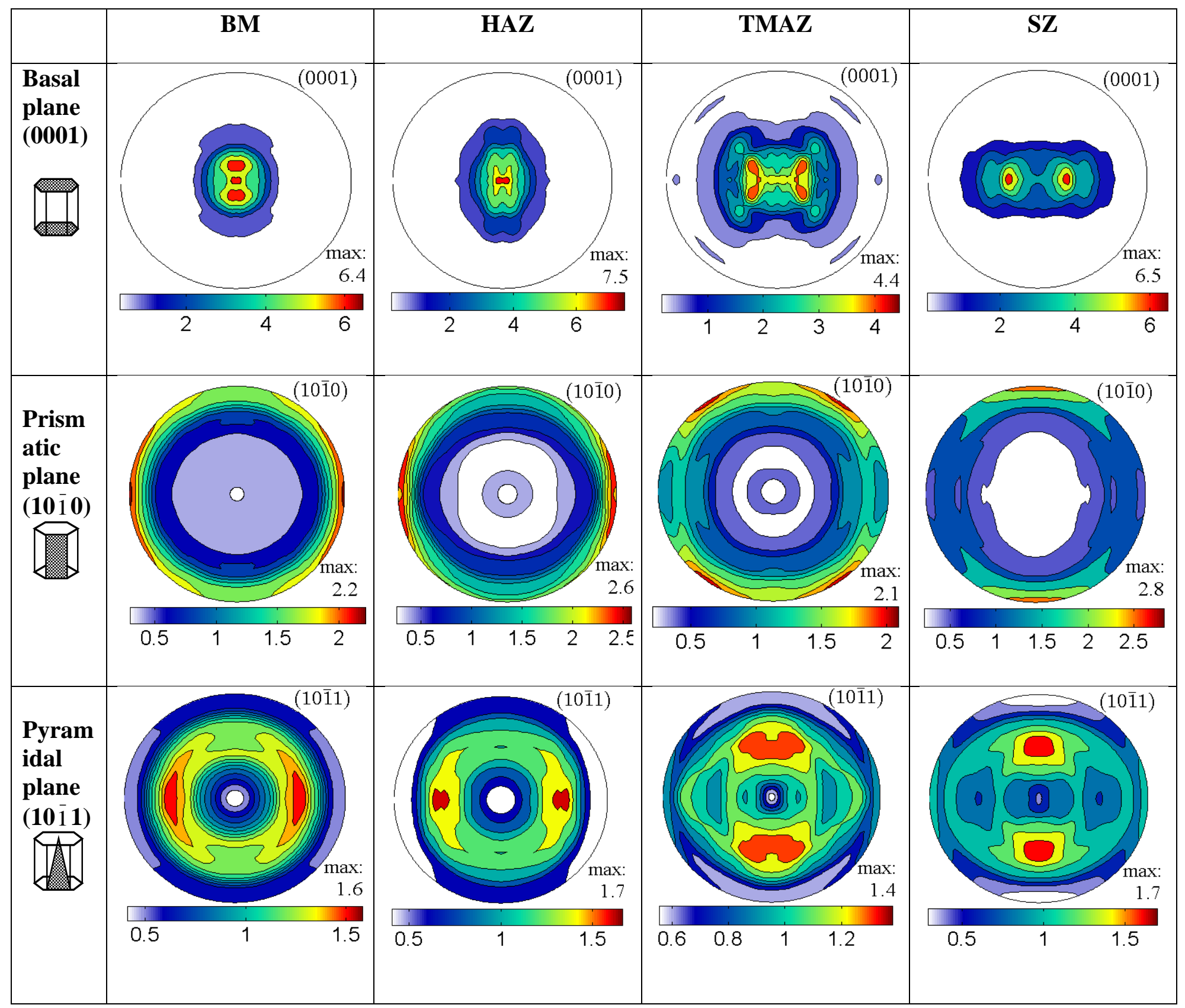

(b)

ADVANCING SIDE

Figure 5.6: (0001) basal, (10 $\overline{1} 0)$ prismatic, and (10 $\overline{1} 1)$ pyramidal plane pole figures of the FSLWed AZ31B-H24 Mg alloy obtained from the SZ, TMAZ, HAZ and BM at (a) $1000 \mathrm{rpm}$ and $20 \mathrm{~mm} / \mathrm{s}$, (b) $1500 \mathrm{rpm}$ and $20 \mathrm{~mm} / \mathrm{s}$ and (c) $1500 \mathrm{rpm}$ and $10 \mathrm{~mm} / \mathrm{s}$. [Repeated] 


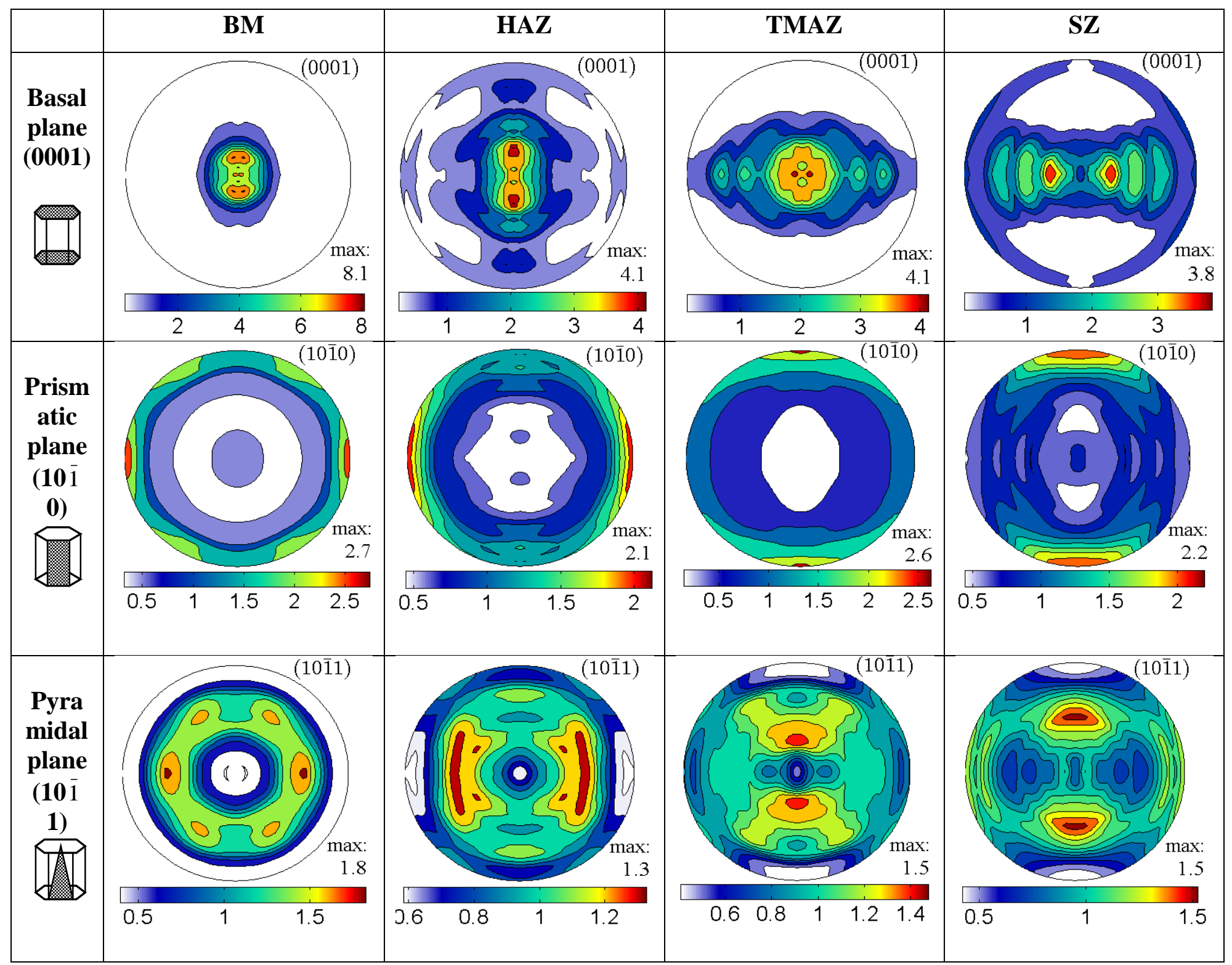

(c)

ADVANCING SIDE

Figure 5.6: (0001) basal, (10ī0) prismatic, and (1011) pyramidal plane pole figures of the FSLWed AZ31B-H24 Mg alloy obtained from the SZ, TMAZ, HAZ and BM at (a) $1000 \mathrm{rpm}$ and $20 \mathrm{~mm} / \mathrm{s}$, (b) $1500 \mathrm{rpm}$ and $20 \mathrm{~mm} / \mathrm{s}$ and (c) $1500 \mathrm{rpm}$ and $10 \mathrm{~mm} / \mathrm{s}$. [Repeated] 
The texture change in the present FSLWed AZ31B-H24 Mg alloy, as shown in Figure 5.7, may be related to the localized shear plastic deformation via an intense circumferential stirring in the SZ likely through both twinning and dislocation slip due to the occurrence of elevated temperatures in the process. To better understand the texture change in the SZ after FSLW, a schematic illustration of a hep unit cell showing the transformation of texture from $(0001)<11 \overline{2} 0>$ component $(\mathrm{BM})$ into the $(0001)<10 \overline{1} 0>$ component (SZ) is shown in Figure 5.7. Let us start with the (0001) basal plane of a hcp unit cell in the BM where the six prismatic planes are perpendicular to the rolled sheet/paper plane and numbered from 1 to 6 . Based on the pole figures of BM shown in Figure 5.6, the initial unit cell in the BM should be positioned in such a way that the prismatic planes (3 and 6) are parallel to the RD direction and perpendicular to the TD (Figure 5.7(a)). As mentioned above, due to the intense circumferential stirring action occurring during FSLW, the $(0001)<1010>$ type of basal texture was formed in the SZ (Figure 5.6), where both the prismatic planes $(10 \overline{1} 0)$ and pyramidal planes $(10 \overline{1} 1)$ exhibited a $30^{\circ}$ clockwise rotation with respect to the paper plane normal (Figure 5.7(b)). However, due to the six-fold symmetry of the hep unit cell, this particular type of texture can be repeated in a certain rotation of the unit cell (Figure 5.7(c-d)). The possible angles of rotation of a unit cell during FSLW can be expressed as follows:

$$
\theta=\theta_{i}+(n-1) \times 60^{\circ}
$$

where $\theta$ is the angle of rotation, $\theta_{\mathrm{i}}$ is the initial angle of rotation (i.e., $\left.30^{\circ}\right)$ and $\mathrm{n}$ is an integer $(\mathrm{n}=$ $1,2,3, \ldots)$. The present finding is also supported by the work of Park et al. [27] on the FSW of 6.3-mm thick wrought AZ61 Mg alloy that revealed that both the prismatic and pyramidal planes were oriented in the RD, which was attributed to the intense stirring/plastic flow in the stirred region. In Mg alloys, the critical resolved shear stress for the basal slip system is much lower 
than those of the prismatic and pyramidal slip systems at room temperature [143]. Therefore, the basal slip may dominate the plastic deformation of the FSWed Mg alloy at room temperature, while both the basal and non-basal slip systems may be operational during hot deformation at temperatures higher than about $600^{\circ} \mathrm{K}\left(327^{\circ} \mathrm{C}\right)$ [144]. Noticeably, the crystallographic orientation changes in the HAZ were smaller; the HAZ had a texture more similar to the BM in the basal plane (0001), and the prismatic (10 $\overline{1} 0)$ and pyramidal planes (10 $\overline{1} 1)$ were mainly oriented towards the TD also, as shown in Figure 5.6(a-c). Meanwhile, the TMAZ texture basically lay in-between those of the HAZ (or BM) and SZ, it was nonetheless more similar to the SZ texture, i.e., the $(0001)<10 \overline{1} 0>$ texture (Figure 5.6(a-c)).

The effect of the tool rotational rate and welding speed on the texture is also shown in Figure 5.6(a-c), where the (0001), (1010) and (1011) pole figures were obtained from the center of the SZ in the friction stir lap welds joined at $1000 \mathrm{rpm}$ and $20 \mathrm{~mm} / \mathrm{s}$ (Figure 5.6(a)), $1500 \mathrm{rpm}$ and $20 \mathrm{~mm} / \mathrm{s}$ (Figure 5.6(b)), and $1500 \mathrm{rpm}$ and $10 \mathrm{~mm} / \mathrm{s}$ (Figure 5.6(c)). As mentioned above, these pole figures indicate that similar texture changes occurred in the AZ31B-H24 Mg alloy after FSLW. However, the relative texture intensity in the SZ was different, which is summarized in Table 5.3 with the values given in multiples of random distribution (MRD). It is clear that after FSLW the intensity of the basal plane (0001), prismatic plane (10 $\overline{1} 0)$ and pyramidal plane (10 $\overline{1} 1)$ in the SZ all increased at a welding speed of $20 \mathrm{~mm} / \mathrm{s}$ and a rotational rate of $1000 \mathrm{rpm}$ or 1500 rpm, in comparison with the BM. Specifically, the maximum intensity of (0001) poles in the SZ was observed to decrease with increasing rotational rate or decreasing welding speed. This was due to the fact that the higher tool rotational rate (i.e., $1500 \mathrm{rpm}$ ) or lower welding speed (i.e. 10 $\mathrm{mm} / \mathrm{s}$ ) generated a higher temperature in the SZ, which then resulted in more complete dynamic 
recrystallization. This would in turn lead to a progressively weaker texture or more random orientation when the tool rotational rate increases from $1000 \mathrm{rpm}$ to $1500 \mathrm{rpm}$ and the welding speed decreases from $20 \mathrm{~mm} / \mathrm{s}$ to $10 \mathrm{~mm} / \mathrm{s}$. Overall, these findings are supported by Patel et al. [145] who used an ultrasonic spot welding technique to lap weld AZ31B-H24 Mg alloy and reported that the crystallographic texture corresponded to the change in the deformation and recrystallization mechanisms. Similar observations were also reported for FSWed AZ31B billets and extruded plates [55], where a more random orientation at higher rotational rates was observed.

Table 5.3: Effect of tool rotational rate and welding speed on the maximum pole intensities (in multiples of random distribution (MRD)) in FSLWed AZ31B-H24 Mg alloy.

\begin{tabular}{|c|c|c|c|c|c|c|c|c|c|}
\hline & \multicolumn{3}{|c|}{$\begin{array}{l}\text { Rotational rate: } 1000 \mathrm{rpm} \text {, } \\
\text { Welding speed: } 20 \mathrm{~mm} / \mathrm{s}\end{array}$} & \multicolumn{3}{|c|}{$\begin{array}{l}\text { Rotational rate: } 1500 \mathrm{rpm} \text {, } \\
\text { Welding speed: } 20 \mathrm{~mm} / \mathrm{s}\end{array}$} & \multicolumn{3}{|c|}{$\begin{array}{l}\text { Rotational rate: } 1500 \mathrm{rpm} \text {, } \\
\text { Welding speed: } 10 \mathrm{~mm} / \mathrm{s}\end{array}$} \\
\hline & $\begin{array}{l}(0001) \\
\text { basal } \\
\text { plane }\end{array}$ & $\begin{array}{c}(1010) \\
\text { prismatic } \\
\text { plane }\end{array}$ & $\begin{array}{c}(10 \overline{1} 1) \\
\text { pyramidal } \\
\text { plane }\end{array}$ & $\begin{array}{l}(0001) \\
\text { basal } \\
\text { plane } \\
\end{array}$ & $\begin{array}{c}(1010) \\
\text { prismatic } \\
\text { plane }\end{array}$ & $\begin{array}{c}(10 \overline{1} 1) \\
\text { pyramidal } \\
\text { plane }\end{array}$ & $\begin{array}{l}\text { (0001) } \\
\text { basal } \\
\text { plane }\end{array}$ & $\begin{array}{c}(1010) \\
\text { prismatic } \\
\text { plane }\end{array}$ & $\begin{array}{c}(1011) \\
\text { pyramidal } \\
\text { plane }\end{array}$ \\
\hline $\mathrm{BM}$ & 6.1 & 1.9 & 1.5 & 6.4 & 2.2 & 1.6 & 8.1 & 2.7 & 1.8 \\
\hline HAZ & 5.3 & 2.5 & 1.6 & 7.5 & 2.6 & 1.7 & 4.1 & 2.1 & 1.3 \\
\hline TMAZ & 5.9 & 2.5 & 1.7 & 4.4 & 2.1 & 1.4 & 4.1 & 2.6 & 1.5 \\
\hline SZ & 6.8 & 2.7 & 1.8 & 6.5 & 2.8 & 1.7 & 3.8 & 2.2 & 1.5 \\
\hline
\end{tabular}




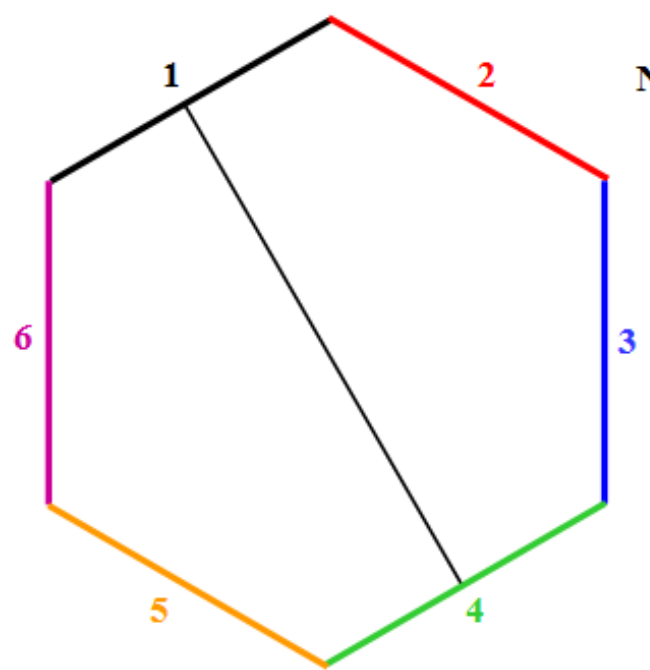

(a)

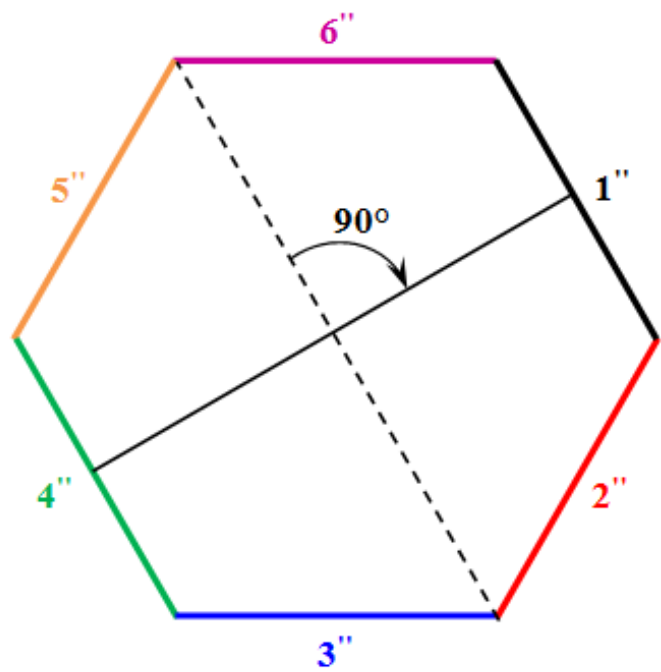

(c)

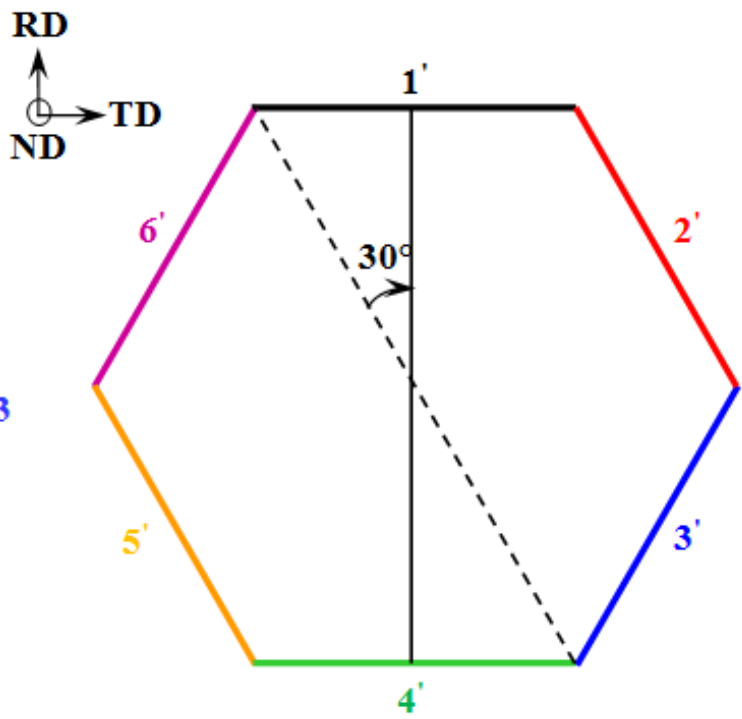

(b)

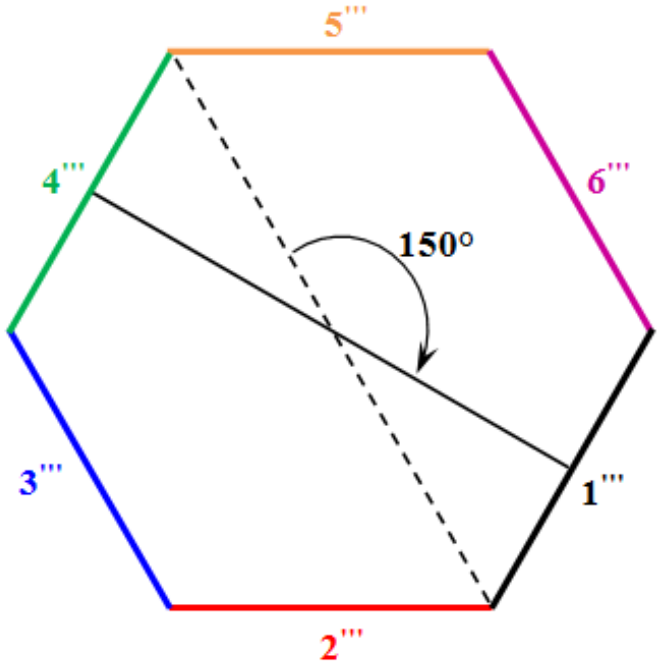

(d)

Figure 5.7: Schematic illustration of the basal plane (0001) in a hcp unit cell, where the six prismatic planes $\{10 \overline{1} 0\}$ are perpendicular to the paper plane and indicated by $1,2, \ldots, 6$, showing the change of texture from $(0001)<11 \overline{2} 0>$ component $(\mathrm{BM})$ into the $(0001)<10 \overline{1} 0>$ component (SZ), (a) BM, and (b-d) SZ with different angles of rotation after FSLW. 


\subsection{Microhardness}

Figure 5.8 shows the Vickers microhardness profiles across the SZ of the FSLWed AZ31B-H24 $\mathrm{Mg}$ alloy. For all the welds joined at different tool rotational rates and welding speeds, the hardness profiles were measured along the weld cross-section at the mid-thickness of the top sheet. In each welding condition, a hardness trough was observed with higher values in the BM relative to those in the HAZ, TMAZ and SZ. Specifically, the hardness decreased gradually from about 70-75 $\mathrm{HV}$ in the BM to approximately 55-60 HV at the center of the SZ of the welds, representing a decrease of up to $\sim 25 \%$. This hardness change can be attributed to the effect of the welding parameters on the heat input during FSW and the resulting microstructural evolution (i.e., grain shape, size and texture) in the SZ, as depicted previously in Figures 5.1-5.3 and tabulated in Table 5.1. Specifically, at a constant welding speed of $20 \mathrm{~mm} / \mathrm{s}$, an increase in the rotational rate from $1000 \mathrm{rpm}$ to $1500 \mathrm{rpm}$ was observed to decrease the average value of the hardness in the SZ from $60 \mathrm{HV}$ to about $55 \mathrm{HV}$, inevitably due to the greater heat input and coarser SZ grain size in the latter welding condition. At $1500 \mathrm{rpm}$, a decrease in the welding speed from $20 \mathrm{~mm} / \mathrm{s}$ to $10 \mathrm{~mm} / \mathrm{s}$ was observed to reduce the average hardness in the SZ slightly further to roughly $52 \mathrm{HV}$. Moreover, within different regions of the lap weld, there was a progressive increase in the grain size from the BM to the $\mathrm{SZ}$ as tabulated in Table 5.1, which corresponded well to the observed evolution in the microhardness, as shown in Figure 5.8. 


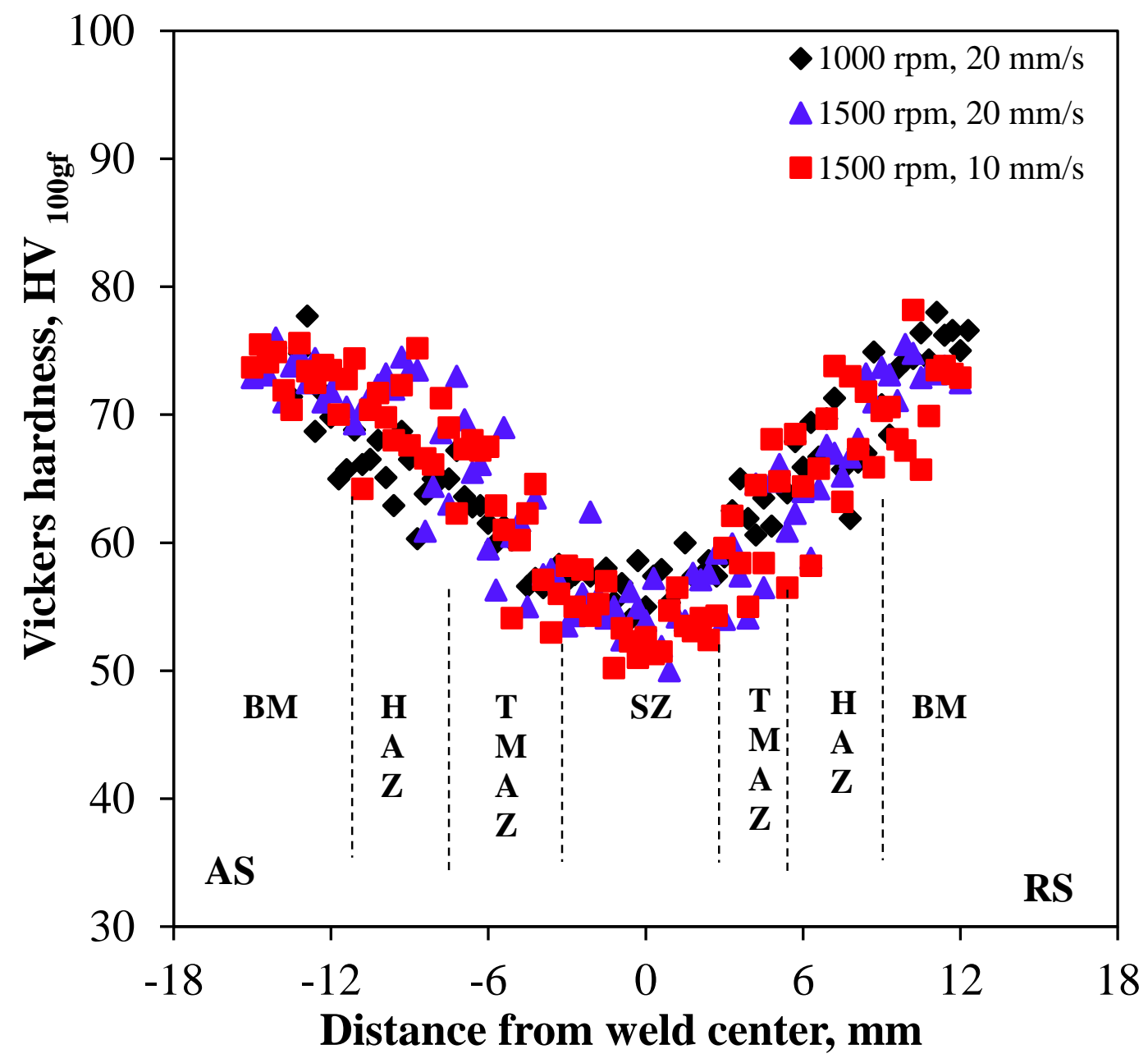

Figure 5.8: Typical microhardness profiles at the mid-thickness of the top sheet in the FSLWed AZ31B-H24 Mg alloy assembled at different tool rotational rates and welding speeds.

Another reason for the lower hardness in the SZ may be related to the texture variation. During FSW, plastic material flow occurred in the SZ and resulted in a more random orientation (Figure 5.6(a-c)) relative to that in the BM, i.e., the basal plane (0001) rotated around the periphery of the stirring pin, thereby producing a soft region around the SZ [27]. As a result, the low hardness value observed in the SZ of the FSLWed joints in the present study may also be associated with the local texture variation. 


\section{$5.4 \quad$ Tensile shear properties}

Figure 5.9 shows typical load-displacement curves of the FSLWed AZ31B-H24 Mg alloy joined at different tool rotational rates and welding speeds and then tensile shear tested at a crosshead speed of $1 \mathrm{~mm} / \mathrm{min}$. Significant changes in the failure load for the friction stir lap welds joined in the different conditions (Table 5.1) were observed. Specifically, the friction stir lap weld joined at a rotational rate of $1000 \mathrm{rpm}$ and welding speed of $20 \mathrm{~mm} / \mathrm{s}$ was noted to have the highest failure load of $6.52 \mathrm{kN}$. At a constant welding speed of $20 \mathrm{~mm} / \mathrm{s}$, an increase in the tool rotational rate to $1500 \mathrm{rpm}$ resulted in a significant decrease $(58 \%)$ in the failure load to $2.16 \mathrm{kN}$ (Figure 5.9 and Table 5.1). In contrast, a decrease in the welding speed from $20 \mathrm{~mm} / \mathrm{s}$ to 10 $\mathrm{mm} / \mathrm{s}$ at a constant tool rotational rate of $1500 \mathrm{rpm}$ gave almost the same failure load (i.e., 2.16 $\mathrm{kN}$ and $2.22 \mathrm{kN}$ ).

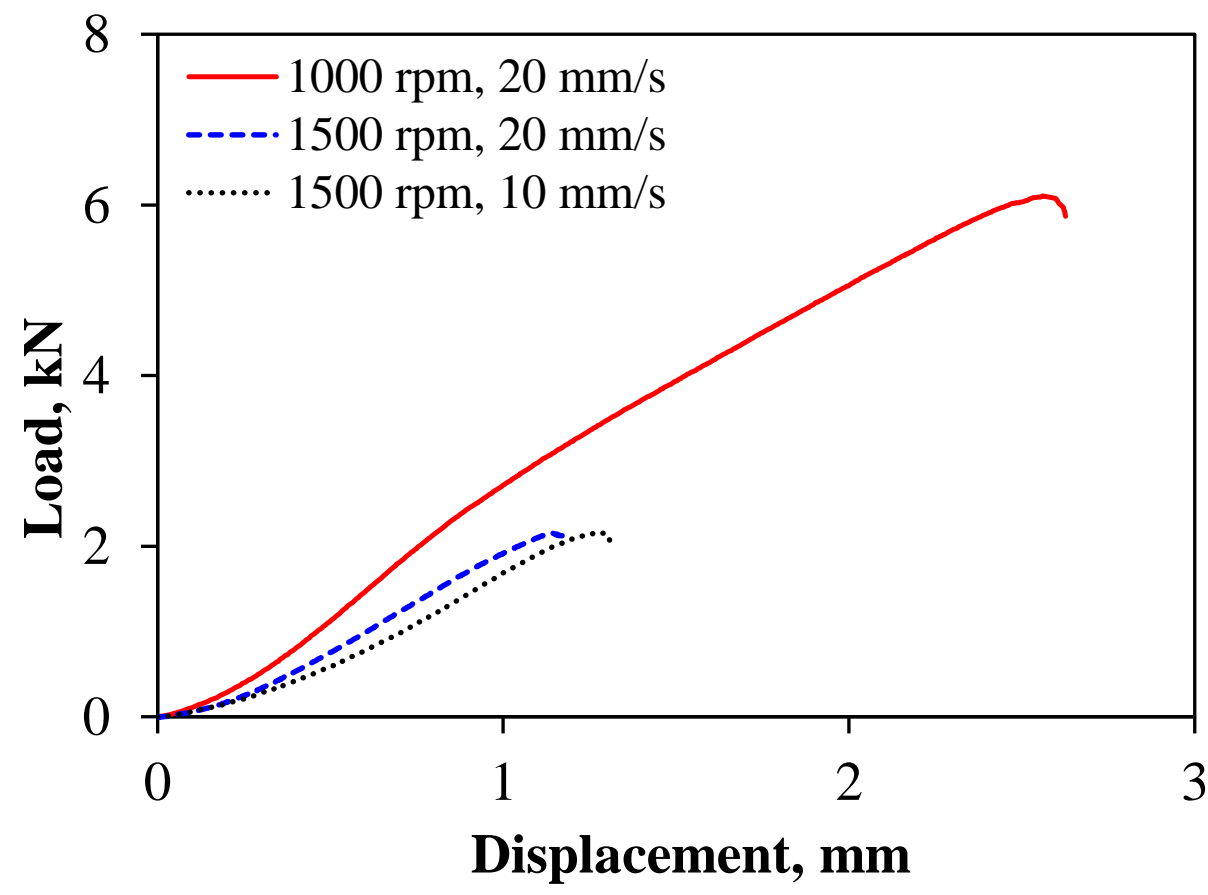

Figure 5.9: Typical load versus displacement curves of the FSLWed AZ31B-H24 Mg alloy assembled at different tool rotational rates and welding speeds. 
A decrease in the failure load with increasing tool rotational rate $(1000 \mathrm{rpm}$ to $1500 \mathrm{rpm})$ at a constant welding speed of $20 \mathrm{~mm} / \mathrm{s}$ can be reasoned on the basis of the heat input during FSLW and the resulting increase in grain size in the weldment. As grain boundaries are major obstacles to dislocation slip in the material, a smaller grain size would more effectively hinder dislocation motion and render a higher resistance to localized plastic deformation that then culminates to a higher failure load. However, the heat input and grain size are evidently not the only factors influencing the failure load as evidenced from the $1500 \mathrm{rpm}$ and $10 \mathrm{~mm} / \mathrm{s}$ FSLW condition. That is, both the heat input and grain size are higher in the $1500 \mathrm{rpm}$ and $10 \mathrm{~mm} / \mathrm{s}$ FSLW condition relative to the $1500 \mathrm{rpm}$ and $20 \mathrm{~mm} / \mathrm{s}$ condition, but their failure loads are similar. One explanation for this occurrence may be related to the nature of hooking defects in the friction stir lap welds as reported in [26]. In particular at $1000 \mathrm{rpm}$ and $10 \mathrm{~mm} / \mathrm{s}$, the relatively "cold" weld conditions led to almost complete elimination of the hooking defect, which was quite prominent in the AZ31B-H24 Mg alloy friction stir lap welds assembled at $1500 \mathrm{rpm}$ with an advancing speed of $10 \mathrm{~mm} / \mathrm{s}$ or $20 \mathrm{~mm} / \mathrm{s}$.

Besides the influence of these microstructural changes on the properties, crystallographic texture/orientation distribution can also strongly influence the flow stress behavior during tensile loading, since the plastic deformation arises mainly from the dislocations slip on the closedpacked basal planes with the minimum critical resolved shear stress [1]. When the FSLWed joints were deformed at room temperature along the RD (loading direction), the basal planes had a tendency to rotate and lie parallel to the rolled sheet surface and the tensile axis. This may be a result of the twinning and dislocation activity in favorably oriented grains as well as twindislocation interactions during deformation $[15,132,146-148]$. For instance, in comparison to the 
welding conditions at a tool rotational rate of $1500 \mathrm{rpm}$, the stronger intensity of the basal plane (0001) present in the higher hardness SZ of the $1000 \mathrm{rpm}$ and $20 \mathrm{~mm} / \mathrm{s}$ condition (i.e., $6.8 \mathrm{MRD}$ vs. 6.5 MRD and 3.8 MRD in Table 5.3 or Figure 5.6) suggests that the basal planes of more grains were oriented parallel to the rolled sheet surface, i.e., the basal plane normal of more grains was perpendicular to the sheet surface. While performing the tensile test in such a case, plastic deformation becomes more difficult in the SZ, which has the lowest hardness in all the FSLWed joints (Figure 5.8), since the Schmid factor $m=\cos \phi \cdot \cos \lambda$ [149] is nearly zero due to the basal (0001) slip plane of most grains being parallel to the rolled sheet surface; $\phi$ is the angle between the normal to the slip plane and the tensile axis, and $\lambda$ is the angle between the slip direction and the tensile axis. As a result, an increasingly higher load is needed to continue the tensile deformation until failure occurs, leading to a higher failure load in the case of $1000 \mathrm{rpm}$ and $20 \mathrm{~mm} / \mathrm{s}$ welding condition (Table 5.1).

Figure 5.10 shows the ruptured tensile samples of the FSLWed AZ31B-H24 Mg alloy that were joined at different tool rotational rates and welding speeds. It is clear that the tensile failure of the lap welds occurred basically in the vicinity of the SZ/TMAZ on the AS. This region experienced maximum tensile stresses during tensile shear testing and had the maximum hooking defects, which can not only reduce the effective sheet thickness but also cause stress/strain concentration [26]. In addition, it has been reported that the texture distribution of the basal plane (0001) has strongly influences on the tensile failure which decreases the tensile properties of a friction stir welded AZ61 Mg alloy [144]. As seen in Figure 5.6(a-c), the texture distribution of the basal plane (0001) from the BM to the TMAZ and SZ of the FSLWed AZ31B-H24 Mg alloy has been changed, i.e., the c-axes of the hcp unit cells in most grains were rotated from the orientation 
distributed slightly in the RD in the BM to that distributed in the TD in the TMAZ and SZ. In the deformation of $\mathrm{Mg}$ alloys at room temperature, both extension twinning and basal slip may normally occur, since both deformation modes have a relatively lower critical resolved shear stress (CRSS) at room temperature [150]. However, which mode would be activated is dependent on the direction of the applied load during tension. In general, the extension twinning occurs when a tensile load is applied along the c-axes of an hcp unit cell, or when a compressive load is applied perpendicularly to the c-axes [151-154]. As mentioned above, the c-axes of the hcp unit cells in the TMAZ and SZ are mainly distributed in the TD direction, i.e., being always perpendicular to the tensile loading direction (or $\mathrm{RD}$ ). The loading condition present in the TMAZ and SZ is equivalent to a compressive loading along the c-axes of the hcp unit cells. In this case only basal slip, rather than extension twinning, would be activated along the RD in the TMAZ/SZ during the tensile tests. Magnesium alloys deformed in the mode of basal slip exhibited higher yield strength than those deformed in the mode of extension twinning [137, 155]. For instance, the yield strength was observed to be considerably (over 2 times) higher than that obtained in the deformation mode of extension twinning, as reported recently by Sarker and Chen [156] in an extruded AM30 Mg alloy. Therefore, the TMAZ and SZ would be expected to be strengthened locally by the texture distribution after FSW. As such, the texture distribution has little influence on the tensile failure location. Therefore, the failure of the FSLWed AZ31B$\mathrm{H} 24 \mathrm{Mg}$ alloy joints around the TMAZ and SZ on the AS (Figure 5.10) was mainly attributed to the two major dominant factors: (1) maximum tensile stress experienced and (ii) the presence of the hooking defects. 

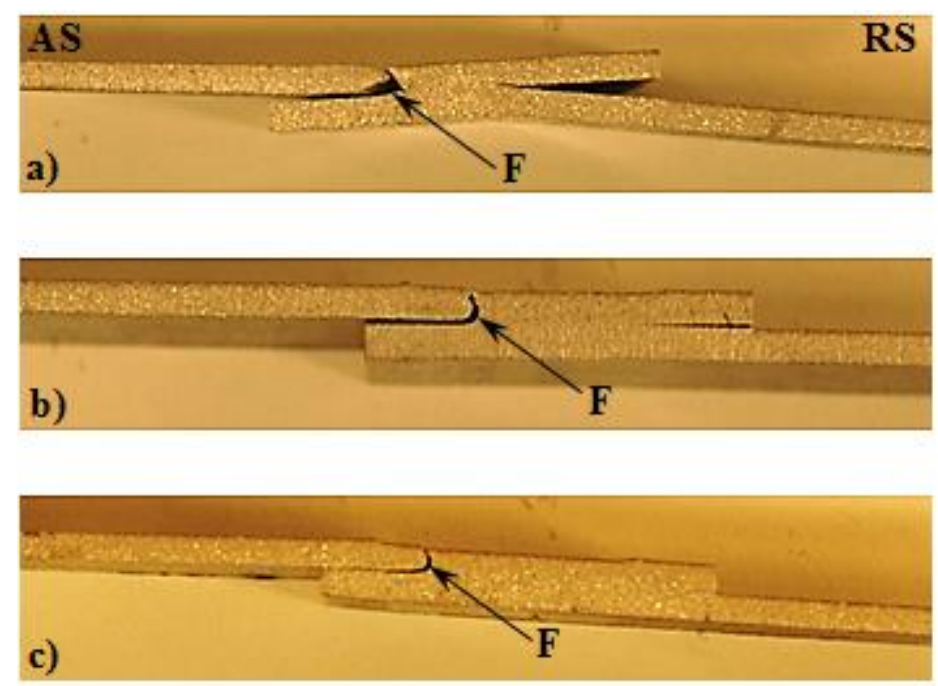

Figure 5.10: The fracture location, demarcated by the symbol "F", in the ruptured tensile samples of FSLWed AZ31B-H24 Mg alloy obtained at various combinations of tool rotational rate and welding speed: (a) $1000 \mathrm{rpm}-20 \mathrm{~mm} / \mathrm{s}$, (b) $1500 \mathrm{rpm}-20 \mathrm{~mm} / \mathrm{s}$, and (c) $1500 \mathrm{rpm}-10$ $\mathrm{mm} / \mathrm{s}$.

\section{$5.5 \quad$ Tensile Fractography}

After tensile testing, the fractured surfaces of the samples were examined using SEM. Figures 5.11-5.13 shows the secondary electron images of the tensile fracture surfaces of the FSLWed joints assembled at the different tool rotational rates and welding speeds. The tensile fracture surface characteristics appeared to be relatively similar in all the welding conditions. Figures 5.11(a), 5.12(b) and 5.13(b) show that crack initiation occurred essentially from the local stress concentration due to the welding defects, such as the hooking defect in the SZ/TMAZ region in the AS or near the surface [125], as indicated by the arrows. Such welding defects were considered to form due to excessive heat input during FSLW [108]. Figure 5.11 (c,d) show the crack propagation regions in the $1000 \mathrm{rpm}$ and $20 \mathrm{~mm} / \mathrm{s}$ condition which exhibited some characteristics of ductile fracture (e.g., parabolic dimples from the shear loading). In contrast, 
Figures 5.12(c,d) and 5.13(c,d) show the crack propagation regions in the $1500 \mathrm{rpm}$ at $10 \mathrm{~mm} / \mathrm{s}$ and $20 \mathrm{~mm} / \mathrm{s}$ conditions, respectively, where the fracture characteristics contained both facets and dimples. The inherently greater ductility and load-bearing capacity of the welds manufactured at $1000 \mathrm{rpm}$ and $20 \mathrm{~mm} / \mathrm{s}$ as reflected in the tensile shear properties and fracture behavior was linked to the microstructural evolutions during FSLW, including the defects, grain size, phase constituents and texture, as described previously.
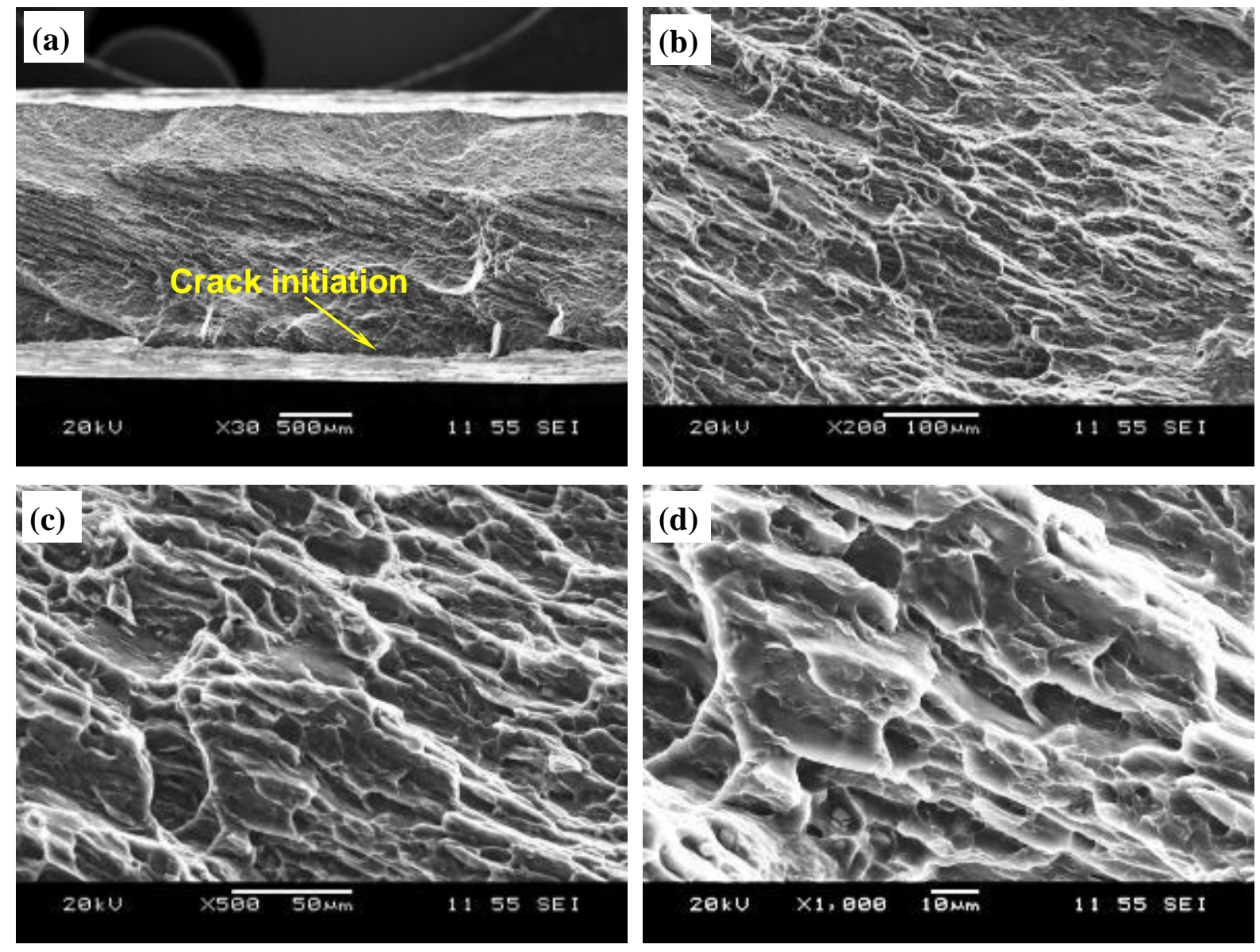

Figure 5.11: Typical SEM images of the tensile shear fracture surface of a FSLWed AZ31B$\mathrm{H} 24 \mathrm{Mg}$ alloy assembled at a rotational rate of $1000 \mathrm{rpm}$ and a welding speed of $20 \mathrm{~mm} / \mathrm{s}$ : (a) overall view of a fracture surface and crack initiation site, (b) crack initiation site at a higher magnification, (c) crack propagation region at a lower magnification and (d) crack propagation region at a higher magnification. 

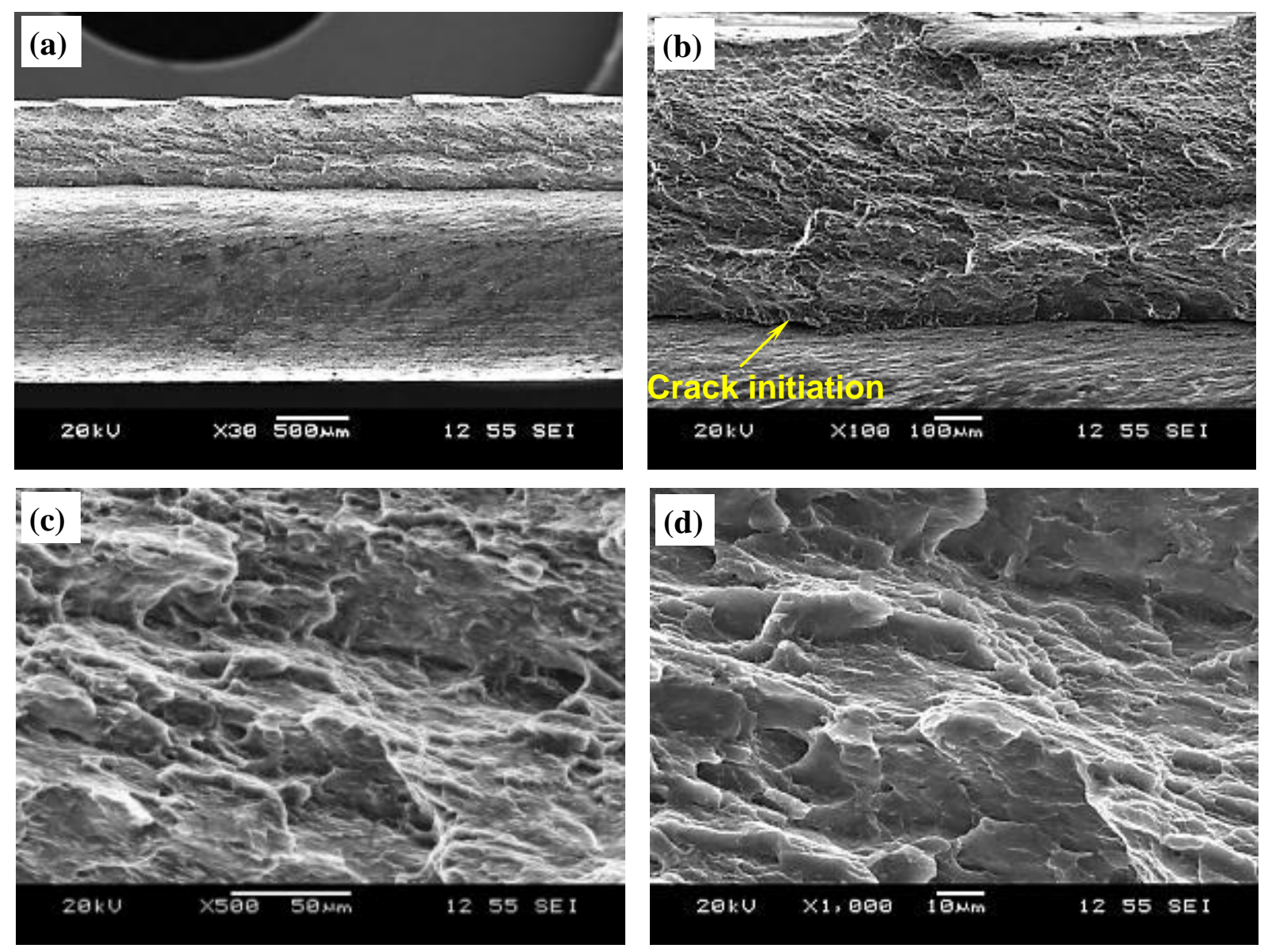

Figure 5.12: Typical SEM images of the tensile fracture surface of a FSLWed AZ31B-H24 Mg alloy assembled at a rotational rate of $1500 \mathrm{rpm}$ and a welding speed of $20 \mathrm{~mm} / \mathrm{s}$ : (a) overall view of a fracture surface, (b) crack initiation site, (c) crack propagation region at a lower magnification and (d) crack propagation region at a higher magnification. 

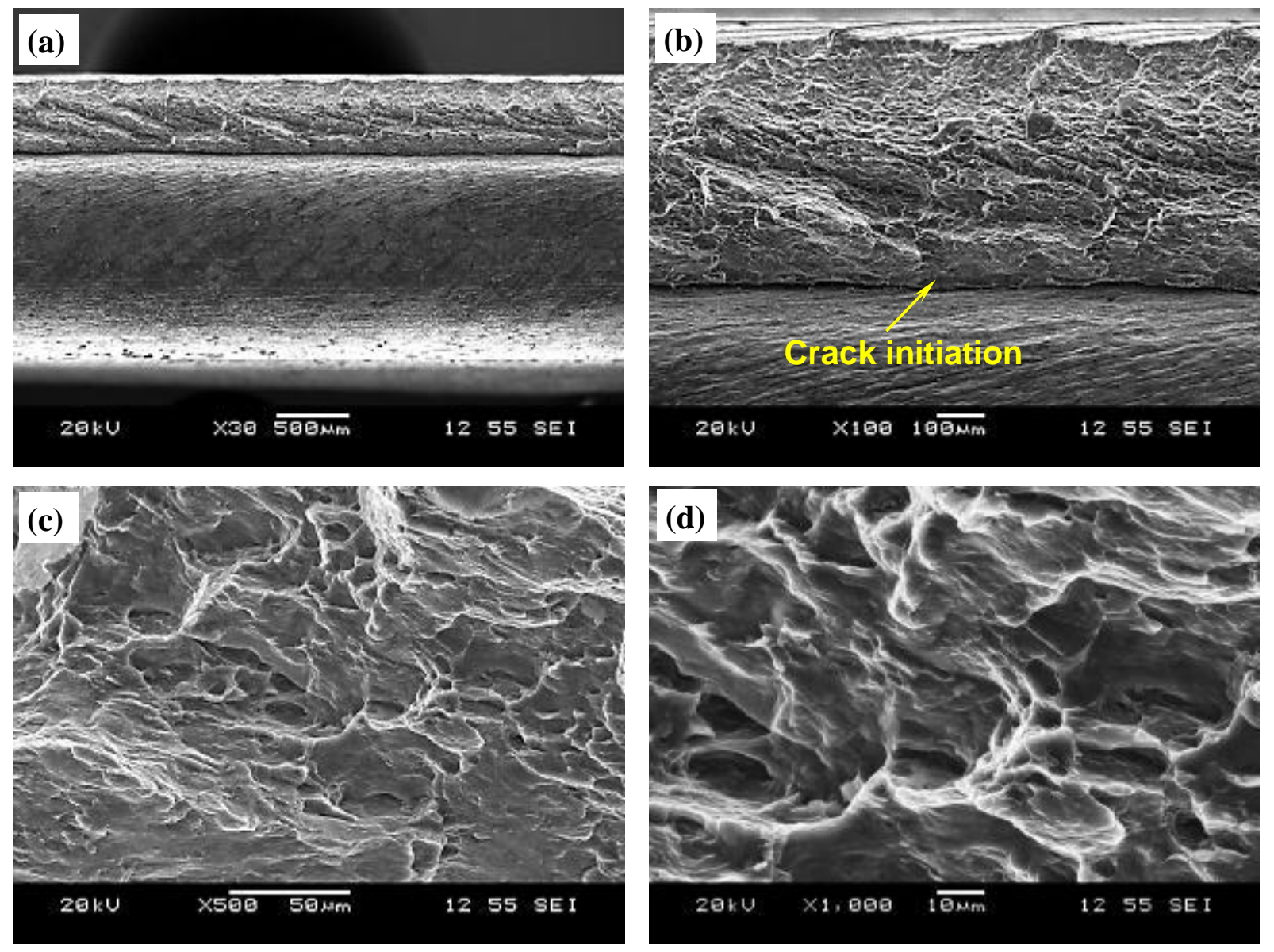

Figure 5.13: Typical SEM images of the tensile fracture surface of a FSLWed AZ31B-H24 Mg alloy assembled at a rotational rate of $1500 \mathrm{rpm}$ and a welding speed of $10 \mathrm{~mm} / \mathrm{s}$ : (a) overall view of a fracture surface, (b) crack initiation site, (c) crack propagation region at a lower magnification and (d) crack propagation region at a higher magnification. 


\subsection{Summary of the results in this chapter}

- Under the welding conditions examined in this work, the stir zone, thermomechanicallyaffected zone and heat affected zone exhibited grain coarsening relative to the base material microstructure. In addition, the grain size in each region of the weldment increased with increasing heat input (i.e., increasing tool rotational rate and decreasing welding speed).

- Microstructural characterization showed that the stir zone of the friction stir lap welds contained $\mathrm{Al}_{8} \mathrm{Mn}_{5}$ and $\beta-\mathrm{Al}_{12} \mathrm{Mg}_{17}$ particles, similar to that in $\mathrm{AZ31B}-\mathrm{H} 24 \mathrm{Mg}$ alloy base metal.

- The base metal contained a strong crystallographic texture of type $(0001)<11 \overline{2} 0>$, with the basal planes (0001) largely parallel to the rolled sheet surface (or slightly tilted towards the rolling direction) and the $\langle 11 \overline{2} 0>$ directions aligned in the rolling direction of the sheet. After friction stir lap welding, the texture in the stir zone (and thermomechanically-affected zone) became another type of texture $(0001)<10 \overline{1} 0>$, where the basal planes $(0001)$ were slightly tilted towards the transverse direction, and the prismatic planes (10 10$)$ and pyramidal planes (10ī1), exhibiting a certain degree of fiber-like textures, had a $30^{\circ}+(n-1) \times 60^{\circ}$ rotation $(n=1$, $2,3, \ldots)$ with respect to the rolled sheet normal, with the situation of heat affected zone texture laying in-between those of base metal and thermomechanically-affected zone or stir zone. This was attributed to the intense circumferential stirring/shear plastic flow in the vicinity of the pin surface.

- With increasing tool rotational rate and decreasing welding speed, the maximum intensity of basal poles (0001) in the stir zone decreased due to the higher heat input during friction stir 
lap welding, which would allow a higher degree of dynamic recrystallization to completion and thereby render a weaker or more random texture.

- A hardness trough was observed in the friction stir lap welds of AZ31B-H24 Mg alloy; the lowest hardness values, approximately $72-82 \%$ of the base metal hardness depending on the welding conditions, occurred in the stir zone and were related to the microstructural features, including grain size and texture.

- The tool rotational rate and welding speed had a strong effect on the failure load of the friction stir lap welds. Based on the conditions applied in the present work, a combination of relatively high welding speed $(20 \mathrm{~mm} / \mathrm{s})$ and low tool rotational rate $(1000 \mathrm{rpm})$ led to a high failure load. This was attributed to the lower heat input that limited the grain coarsening in the stir zone, whilst minimizing the hooking defect and maximizing the intensity of the basal poles.

- The texture distribution was reasoned to locally strengthen the thermomechanically-affected zone and stir zone and thus the tensile failure, which occurred at the interface of thermomechanically-affected zone and stir zone on the advancing side, was mainly attributed to the maximum tensile stress experienced during the tensile testing and the presence of the hooking defects. 


\section{CHAPTER 6}

\section{RESIDUAL STRESSES AND TENSILE PROPERTIES OF FRICTION STIR WELDED AZ31B-H24}

The aim of this study is to determine the residual stresses in the longitudinal and transverse directions which occur during friction stir welding and how it affects the shear tensile properties. The residual stresses test was performed using X-ray diffraction. The shear tensile behavior of the lap joints were evaluated at low $\left(-40^{\circ} \mathrm{C}\right)$, room $\left(25^{\circ} \mathrm{C}\right)$, and elevated $\left(180^{\circ} \mathrm{C}\right)$ temperatures at different tool rotational and welding speeds.

\subsection{Residual stresses}

Figure 6.1(b) shows a typical pre-scan XRD pattern on a FSLWed AZ31B-H24 Mg alloy lap joint. All the peaks in the diffraction pattern well correspond to those for $\mathrm{Mg}$. The (105) diffraction peak positioned at a $2 \theta$ angle of $105^{\circ}$ was selected for the residual stress measurements. Figure 6.1(c) shows the change of diffraction peaks of the selected plane (105) with the tilt of psi $(\psi)$, where $\psi$ is the angle between the sample normal and normal of the diffraction plane). It is seen that the (105) peak position shifts to a higher diffraction angle with increasing $\psi$, indicating that the interplanar spacing (d) decreases and thus the residual stress in the subsurface layer is compressive in nature. Figure 6.1(d) shows a typical $\sin ^{2} \psi$ diagram for the (105) diffraction plane of the FSLWed AZ31B-H24 Mg weld at room temperature. The triangle symbol indicates positive and zero $\psi$ tilt. The solid line represents the linear leastsquares fitting to a set of data points. Although these data are slightly scattered, the lattice strain 
( $\varepsilon$ ) decreases approximately linearly with increasing $\sin ^{2} \psi$. Residual stress can therefore be estimated from the slope of the $\varepsilon-\sin ^{2} \psi$ best-fitted line as detailed in [86].

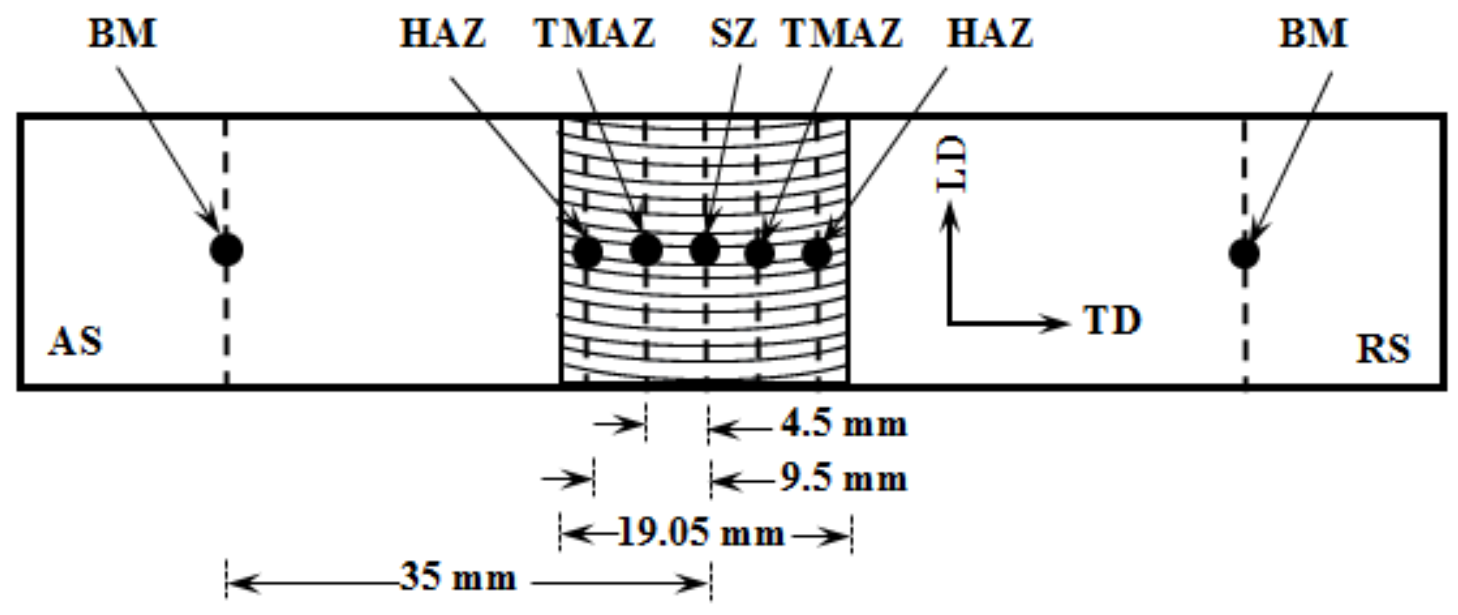

(a)

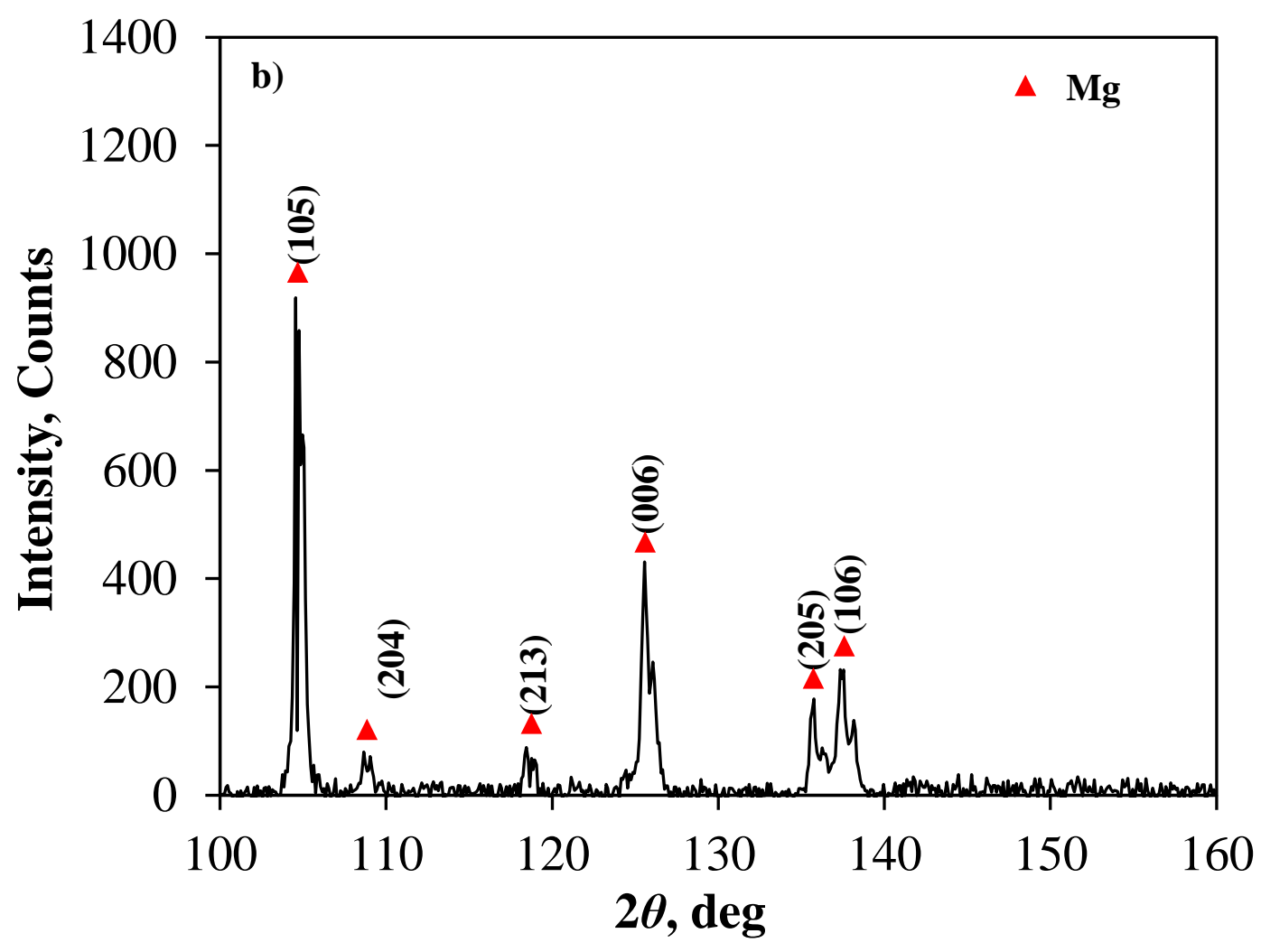



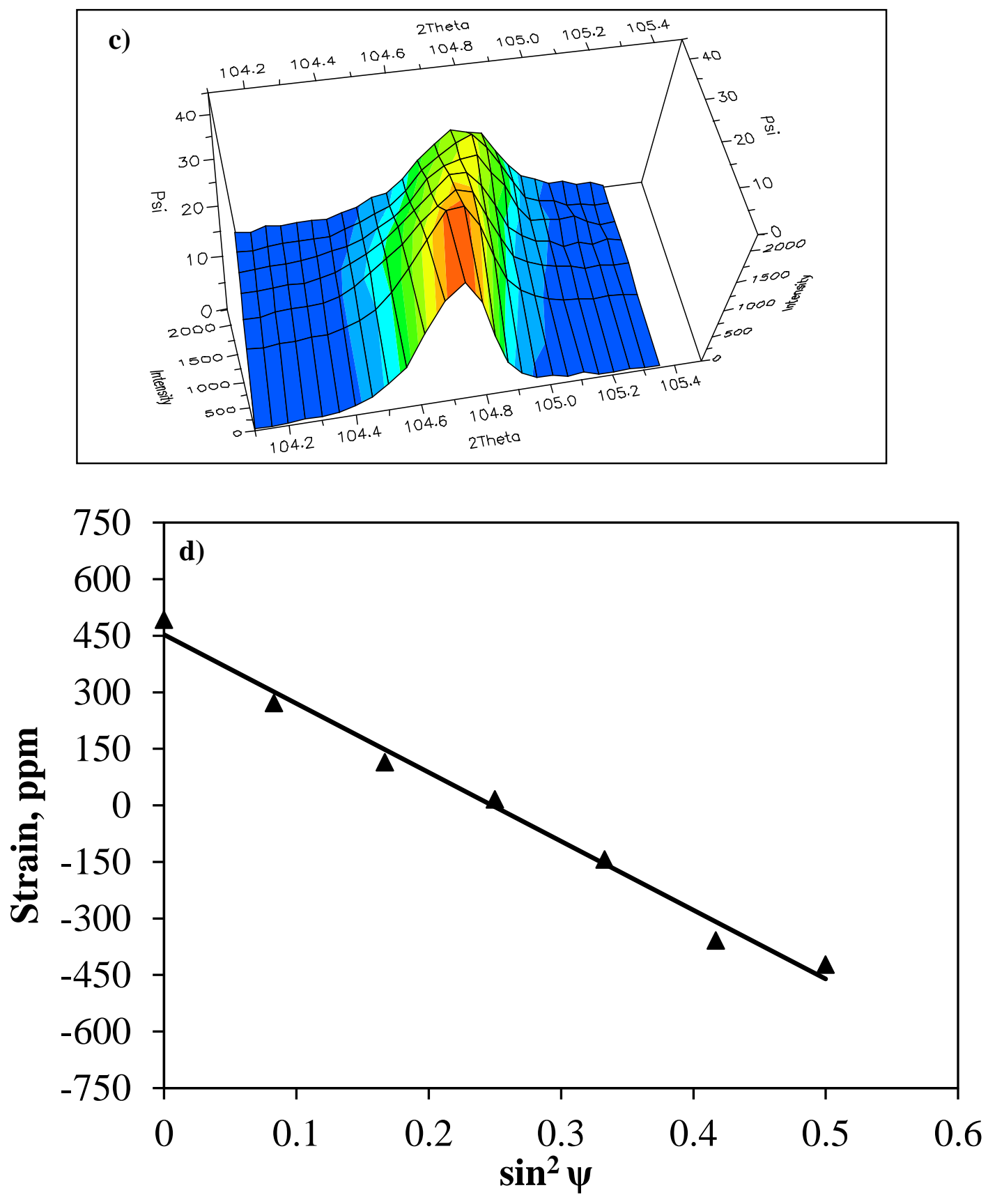

Figure 6.1: a) Schematic diagram showing the corresponding locations for residual stress measurements, b) a typical pre-scan XRD pattern, c) changes of typical XRD pattern, and d) $\sin ^{2} \psi$ diagram for the (105) diffraction plane of the $1000 \mathrm{rpm}-20 \mathrm{~mm} / \mathrm{s}$ joint determined at room temperature, where the solid line represents the linear least-squares fitting. 
The residual stresses in the longitudinal and transverse directions of the AZ31B-H24 Mg welds are shown in Figure 6.2(a-b). It was observed that both the longitudinal and transverse residual stresses exhibited similar distribution profiles for each weld examined in this work. Specifically, the longitudinal residual stress tends to be tensile on the AS regions of the SZ and TMAZ. All other regions seem to have compressive longitudinal residual stresses. The maximum tensile longitudinal residual stress is located around the SZ/TMAZ interface on the AS for each weld. It is noteworthy that the SZ/TMAZ interface location was estimated from the mid-thickness of the lap joint. The tensile longitudinal residual stress in the SZ is lower than that in the TMAZ on the AS, mainly due to the relaxation of thermal stresses caused by recrystallization [157]. In addition, it is apparent that the largest tensile longitudinal residual stress of $\sim 100 \mathrm{MPa}$ occurred in the weld assembled at $1500 \mathrm{rpm}$ and $10 \mathrm{~mm} / \mathrm{s}$ that had the highest heat input. With decreasing heat input (i.e. increasing welding speed or decreasing tool rotational rate), the maximum tensile longitudinal residual stress decreases. At a higher welding speed $(20 \mathrm{~mm} / \mathrm{s})$, the residual stresses are lower due to the lesser deformation and heat generation in the weld per tool rotation [158]. At a higher tool rotational rate $(1500 \mathrm{rpm})$, the temperatures may be higher during FSW. If the residual stress within the joint is greater than its yield strength at these elevated temperatures, the assembly can deform and may lead to the partial relief of the residual stresses. However, little variation is observed for the longitudinal residual stress in the SZ and TMAZ for the two conditions (1000 rpm-20 mm/min and $1500 \mathrm{rpm}-20 \mathrm{~mm} / \mathrm{s})$. 

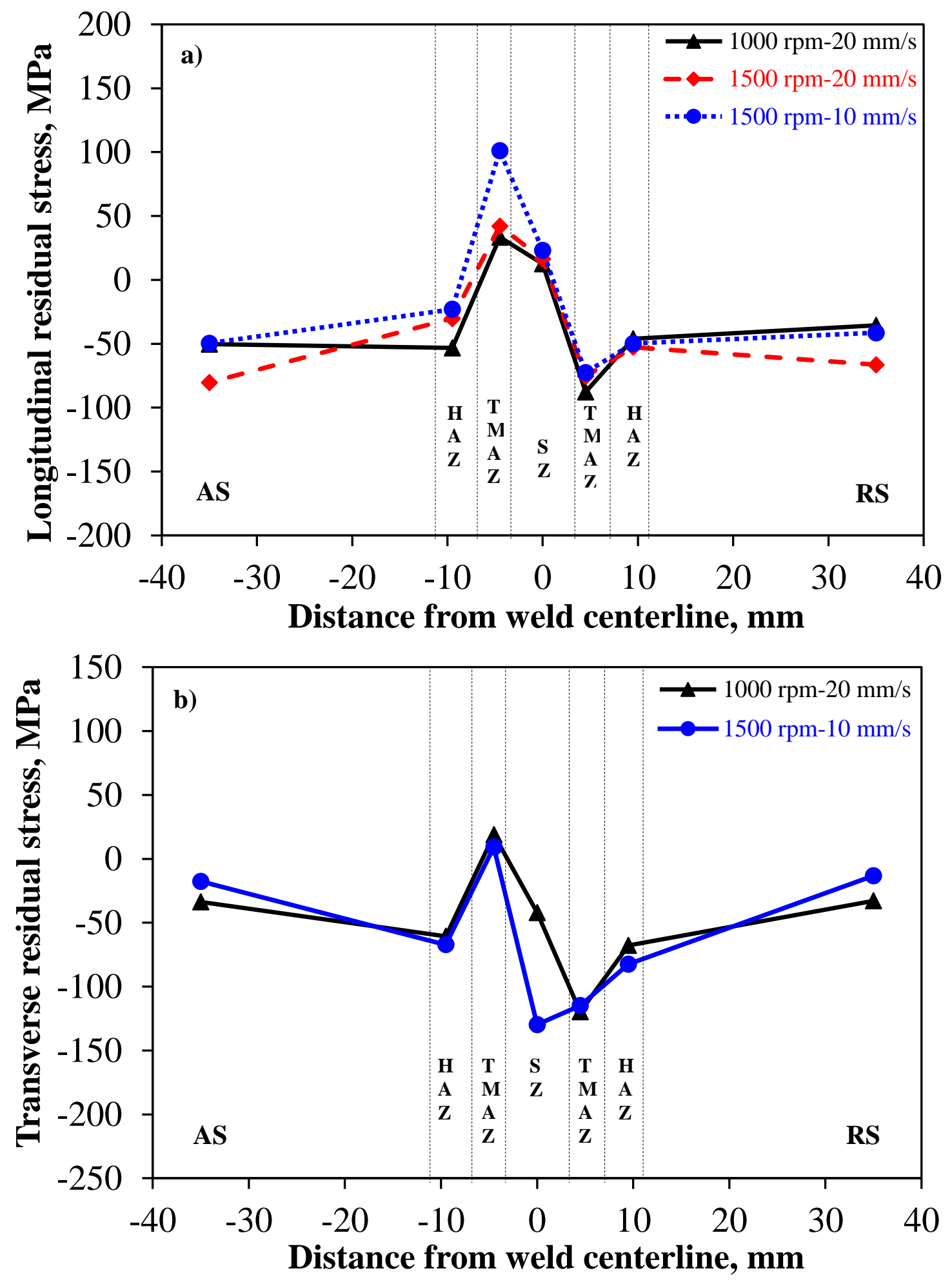

Figure 6.2: a) Longitudinal and b) transverse residual stress distributions of FSLWed AZ31B$\mathrm{H} 24 \mathrm{Mg}$ alloy in different welding conditions. 
In contrast, the tensile transverse residual stress is only located within a small region around the SZ/TMAZ interface on the AS and the highest value of 20 MPa was observed for two welding conditions (Figure 6.2(b)). The transverse residual stresses in all the other regions tend to be compressive with the minimum value of -125 MPa around the SZ/TMAZ interface on the RS. Therefore, the region around the SZ/TMAZ interface on the AS tends to have both maximum longitudinal and transverse tensile residual stresses. Similar observations were also reported by Commin and co-workers for butt joints in wrought AZ31 magnesium alloy that were assembled by FSW [159]. As shown in the $1000 \mathrm{rpm}-20 \mathrm{~mm} / \mathrm{s}$ condition, the maximum tensile residual stress around the SZ/TMAZ interface on the AS is slightly higher in the longitudinal ( $30 \mathrm{MPa})$ than in the transverse $(\sim 20 \mathrm{MPa})$ directions. In contrast, the maximum tensile residual stress around the SZ/TMAZ interface on the AS is much higher in the longitudinal ( 100 MPa) than in the transverse $(\sim 20 \mathrm{MPa})$ directions for the $1500 \mathrm{rpm}-10 \mathrm{~mm} / \mathrm{s}$ condition with the highest heat input. Overall, the measured tensile residual stresses are only up to $100 \mathrm{MPa}$ which is relatively low, as compared to that $(225 \mathrm{MPa})$ reported for FSWed AZ31 wrought magnesium alloy butt joint [159]. This may be due to the partial release of the residual stresses caused by the formation of the hooking crack in the lap joints.

\subsection{Hooking defects}

On both sides of the stir zone in each lap joint, the original faying surfaces between the top and bottom sheets can be clearly observed, as shown in Figure 6.3(a). These surfaces, however, experience deformations and may deviate from the original straight and flat contact interface. This distorted interface is usually termed as hooking defect in the FSLWed. The hooking defect 
appears only in the TMAZ which undergoes some deformation caused by the passage of the tool but experiences much lower plastic strains and heat than the stir zone [160]. Some important geometrical characteristics, such as hooking height $\mathrm{H}_{\mathrm{h}}$ (the distance of the hook tip from the initial sheet surface) and effective sheet thickness EST (the distance between the hook tip and the top surface of the work-piece) are shown in Figure 6.3(a). The high magnification observations of the hooking defects are indicated in Figure 6.3(b-g) for each weld on the AS and RS. It was noted that the hook tends to be curved downwards on the AS but upwards on the RS for the 1000 $\mathrm{rpm}-20 \mathrm{~mm} / \mathrm{s}$ welding condition. In the other two welding conditions (i.e. $10 \mathrm{~mm} / \mathrm{s}$ and $20 \mathrm{~mm} / \mathrm{s}$ at $1500 \mathrm{rpm}$ ), the hooks on both the AS and RS are always curved upwards and the hooking height on the AS is always much larger than that on the RS. In the $1000 \mathrm{rpm}-20 \mathrm{~mm} / \mathrm{s}$ condition, the hook was the smallest and oriented downwards towards the bottom sheet. Thus the EST for the $100 \mathrm{rpm}-20 \mathrm{~mm} / \mathrm{s}$ condition was the highest $(2.18 \mathrm{~mm})$ and larger than the sheet thickness, as compared to the other two welding conditions (Table 6.1).

Table 6.1: Hooking height and effective sheet thickness for FSLWed AZ31B-H24 Mg alloy assembled at different tool rotational rates and welding speeds.

\begin{tabular}{|c|c|c|c|c|}
\hline \multirow{2}{*}{ Welding condition } & \multicolumn{2}{|c|}{ Hooking height $\mathrm{H}_{\mathrm{h}}(\mathrm{mm})$} & \multicolumn{2}{c|}{ Effective sheet thickness $\mathrm{t}_{\mathrm{e}}(\mathrm{mm})$} \\
\cline { 2 - 5 } & AS & RS & AS & RS \\
\hline $1000 \mathrm{rpm}, 20 \mathrm{~mm} / \mathrm{s}$ & $0.18 \pm 0.02$ & $0.23 \pm 0.03$ & $2.18 \pm 0.02$ & $1.77 \pm 0.03$ \\
\hline $1500 \mathrm{rpm}, 20 \mathrm{~mm} / \mathrm{s}$ & $1.31 \pm 0.05$ & $0.30 \pm 0.01$ & $0.69 \pm 0.05$ & $1.70 \pm 0.01$ \\
\hline $1500 \mathrm{rpm}, 10 \mathrm{~mm} / \mathrm{s}$ & $1.41 \pm 0.03$ & $0.52 \pm 0.02$ & $0.59 \pm 0.03$ & $1.48 \pm 0.02$ \\
\hline
\end{tabular}

Note: One standard deviation is indicated. 

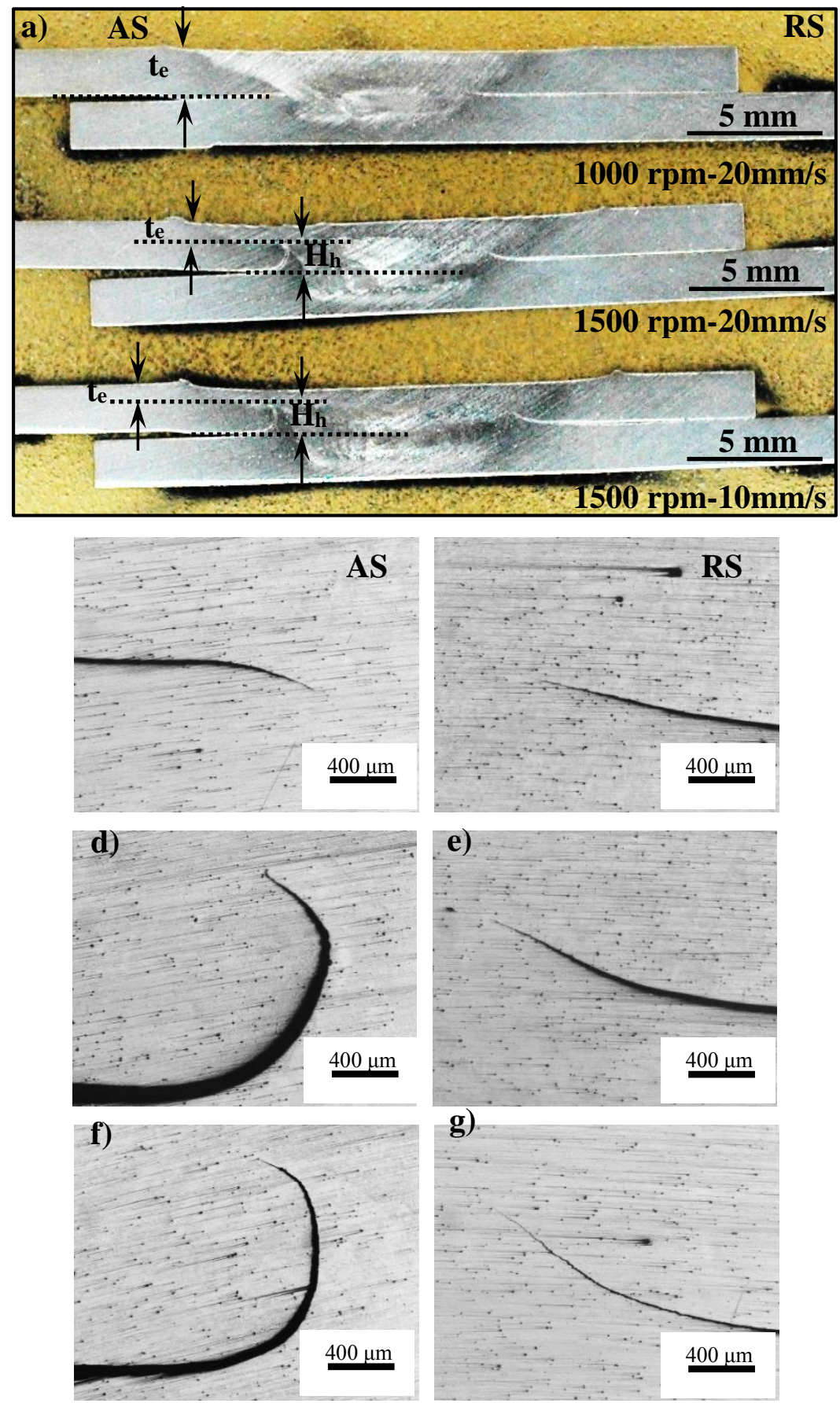

Figure 6.3: a) Metallographic cross-sectional views of the welds showing the various features (hooking height $\mathrm{H}_{\mathrm{h}}$ and effective sheet thickness $t_{e}$ ), and (b-g) magnified views of the hooking defects on the advancing (left) and retreating (right) sides at different tool rotational rates and welding speeds, (b-c) $1000 \mathrm{rpm}-20 \mathrm{~mm} / \mathrm{s}$, (d-e) $1500 \mathrm{rpm}-20 \mathrm{~mm} / \mathrm{s}$, and (f-g) $1500 \mathrm{rpm}-10 \mathrm{~mm} / \mathrm{s}$. 


\subsection{Tensile properties}

Figure 6.4(a-c) compares the typical load-displacement curves obtained from tensile shear testing of each weld at the LT, RT and ET conditions. Although failure occurred exclusively for the majority of the welds on the AS of the top sheet (Figure 6.5), the failure load, as given in Table 6.2 and plotted in Figure 6.6(a), was observed to vary with the test temperature and welding conditions applied. Specifically, the highest failure load $(6.5 \mathrm{kN})$ was obtained for the $1000 \mathrm{rpm}-$ $20 \mathrm{~mm} / \mathrm{s}$ welding condition that was tensile tested at RT. Increasing the tool rotational rate to $1500 \mathrm{rpm}$ led to a $68 \%$ decrease in the failure load at RT regardless of the welding speed, which can be reasoned on the basis of the heat input during FSW. In particular, the higher heat input at $1500 \mathrm{rpm}$ relative to the $1000 \mathrm{rpm}$ resulted in a fivefold increase in the $\mathrm{H}_{\mathrm{h}}$ and a marked reduction in the effective load bearing area (halving the EST on the AS, as shown in Table 1). Moreover, from the fractured weld it could be seen that the failure initiated at the tip of the hooking defect, due to the presence of a severe stress concentration, and then propagated into the SZ/TMAZ.

Relative to the RT failure load $(6.5 \mathrm{kN})$ for the welding condition of $1000 \mathrm{rpm}$ and $20 \mathrm{~mm} / \mathrm{s}$, the values at LT $(5.6 \mathrm{kN})$ and ET $(3.3 \mathrm{kN})$ were both lower. However, the extent of the local plastic deformation, which also varied with the test temperature and welding conditions (Figure 6.4), was the highest for the $1000 \mathrm{rpm}-20 \mathrm{~mm} / \mathrm{s}$ condition that was tested at ET (Figure 6.4(a) and 6.5(g)). At both RT and LT, the extent of plastic deformation for this weld condition was reduced by more than 70\%, as reflected in the lower energy absorption values given in Table 6.2 and plotted in Figure 6.6(b). 
Table 6.2: Effect of test temperature on tensile failure load, energy absorption and failure mode of the FSLWed AZ31B-H24 Mg alloy assembled at different tool rotational rates and welding speeds.

\begin{tabular}{|c|c|c|c|c|c|c|}
\hline \multirow{2}{*}{$\begin{array}{l}\text { Welding } \\
\text { condition }\end{array}$} & \multicolumn{2}{|c|}{$\begin{array}{l}\text { Low temperature } \\
\left(-40^{\circ} \mathrm{C}\right)\end{array}$} & \multicolumn{2}{|c|}{$\begin{array}{c}\text { Room temperature } \\
\left(25^{\circ} \mathrm{C}\right)\end{array}$} & \multicolumn{2}{|c|}{$\begin{array}{c}\text { Elevated temperature } \\
\left(180^{\circ} \mathrm{C}\right)\end{array}$} \\
\hline & $\begin{array}{c}\text { Failure load } \\
(\mathrm{kN})\end{array}$ & $\begin{array}{c}\text { Energy } \\
\text { absorption (J) }\end{array}$ & $\begin{array}{c}\text { Failure } \\
\text { load }(\mathrm{kN})\end{array}$ & $\begin{array}{c}\text { Energy } \\
\text { absorption (J) }\end{array}$ & $\begin{array}{c}\text { Failure } \\
\text { load }(\mathrm{kN})\end{array}$ & $\begin{array}{c}\text { Energy } \\
\text { absorption (J) }\end{array}$ \\
\hline \multirow{2}{*}{$\begin{array}{l}1000 \mathrm{rpm}, \\
20 \mathrm{~mm} / \mathrm{s}\end{array}$} & $5.6 \pm 0.39$ & $6.8 \pm 1.12$ & $6.5 \pm 0.42$ & $10.3 \pm 1.93$ & $3.3 \pm 0.09$ & $26.8 \pm 0.10$ \\
\hline & \multicolumn{2}{|c|}{ Failure mode 3} & \multicolumn{2}{|c|}{ Failure mode 3} & \multicolumn{2}{|c|}{ Failure mode 1} \\
\hline \multirow{2}{*}{$\begin{array}{c}1500 \mathrm{rpm} \text {, } \\
20 \mathrm{~mm} / \mathrm{s}\end{array}$} & $2.2 \pm 0.10$ & $1.3 \pm 0.13$ & $2.1 \pm 0.17$ & $1.3 \pm 0.05$ & $2.3 \pm 0.09$ & $3.8 \pm 0.60$ \\
\hline & \multicolumn{2}{|c|}{ Failure mode 2} & \multicolumn{2}{|c|}{ Failure mode 2} & \multicolumn{2}{|c|}{ Failure mode 2} \\
\hline \multirow{2}{*}{$\begin{array}{l}1500 \mathrm{rpm}, \\
10 \mathrm{~mm} / \mathrm{s}\end{array}$} & $1.8 \pm 0.10$ & $1.0 \pm 0.06$ & $2.2 \pm 0.03$ & $1.3 \pm 0.15$ & $1.9 \pm 0.09$ & $2.2 \pm 0.18$ \\
\hline & \multicolumn{2}{|c|}{ Failure mode 2} & \multicolumn{2}{|c|}{ Failure mode 2} & \multicolumn{2}{|c|}{ Failure mode 2} \\
\hline
\end{tabular}

Note: One standard deviation is indicated.

This may be explained by considering the mechanism for plastic deformation that involves the gliding of dislocations along definite crystallographic or slip planes. The movement of dislocations occurs only if the critical resolved shear stress (CRSS) applied on the slip plane and in the slip direction exceeds a critical value. In general, the CRSS for magnesium alloys varies with the temperature. At RT, the movement of dislocations is easier on the basal slip systems due to the lower CRSS value. Thus, the basal plane slip is expected to dominate at RT and only small amounts of non-basal slip may occur $[161,162]$. At LT, the CRSS for the non-basal slip systems decreases and thus the prismatic and pyramidal slip systems become less active, causing a reduction in the deformability of the magnesium alloys. At ET, however, the non-basal slip systems can be activated, leading to significantly increased deformability for magnesium alloys $[163,164]$. 

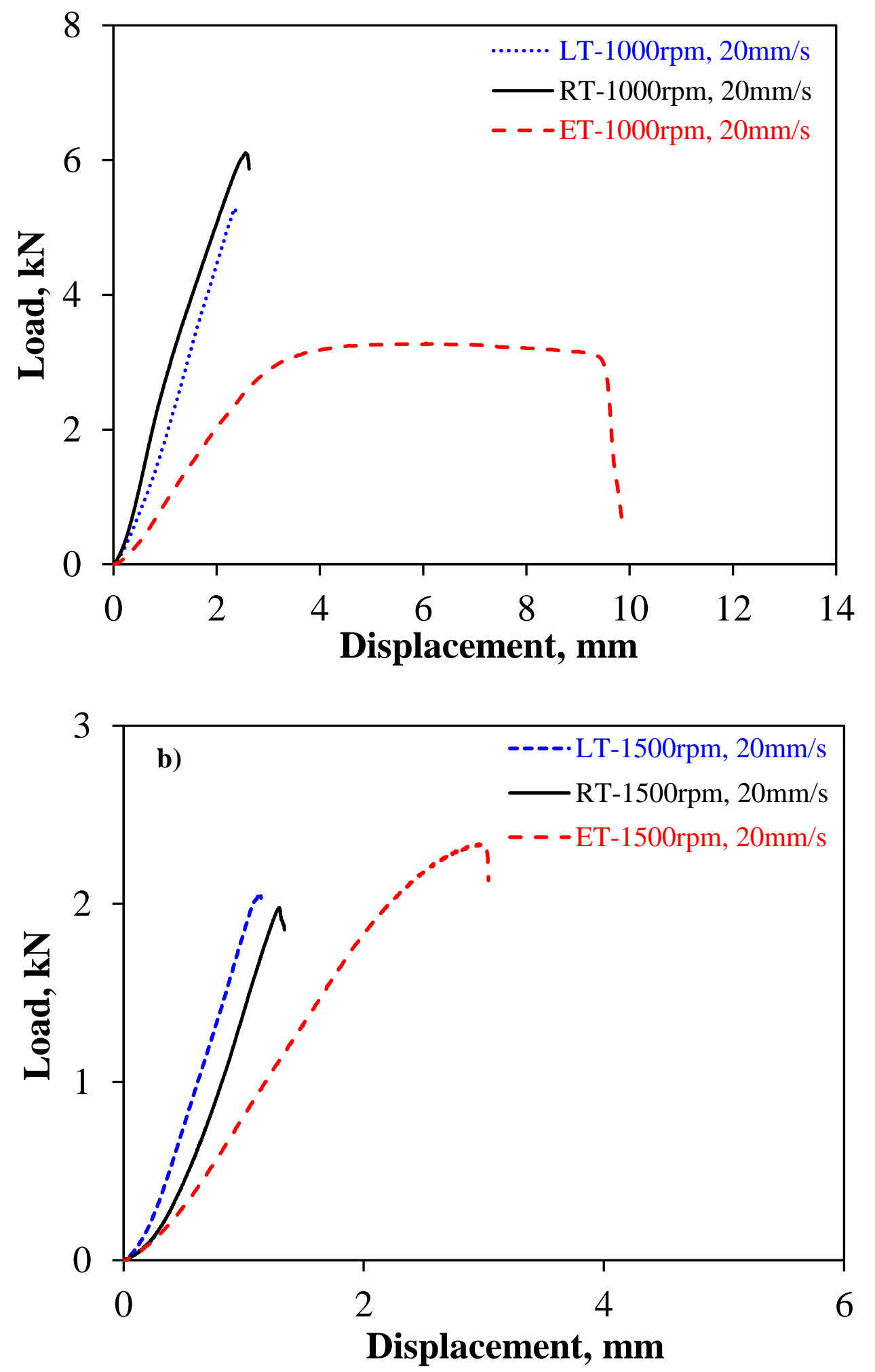


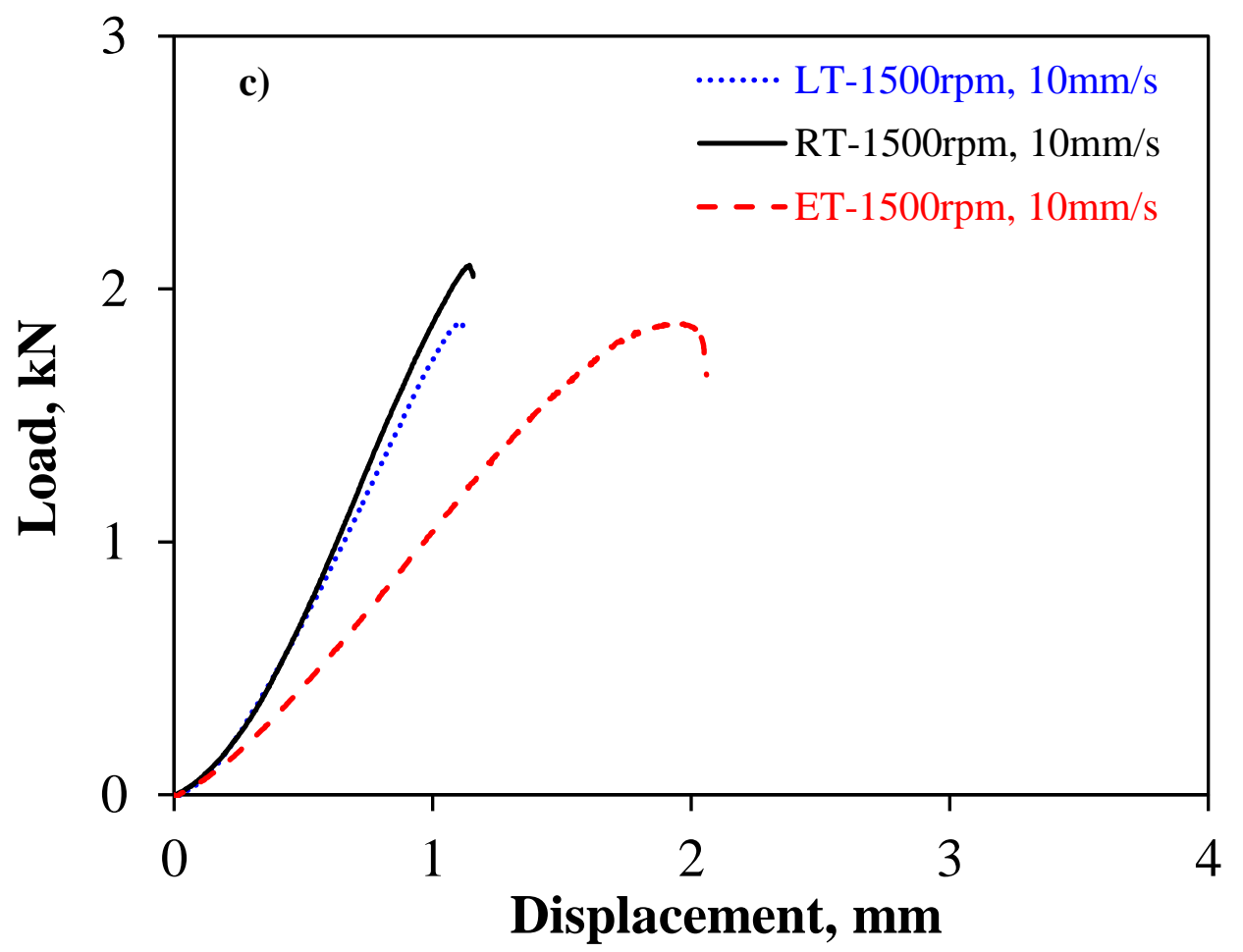

Figure 6.4: Comparison of the different load versus displacement curves for FSLWed AZ31B$\mathrm{H} 24 \mathrm{Mg}$ alloy tested at different temperatures. Specimens welded at a) $1000 \mathrm{rpm}-20 \mathrm{~mm} / \mathrm{s}, \mathrm{b}$ ) $1500 \mathrm{rpm}-20 \mathrm{~mm} / \mathrm{s}$, and c) $1500 \mathrm{rpm}-10 \mathrm{~mm} / \mathrm{s}$.

In the welding conditions at $1500 \mathrm{rpm}$, the change in the failure load and energy absorption at temperatures above or below RT was minor and suggests the overriding influence of the hooking defect on the shear tensile properties. One tendency that could be noted, however, was the slightly greater plasticity (Figure 6.4(b-c)) and energy absorption (Table 6.2 and Figure 6.6(b)) at ET relative to that obtained for the RT and LT test conditions, which is reasonable considering the temperature dependence of the CRSS, slip system activation and atomic mobility, as described above.

As mentioned earlier, the failure initiated exclusively for each weld on the AS of the top sheet and propagated into the SZ/TMAZ. This fracture region is consistent with the stress distribution 
profiles in the top and bottom sheets that indicate the occurrence of a maximum stress in the top sheet at the location where failure initiates [25]. In addition, the region around SZ/TMAZ of the top sheet on the AS usually has a higher hooking height than that on the RS, and, thus, a lower EST (Figure 6.3d-g). As well, the SZ and TMAZ have softened microstructures compared to the base material. Moreover, this study has indicated that the residual stress may play a supplementary role in the shear tensile failure as the maximum tensile residual stress appears around the SZ/TMAZ on the AS. As a consequence, the region around SZ/TMAZ on the AS is probably the weakest zone in the lap joints and this leads to premature tensile shear failure. The welded samples can be fractured by three modes, namely shear fracture (Mode 1), tensile fracture (Mode 2) and TMAZ softening (Mode 3). In Mode 1, shear fracture occurs along the joint interface between the top and bottom sheets due to the occurrence of a large amount of plastic deformation, as evidenced in the load-displacement curve of the ET condition for the weld assembled at $1000 \mathrm{rpm}$ and $20 \mathrm{~mm} / \mathrm{s}$ (Figures 6.4(a) and 6.5(g)). The considerable plastic deformation for this joining condition is attributed to both the high weld integrity and elevated test temperature.
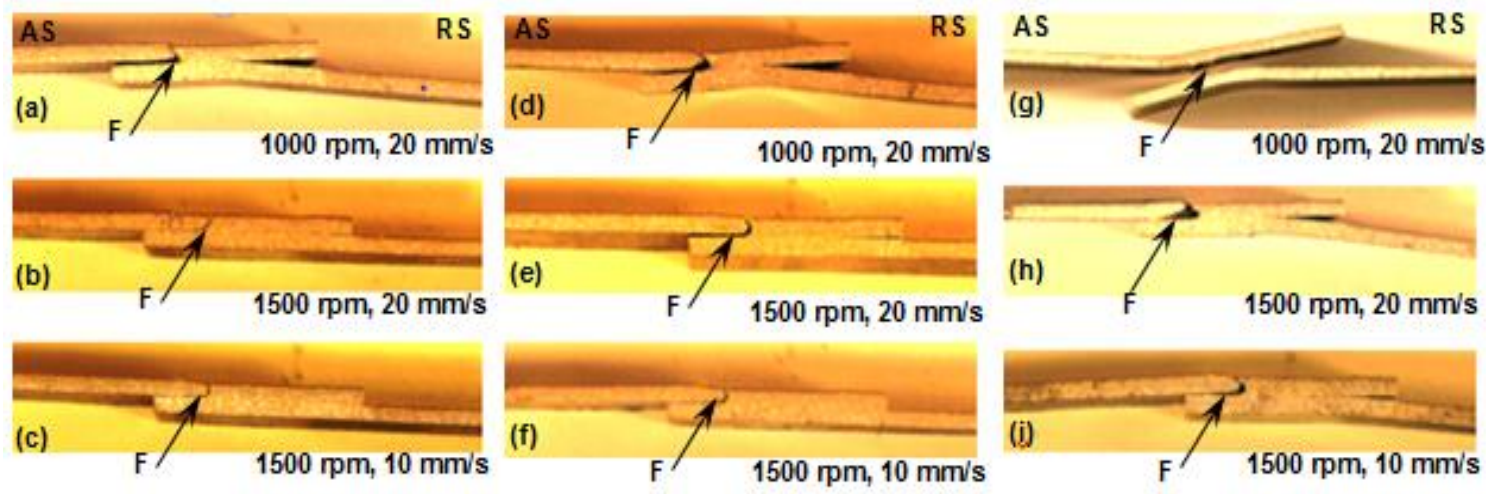

Figure 6.5: Tensile failure locations (as demarcated by the arrow labelled with F) in FSLWed AZ31B-H24 Mg alloy fabricated at various combinations of tool rotational rate and welding speed and tested at (a-c) LT $\left(-40^{\circ} \mathrm{C}\right),(\mathrm{d}-\mathrm{f}) \mathrm{RT}\left(25^{\circ} \mathrm{C}\right)$ and $(\mathrm{g}-\mathrm{i}) \mathrm{ET}\left(180^{\circ} \mathrm{C}\right)$ 
The high weld integrity is mainly due to (i) the downward hooking orientation, (ii) the larger EST( 2.18 mm), and (iii) low tensile residual stress (especially low transverse residual stress) around the area surrounding the SZ/TMAZ on the AS. Tensile shear testing of the $1000 \mathrm{rpm}-$ $20 \mathrm{~mm} / \mathrm{s}$ welding condition at ET then enabled the activation of the non-basal slip systems, leading to a reduced failure load, as less force would be needed to move dislocations and atoms at higher temperatures, but increased the total energy absorbed due to the high plastic deformation. Mode 2 fracture (e.g. Figure 6.5(e)) occurred from the rapid propagation of the initiated crack due to the presence of a considerable hooking defect on the AS of the upper sheet that reduced the EST. Under these conditions, the reduction in the load-bearing area resulted in a low failure load and low energy absorption. Mode 3 fracture occurred when the weld integrity was relatively good but the dislocation movement was limited to the basal slip systems at the lower test temperatures (LT or RT). Hence, the initiated crack propagates towards the softened TMAZ and/or SZ on the AS, as shown in Figure 6.5(a, d). Compared to the ET test condition, the relatively higher failure loads at LT or RT are due to the larger forces needed to move dislocations at these lower temperatures, but the energy absorbed is lower as the deformation resistance increases due to limited slip system activity.

\subsection{Fractography}

Fracture surfaces of the shear tensile samples were examined using SEM. Figures 6.7-6.9 show the secondary electron images of the typical tensile fracture surfaces of some selected FSLWed joints assembled at different tool rotational rates, welding speeds and test temperatures. 

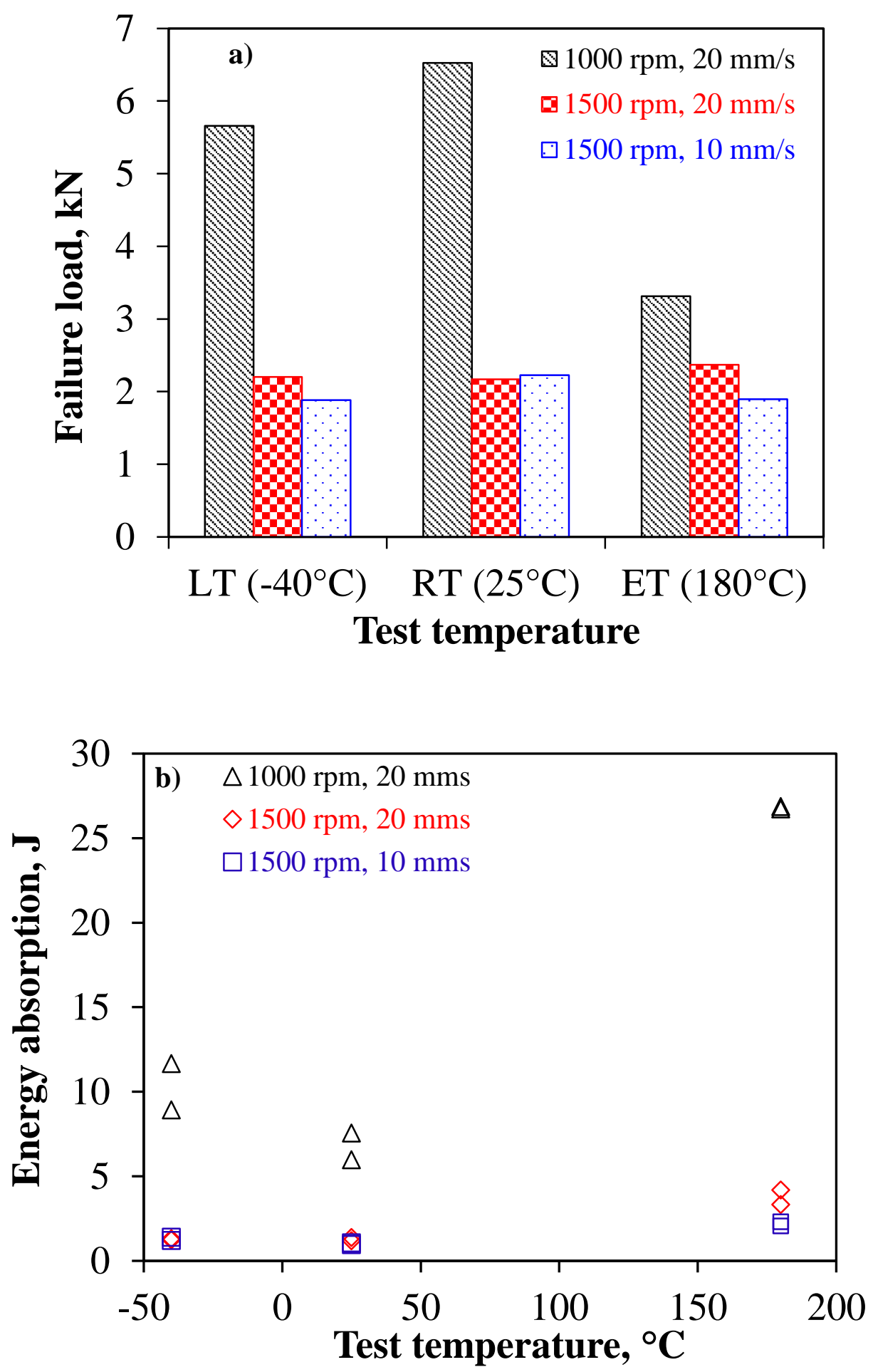

Figure 6.6: Influence of the test temperature on the (a) tensile shear failure load and (b) energy absorption of the FSLWed AZ31B-H24 Mg alloy joined in different welding conditions. 
Figures 6.7(a, c, e), 6.8(a, c, e) and 6.9(a, c, e) show the fracture surfaces in the crack initiation regions, where it appears that initiation occurs basically from the local stress concentration zones due to the presence of the hooking defect in the region of the SZ/TMAZ on the AS. Also, the interfacial fracture (i.e. shear along the interface between the top and bottom sheets) in the 1000 rpm-20 mm/s welding condition, as shown in Figure 6.9(a), is also due to the failure initiation at the hooking defect. However, the hooks on both the AS and RS are almost similar in height (Figure. 6.3(b, c) ) and this may either initiate shear tensile failure or cause propagation along the interface of a lap joint.

Figures $6.7(\mathrm{~b}, \mathrm{~d}, \mathrm{f}), 6.8(\mathrm{~b}, \mathrm{~d}, \mathrm{f})$ and $6.9(\mathrm{~b}, \mathrm{~d}, \mathrm{f})$ show the crack propagation regions observed at high magnifications after testing at LT, RT and ET in different welding conditions, respectively. In the LT and RT test conditions, the tensile fracture surfaces of each weld have some features that appear to be typical of brittle intragranular fracture. In contrast, at ET, as shown in Figure 6.9(b, d, f), the fracture surface along the loading direction of the weldment exhibits unidirectionality in the shearing overload region, and the presence of elongated dimples indicates that ductile shearing occurs in the final stages of the fracture. It is also clear that the dimple characteristics on the fracture surfaces appear more obvious with increasing test temperature. 

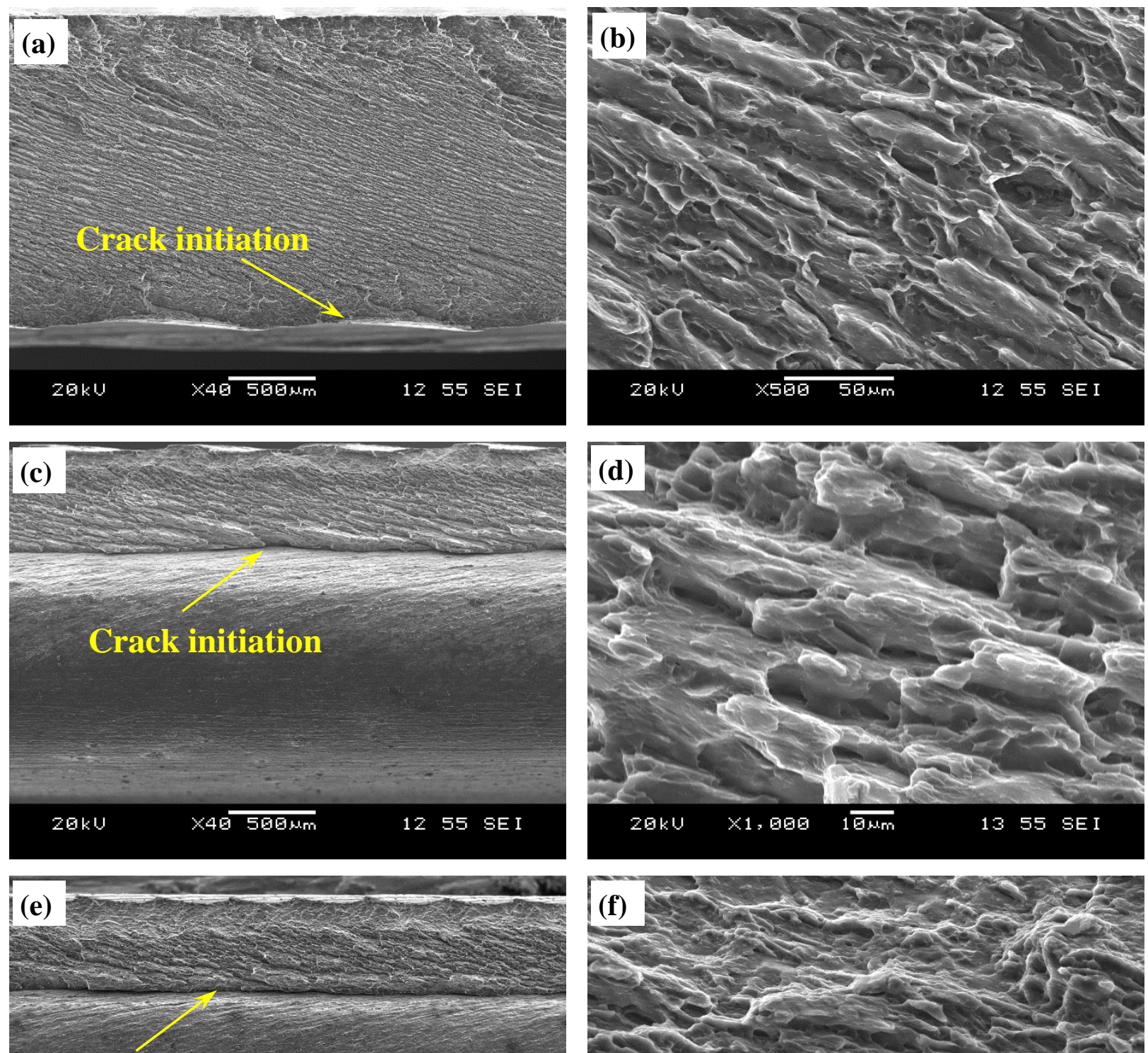

Crack initiation
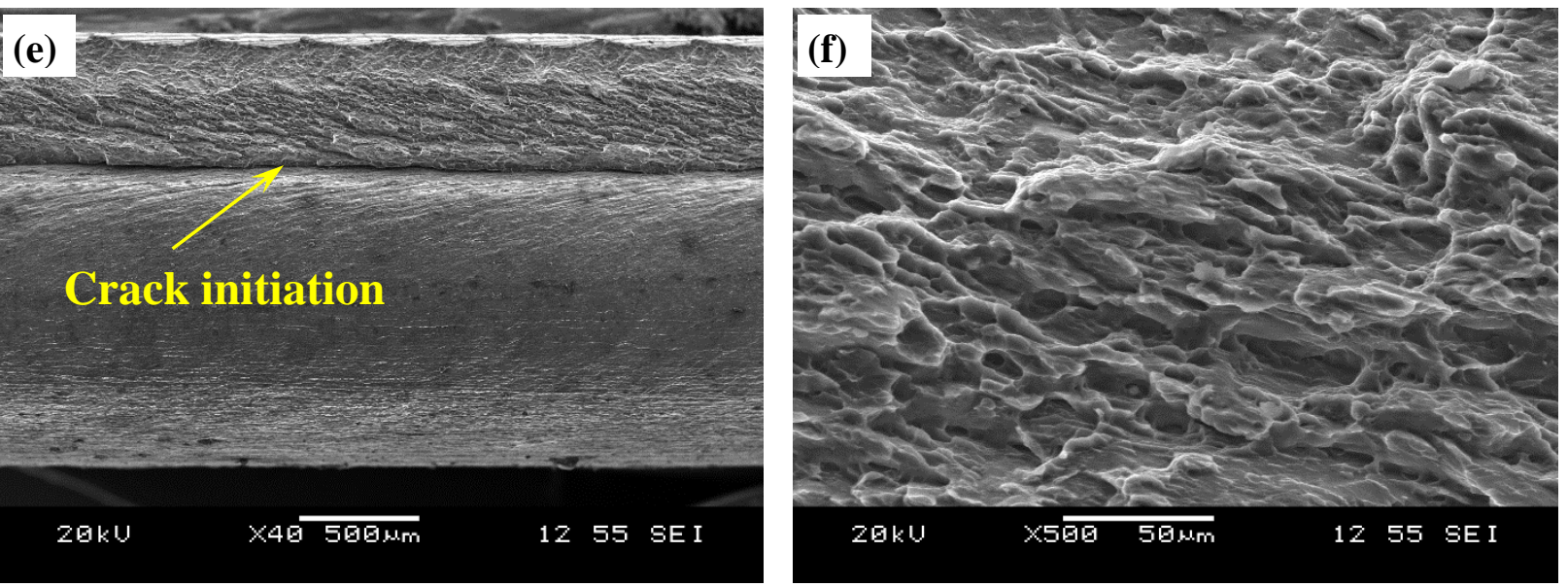

Figure 6.7: Typical SEM images of the tensile shear fracture surfaces obtained at low temperature $\left(-40^{\circ} \mathrm{C}\right)$ for welding conditions of (a-b) $1000 \mathrm{rpm}-20 \mathrm{~mm} / \mathrm{s}$, (c-d) $1500 \mathrm{rpm}-20 \mathrm{~mm} / \mathrm{s}$, and (e-f) $1500 \mathrm{rpm}-10 \mathrm{~mm} / \mathrm{s}$. 

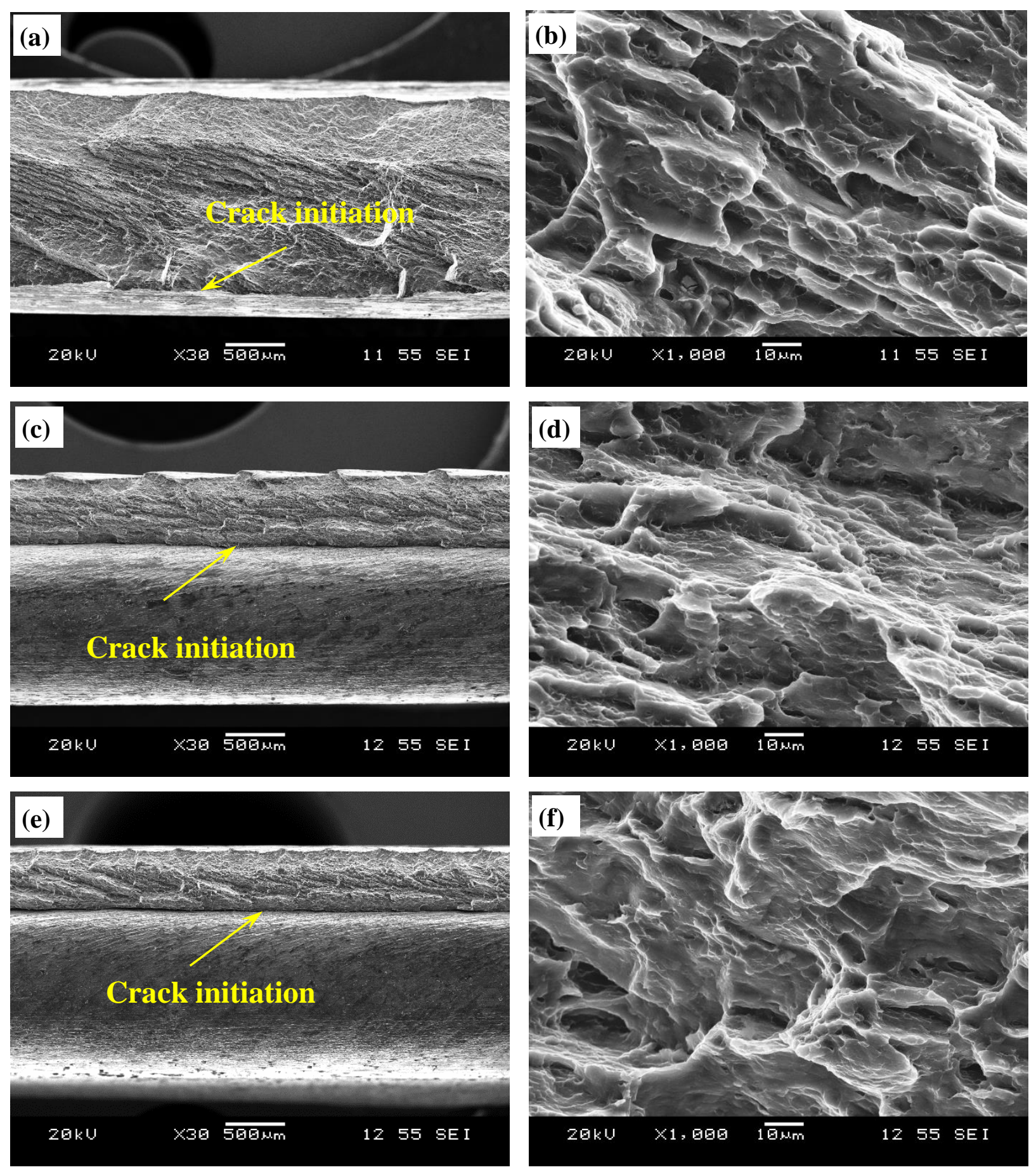

Figure 6.8: Typical SEM images of the tensile shear fracture surfaces obtained at room temperature $\left(25^{\circ} \mathrm{C}\right)$ for welding conditions of (a-b) $1000 \mathrm{rpm}-20 \mathrm{~mm} / \mathrm{s}$, (c-d) $1500 \mathrm{rpm}-20 \mathrm{~mm} / \mathrm{s}$ and (e-f) $1500 \mathrm{rpm}-10 \mathrm{~mm} / \mathrm{s}$. 

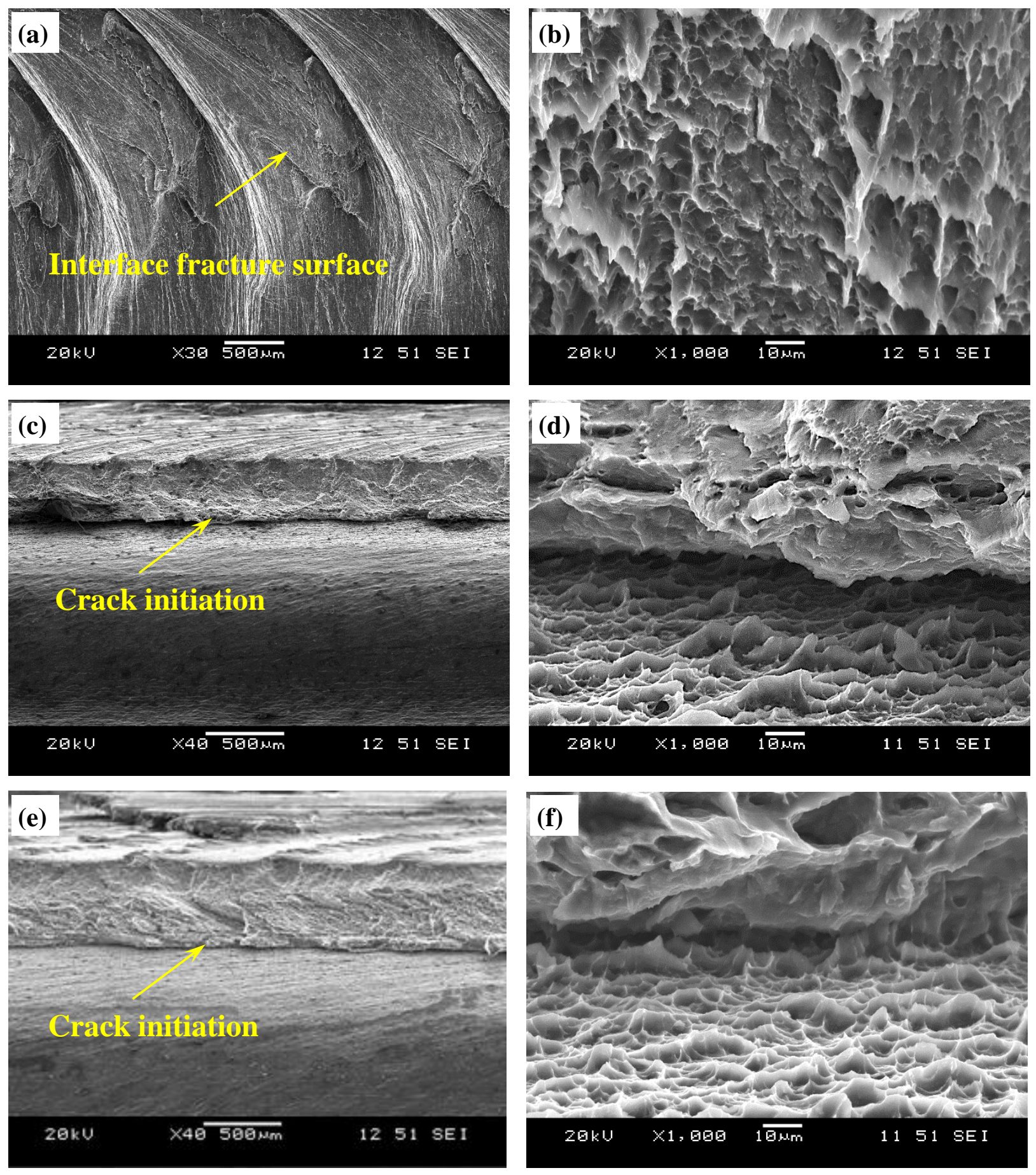

Figure 6.9: Typical SEM images of the tensile shear fracture surfaces obtained at elevated temperature $\left(180^{\circ} \mathrm{C}\right)$ for welding conditions of (a-b) $1000 \mathrm{rpm}-20 \mathrm{~mm} / \mathrm{s}$, (c-d) $1500 \mathrm{rpm}-20$ $\mathrm{mm} / \mathrm{s}$ and (e-f) $1500 \mathrm{rpm}-10 \mathrm{~mm} / \mathrm{s}$. 


\subsection{Summary of the results in this chapter}

- The tool rotational rate and welding speed have a strong effect on the tensile shear failure load. A higher welding speed of $20 \mathrm{~mm} / \mathrm{s}$ and lower tool rotational rate of $1000 \mathrm{rpm}$ led to higher failure loads at each test temperature (i.e., low, room and elevated) relative to the other welding conditions, due to the smaller hooking height, larger effective sheet thickness, and lower tensile residual stress.

- With increasing test temperature the energy absorbed during tensile shear loading increased in each welding condition, with the greatest effect observed for the high integrity weld assembled at $1000 \mathrm{rpm}-20 \mathrm{~mm} / \mathrm{s}$.

- Shear tensile fracture usually initiates around the region of the SZ/TMAZ interface on the advancing side of the top sheet, arising from the (i) maximum tensile stress experienced during shear tensile testing, (ii) stress concentration caused by the sharp hooking tip, (iii) reduced effective sheet thickness by the presence of an upward hooking crack, (iv) softened microstructure caused by recrystallization, and (v) tensile residual stress. Interface failure occurs during elevated temperature tensile shear testing for the high integrity weld (i.e. small hooking defect and large effective sheet thickness) to allow for the large plastic deformation.

- From the fractographic analysis, crack initiation was observed to originate directly from the stress concentration zone (hooking defect). In the crack propagation region, some brittle features along with some elongated dimples were apparent indicating some extent of ductile shearing. 


\section{CHAPTER 7}

\section{SUMMARY AND FUTURE WORK}

\subsection{Summary and conclusions}

Friction stir lap welding of similar AZ31B-H24 Mg alloy sheets were performed. From the Chapter 2, it was found that very limited works have been reported for FSW of AZ31 Mg alloy, particularly in lap configuration. Therefore, in Chapters 4, 5 and 6 studies were taken to check the feasibility of the FSW process for AZ31B-H24 Mg alloy from residual stress, microstructural evolution, texture, hardness, room and elevated tensile and fatigue properties. This work will not only enhance our understanding of the fundamentals of friction stir lap welding process for AZ31B-H24 Mg alloy, but also provide some practical and important mechanical properties which can contribute to one of world's backbone industries - automotive manufacturing. The research results achieved will be able to effectively promote the applications of lightweight magnesium alloys in the automotive industry, and thus improve the competitiveness of automotive sector on the global market.

\section{Some major conclusions achieved are listed as follows:}

1. The tool rotational rate and welding speed have a strong effect on the tensile shear failure load. A higher welding speed of $20 \mathrm{~mm} / \mathrm{s}$ and lower tool rotational rate of $1000 \mathrm{rpm}$ led to higher failure loads at each test temperature (i.e., low, room and high) relative to the other 
welding conditions, due to the smaller hooking height, larger effective sheet thickness, and lower tensile residual stress.

2. Shear tensile fracture usually initiates around the region of the SZ/TMAZ interface on the advancing side of the top sheet, arising from the (i) maximum tensile stress experienced during shear tensile testing, (ii) stress concentration caused by the sharp hooking tip, (iii) reduced effective sheet thickness by the presence of an upward hooking crack, (iv) softened microstructure caused by recrystallization, and (v) tensile residual stress. Interface failure occurs during elevated temperature tensile shear testing for the high integrity weld (i.e. small hooking defect and large effective sheet thickness) to allow for the large plastic deformation.

3. The existence of hooking defects in friction stir lap welds was the key factor that significantly reduced the fatigue strength or life due to (i) the sharp tips causing severe stress concentration and (ii) the reduced effective sheet thickness (i.e., large hooking height) or reduced load-bearing capacity. Specifically, the fatigue cracks usually initiated at the tip of the hooking defect on the advancing side of the top sheet due to the more severe stress concentration caused by the presence of a larger hook height. The fatigue crack then propagated into the stir zone by the formation of fatigue striations perpendicular to the propagation direction, followed by the final rapid shear failure.

4. Microhardness decreased gradually from the base metal through the HAZ, to the TMAZ and then to the stir zone where the lowest hardness was obtained. The overall hardness across the stir zone was slightly higher at a lower heat input (i.e., at a lower tool rotational rate and/or a higher welding speed). The lowest hardness values, approximately $72-82 \%$ of the 
base metal hardness depending on the welding conditions, occurred in the stir zone and were related to the microstructural features, including grain size and texture.

5. The base metal contained a strong crystallographic texture of type $(0001)<11 \overline{2} 0>$, with the basal planes (0001) largely parallel to the rolled sheet surface (or slightly tilted towards the rolling direction) and the $\langle 11 \overline{2} 0\rangle$ directions aligned in the rolling direction of the sheet. After friction stir lap welding, the texture in the stir zone (and thermomechanically-affected zone) became another type of texture $(0001)<1010>$, where the basal planes $(0001)$ were slightly tilted towards the transverse direction, and the prismatic planes $(10 \overline{1} 0)$ and pyramidal planes (1011), exhibiting a certain degree of fiber-like textures, had a $30^{\circ}+(n-$ 1) $\times 60^{\circ}$ rotation $(\mathrm{n}=1,2,3, \ldots)$ with respect to the rolled sheet normal, with the situation of heat affected zone texture laying in-between those of base metal and thermomechanicallyaffected zone or stir zone. This was attributed to the intense circumferential stirring/shear plastic flow in the vicinity of the pin surface.

6. The residual stresses in the longitudinal and transverse directions of the AZ31B-H24 Mg welds are determined. It was observed that both the longitudinal and transverse residual stresses exhibited similar distribution profiles for each weld examined in this work. Specifically, the longitudinal residual stress tends to be tensile on the advancing side regions of the SZ and TMAZ and all other regions are compressive longitudinal residual stresses. The maximum tensile longitudinal residual stress is located around the SZ/TMAZ interface on the advancing side for each weld. 


\subsection{Recommendations for future work}

The present investigation was aimed at studying the microstructural evolution, microtexture, residual stress, tensile and fatigue behavior of a friction stir lap welded AZ31B-H24 Mg alloy. While a number of results have been obtained in this study, there still remained a lot of work that needs to be done further. The following points are the recommendations for the future work:

1. Further detailed microstructural characterization of the FSLWed AZ31B-H24 Mg alloys with or without post-weld heat treatment needs to be done using high-resolution TEM, high-temperature XRD.

2. A detailed investigation is needed for the residual stress measurements using neutron diffraction.

3. To improve the mechanical properties of the lap weld, a detailed investigation needs to be done during welding to minimize the hooking defects.

4. It would be interesting to friction stir weld on dissimilar alloys like $\mathrm{Mg}-\mathrm{Al}$ and $\mathrm{Mg}-\mathrm{Steel}$ to understand the effects of various processing parameters on mechanical properties.

5. The work related to the corrosion behavior is very limited for FSLWed AZ31B-H24 Mg alloy. The further extension of this study is to characterize the corrosion behavior of the FSLWed AZ31B-H24 Mg alloy in $\mathrm{NaCl}$ solution and investigate the effect of the corrosion behavior on mechanical properties of the joints based on potentiodynamic test, constant immersion test results and SEM observation.

6. It would be interesting to do modelling of friction stir lap welding magnesium alloys to optimize the welding tool parameters and compare the simulation results with the experimental results. 


\section{REFERENCES}

[1] T.M. Pollock, Weight Loss with Magnesium Alloys, Science, 328 (2010) 986-987.

[2] M. Wise, K. Calvin, A. Thomson, L. Clarke, B. Bond-Lamberty, R. Sands, S.J. Smith, A. Janetos, J. Edmonds, Implications of limiting $\mathrm{CO} 2$ concentrations for land use and energy, Science, 324 (2009) 1183-1186.

[3] D. Shindell, G. Faluvegi, M. Walsh, S.C. Anenberg, R.V. Dingenen, N.Z. Muller, J. Austin, D. Koch, and G. Milly, Climate, health, agricultural and economic impacts of tighter vehicle-emission standards, Nature Climate Change, 1 (2011) 59-66.

[4] D.A. Howey, A challenging future for cars, Nature Climate Change, 2 (2012) 28-29.

[5] S.J. Davis, K. Caldeira, H.D. Matthews, Future CO2 emissions and climate change from existing energy infrastructure, Science, 329 (2010) 1330-1333.

[6] J. Murray, and D. King, Climate policy, Oil's tipping point has passed Nature, 481 (2012) 433-435.

[7] L.R. Kump, Reducing uncertainty about carbon dioxide as a climate driver, Nature, 419 (2012) 188-190.

[8] W.M. Thomas, E.D. Nicholas, J.C. Needham, M.G. Church, P. Templesmith, and C.J. Dawes: GB Patent Application No 9125978.9, 1991.

[9] B. Jordon, J.B. Gibson, M.F. Horstemeyer, H.EI. Kadiri, J.C. Baird, A.A. Luo, Effect of twinning, slip, and inclusions on the fatigue anisotropy of extrusion-textured AZ61 magnesium alloy, Material Science and Engineering A, 528(22-23) (2011) 6860-6871. 
[10] Q. Yu, J.X. Zhang, Y.Y. Jiang Q.Z. Li, Effect of strain ratio on cyclic deformation and fatigue of extruded AZ61A magnesium alloy, International Journal of Fatigue, 36 (2012) $47-58$.

[11] S. Begum, D.L. Chen, S. Xu A.A. Luo, Effect of strain ratio and strain rate on low cycle fatigue behavior of AZ31 wrought magnesium alloy, Material Science and Engineering A, 517(1-2) (2009) 334-43.

[12] H.Y. Wu, J.C. Yang, J.H. Liao, F.J. Zhu, Dynamic behavior of extruded AZ61 Mg alloy during hot compression, Material Science and Engineering A, 535 (2012) 68-75.

[13] H.Y. Wang, L.M. Liu, and Z.Y. Jia, The influence of adhesive on the Al alloy in laser weld bonding Mg-Al process, J. Mater. Sci, 46 (2011) 5534-5540.

[14] Q. Yu, J. Zhang, Y. Jiang, and Q. Li, Multiaxial fatigue of extruded AZ61A magnesium alloy, International Journal of Fatigue, 33 (2011) 437-447.

[15] C.L. Fan, D.L. Chen, A.A. Luo, Dependence of the distribution of deformation twins on strain amplitudes in an extruded magnesium alloy after cyclic deformation, Material Science and Engineering A, 519(1-2) (2009) 38-45.

[16] X. Cao, and M. Jahazi, Effect of welding speed on the quality of friction stir welded butt joints of a magnesium alloy, Materials and Design, 30 (2009) 2033-2042.

[17] D. Fersini, and A. Pirondi, Fatigue behaviour of Al2024-T3 friction stir welded lap joints, Engineering Fracture Mechanics, 74 (2007) 468-480.

[18] B.L. Mordike, and T. Ebert, Magnesium: properties-applications-potential, Material Science and Engineering A, 30 (2001) 37-45.

[19] W.R. Oates, editor, Welding Handbook, Materials and Applications, pt. 1, Vol. 3, 8th edition, American Welding Society, Miami, Florida, 1996 121-162. 
[20] K.G. Watkins, Laser welding of magnesium alloys, Magnesium Technology 2003, edited by Howard I. Kaplan TMS (The Minerals, Metals \& Materials Society), 2003

[21] Magnesium and Magnesium Alloy, ASM Specialty Handbook, ASM International, 1999 94-199.

[22] H. Zhao, and T. Debroy, Pore formation during laser beam welding of die-cast magnesium alloy AM60B - Mechanism and remedy Welding Research Supplement, ( 2001) 204s-210s.

[23] B.A. Mickucki, and J.D. Shearhouse: Proceedings of Magnesium and Magnesium properties and Applications for Automobiles Conference, (Detroit, SAE Inc, 1993), 107115.

[24] K.H. Leong, G. Kornecki, P. G. Sanders, J. S. Keske: Proc ICALEO 1998 (Orlando, Laser Institute of America, 1998, Section F, 28-36.

[25] H.B. Chen, K. Yan, T. Lin, S.B. Chen, C.Y. Jiang, Y. Zhao, The investigation of typical welding defects for 5456 aluminum alloy friction stir welds, Material Science and Engineering A, 433 (2006) 64-69.

[26] R.S. Mishra, and Z.Y. Ma, Friction Stir Welding and Processing, Material Science and Engineering R, 50 (2005) 1-78.

[27] M.W. Mahoney, C.G. Rhodes, J.G. Flintoff, R.A. Spurling, W.H. Bingel, Properties of friction-stir-welded 7075 T651 aluminum, Metallurgical and Material Transaction A, 29 (1998) 1955-1964.

[28] A.P. Reynolds, W. Tang, T.G. Herold, H. Prask, Structure, properties, and residual stress of 304L stainless steel friction stir welds, Scripta Materialia, 48 (2003) 1289-1294. 
[29] S.H.C. Park, Y.S. Sato, H. Kokawa, K. Okamoto, S. Hirano, M. Inagaki, Microstructural Characterisation of Stir Zone Containing Residual Ferrite in Friction Stir Welded 304 Austenitic Stainless Steel, Science and Technology of Welding and Joining, 10 (2005) $550-556$.

[30] Y.S. Sato, T.W. Nelson, C.J. Sterling, Recrystallization in type 304L stainless steel during friction stirring, Acta Materialia, 53 (2005) 637-645.

[31] T. Saeid, A. Abdollah-zadeh, T. Shibayanagi, K. Ikeuchi, H. Assadi, On the formation of grain structure during friction stir welding of duplex stainless steel, Material Science and Engineering A, 527 (2010) 6484-6488

[32] W.M. Thomas and E.D. Nicholas, Friction stir welding for the transportation industries Materials and Design, 18 (1997) 269-273.

[33] G. Liu, L. E. Murr, C.S. Niou, J. C. McClure and F. R. Vega, Microstructural aspects of the friction-stir welding of 6061-T6 aluminum, Scripta Materialia, 37 (1997) 355-361.

[34] C.G. Rhodes, M.W. Mahoney, W.H. Bingel, R.A. Spurling, C. C. Bampton, Effect of friction stir welding on microstructure of 7075 aluminum, Scripta Materialia, 36 (1997) 69-75.

[35] S. Benavides, Y. Li, L.E. Murr, D. Brown, J.C. McClure, Low-temperature friction-stir welding of 2024 aluminum, Scripta Materialia, 41 (1999) 809-815.

[36] K.V. Jata and S.L. Semiatin, Continuous dynamic recrystallization during friction stir welding of high strength aluminum alloys, Scripta Materialia, 43 (2000) 743-749.

[37] Y. Li, L. E. Murr and J.C. McClure, Flow visualization and residual microstructures associated with the friction-stir welding of 2024 aluminum to 6061 aluminum, Material Science and Engineering A, 271 (1999) 213-223. 
[38] Y.N. Wang, C.I. Chang, C.J. Lee, H. K. Lin, J.C. Huang, Texture and weak grain size dependence in friction stir processed Mg-Al-Zn alloy, Scripta Materialia, 55 (2006) 637640.

[39] Y.J. Quan, Z.H. Chen, X.S. Gong, Z.H. Yu, Effects of heat input on microstructure and tensile properties of laser welded magnesium alloy AZ31, Materials Characterization, 59 (2008) 1491-1497.

[40] L.M. Liu and C. Dong, Preparation and photoluminescence of $\gamma$-CuI nanoparticles, Materials Letters, 60 (2006) 2194-2197.

[41] J. Zhu, L. Li, Z. Liu, CO2 and diode laser welding of AZ31 magnesium alloy, Applied Surface Science, 247 (2005) 300-306.

[42] W. Woo, H. Choo, D.W. Brown, P.K. Liaw, Z. Feng, M.B. Prime, Z. Feng, Texture variation and its influence on the tensile behavior of a friction-stir processed magnesium alloy, Scripta Materialia, 54 (2006) 1859-1864.

[43] X.H. Wang and K.S. Wang, Microstructure and properties of friction stir butt-welded AZ31 magnesium alloy, Material Science and Engineering A, 431 (2006) 114-117.

[44] L. Commin, M. Dumont, J.E. Masse, L. Barrallier, Friction stir welding of AZ31 magnesium alloy rolled sheets: Influence of processing parameters, Acta Materialia, 57 (2009) 326-334.

[45] N. Afrin, D.L. Chen, X. Cao, M. Jahazi, Strain hardening behavior of a friction stir welded magnesium alloy, Scripta Materialia, 57 (2007) 1004-1007.

[46] P.B. Srinivasan, R. Zettler, C. Blawert, and W. Dietzel, A study on the effect of plasma electrolytic oxidation on the stress corrosion cracking behaviour of a wrought AZ61 
magnesium alloy and its friction stir weldment, Materials Charactization, 60 (2009) 389396.

[47] L. Yu, K. Nakata, N. Yamamoto, J. Liao, Texture and its effect on mechanical properties in fiber laser weld of a fine-grained Mg alloy, Materials Letters, 63 (2009) 870-872.

[48] U.F. Kocks and H. Mecking, The physics and phenomenology of strain hardening, Progress in Material Science, 48 (2003) 171-273.

[49] J.A. del Valle, F. Carreno, O.A. Ruano, Influence of texture and grain size on work hardening and ductility in magnesium-based alloys processed by ECAP and rolling Acta Materialia, 54 (2006) 4247-4459.

[50] J.A. del Valle and O.A. Ruano, Influence of the grain size on the strain rate sensitivity in an $\mathrm{Mg}-\mathrm{Al}-\mathrm{Zn}$ alloy at moderate temperatures, Scripta Materialia, 55 (2006)775-778.

[51] C.I. Chang, C.J. Lee, J.C. Huang, Relationship between grain size and Zener-Holloman parameter during friction stir processing in AZ31 Mg alloys, Scripta Materialia, 51 (2004) 509-514.

[52] G.M.D. Cantin, S.A. David, W.M. Thomas, E. Lara-Curzio, S.S. Babu, Friction Skew-stir welding of lap joints in 5083-0 aluminium, Science and Technology of Welding and Joining, 10 (2005) 268-280.

[53] M. Ericsson, LZ. Jin, and R. Sandstrom, Fatigue properties of friction stir overlap welds, International Journal of Fatigue, 29 (2007) 57-68.

[54] D. Fersini, and A. Pirondi, Analysis and modelling of fatigue failure of friction stir welded aluminum alloy single-lap joints, Engineering Fracture Mechanics, 75 (2008) 790-803. 
[55] X. Cao, and M. Jahazi: In Proceedings of the 8th international conference on "Trends in welding research", edited by S.A. David, T. DebRoy, J.N. DuPont, T. Koseki, and H.B. Smart, ASM International, Materials Park, OH, 2009.

[56] Q. Yang, X. Li, K. Chen, Y.J. Shi, Effect of tool geometry and process condition on static strength of a magnesium friction stir lap linear weld, Material Science and Engineering A, 528 (2011) 2463-2478.

[57] S.H.C. Park, Y.S. Sato, and H. Kokawa, Basal plane texture and flow pattern in friction stir weld of a magnesium alloy, Metallurgical and Materials Transactions A, 34A (2003) 987-994.

[58] M. Fujimoto, S. Koga, N. Abe, Y.S. Sato, H. Kokawa, Microstructural analysis of stir zone of Al alloy produced by friction stir spot welding, Science and Technology of Welding and Joining, 13 (2008) 663-670.

[59] R.W. Fonda, J.F. Bingert, K.J. Colligan, Development of grain structure during friction stir welding, Scripta Materialia, 51 (2004) 243-248.

[60] P.L. Threadgill and M.E. Nunn, A review on friction stir welding, Part I: Process Overview, TWI report, 13963.2/02/1150.02, November 2002.

[61] P.L. Threadgill and M.E. Nunn, A review on friction stir welding, Part I: Selection of tool materials, TWI report, 13963.2/02/1149.02, November 2002.

[62] S.W. Kallee, E.D. Nicholas, W.M. Thomas, INALCO 2001, 8th International Conference on Joints in Aluminium, March 2001.

[63] Friction stir welding - A general introduction, High tech welding website: http:/www.frictionstirwelding.com/ 
[64] W.M. Thomas, Friction stir welding and related friction process characteristics Proceedings of INALCO 98, TWI, Cambridge, 1998.

[65] A.J. Leonard, Microstructure and Ageing Behavior of FSWs in Aluminium alloys 2014A-T651 and 7075-T651, $2^{\text {nd }}$ International symposium on friction stir welding, Gothenburg Sweden, June 26-28 ${ }^{\text {th }}, 2000$.

[66] V. Soundarajan, E. Yarrapareddy, R. Kovacevic, Investigation of the Friction Stir welding of aluminium alloys AA5182 and AA 6022, The Journal of Materials Engineering and Performance, 16(4) (2007) 477- 484.

[67] K. Nakata, Y.G. Kim, and M. Ushio: Transactions of the Joining Welding Research Institute, 31(2) (2002) 141-146.

[68] J. Yan, Z. Xu, Z. Li, and L. Li. Trans: Nonferrous Met. Soc. China, 15(2) (2005) 21-24.

[69] M. Guerra, J.C. McClure, L.E. Murr, A.C. Nunes, in: K.V. Jata, M.W. Mahoney, R.S. Mishra, S.L. Semiatin, D.P. Filed (Eds.), Friction Stir Welding and Processing, TMS, Warrendale, PA, USA, 2001, 25.

[70] B. Yang, J. Yan, M.A. Sutton, A. P. Reynolds, Banded microstructure in AA2024-T351 and AA2524-T351 aluminum friction stir welds Part I. Metallurgical studies, Material Science and Engineering A, 364 (2004) 55-65

[71] M.A. Gharacheh, A.H. Kokabi, G.H. Daneshi, B. Shalchi, R. Sarrafi, The influence of the ratio of "rotational speed/traverse speed" ( $\omega / \mathrm{v})$ on mechanical properties of AZ31 friction stir welds, International Journal of Machine Tools \& Manufacture, 46 (2006) 1983-1987.

[72] S. Lin, H. Zhang, L. Wu, J. Feng, H. Dai, Friction stir welding of AZ31 magnesium alloy, China welding, 12(2) (2003) 137-141. 
[73] X. Wang and K. Wang, Microstructure and properties of friction stir butt welded AZ31 magnesium alloy, Material Science and Engineering A, 431 (2006) 114-117.

[74] K. Nakata, S. Inoki, Y. Nagano, T. Hashimoto, S. Johgan, M. Ushio, in: Proceedings of the Third International Symposium on Friction Stir Welding, Kobe, Japan, September 27$28,(2001)$.

[75] R. Johnson: Indian Foundry Journal, 48 (3) (2002) 36-37.

[76] R. Johnson, Friction stir welding of magnesium alloys, Material Science Forum, 365 (2003) 419-422.

[77] W.B. Lee, J.W. Kim, Y.M. Yeon, S.B. Jung, The joint characteristics of friction stir welded AZ91D magnesium alloy, Materials Transaction, 44 (2003) 917-923.

[78] W.B. Lee, Y.M. Yeon, S.B. Jung, Joint properties of friction stir welded AZ31B-H24 magnesium alloy, Material Science Technology, 19 (2003) 785-790.

[79] S.H.C. Park, Y.S. Sato, H. Kokawa, S.A. David, T. DebRoy, J.C. Lippold, H.B. Smartt, J.M. Vitek (Eds.), Proceedings of the Sixth International Conference on Trends in Welding Research, Pine Mountain, GA, ASM International, (2003) 267.

[80] J.A. Esparza, W.C. Davis, E.A. Trillo, L.E. Murr, Friction stir welding of magnesium alloy AZ31B, Journal of Material Science Letters, 21 (2002) 917-920.

[81] J.A. Esparza, W.C. Davis, L.E. Murr, Microstructure-property studies in friction-stir welded, thixomolded magnesium alloy AM60, Journal of Material Science, 38 (2003) 941-952.

[82] H. Zhang, S.B. Lin, L. Wu, J.C. Feng, S.L. Ma, Defects formation procedure and mathematic model for defect free friction stir welding of magnesium alloy, Materials and Design, 27 (2006) 805-809. 
[83] W.B. Lee, Y.M. Yeon, K.K. Shae, Y.J Kim, and S.B. Jung, H.I. Kaplan, Editor, Magnesium Technology, (2002) 309-312.

[84] R. Zettler, A.C. Blanco, J.F. dos Santos, and S. Marya, The Effect of Process Parameters and Tool Geometry on Thermal Field Development and Weld Formation in Friction Stir Welding of the Alloys AZ31 and AZ61 Magnesium Technology, (2005) 409-423.

[85] A. Norman, I. Brough, P. Pragnell, High Resolution EBSD Analysis of the Grain Structure in an AA2024 Friction Stir Weld, Materials Science forum, 331-337 (2000) 1713-1718.

[86] M. Karlsen, S. Tangen, J. Hjelen, O. Friggard, O. Grong, Proceedings of III International Symposium on friction stir welding, Kobe, Japan, Sept, (2001).

[87] A. Hassan, A. Norman, P. Pragnell, 6th International conference on trends in welding research, Georgia, USA, April, (2002).

[88] F. Hannour, A. Davenport, S. Williams, P. Morgan, C. Figgures, 3rd international symposium on friction stir welding, Kobe, Japan, Sept (2001).

[89] R. Nandan, T. DebRoy, H.K.D.H. Bhadeshia, Recent advances in friction stir welding Process, weldment structure and properties, Progress in Materials Science, 53 (2008) 980-1023.

[90] T. Hashimoto, S. Jyogan, K. Nakata, Y. G. Kiu, M. Ushio, Proceedings, 1st International Symposium on Friction stir welding, Thousand Oaks, CA, USA, June (1999), TWI.

[91] Y. S. Sato, M. Urata and H. Kokawa, Parameters controlling microstructure and hardness during friction-stir welding of precipitation-hardenable aluminum alloy 6063, Metallurgical and Materials Transactions A, 33A (2002) 625-635. 
[92] A. J. Leonard and S. A. Lockyer, Proceedings, 4th International Symposium On Friction stir welding, Park City, UT, USA, May (2003), TWI.

[93] B. K. Christner and G. D. Sylva, Proceedings, Conference, ICAWT 96, Columbus, OH, USA, November (1996), EWI, 359-368.

[94] T. L. Dickerson, H. R. Shercliff, H. Schmidt: Proceedings, 4th International Symposium On Friction stir welding, Park City, UT, USA, May (2003), TWI.

[95] H. Okamura, K. Aota, M. Sakamoto, M. Ezumi, K. Ikeuchi, Behaviour of oxides during friction stir welding of aluminium alloy and their effect on its mechanical properties, Welding International, 16 (2002) 266-275.

[96] F. Palm, H. Steiger, U. Hennebohle, Proceedings, 4th International Symposium On Friction stir welding, Park City, UT, USA, May (2003), TWI.

[97] C. Z. Zhou, X. Q. Yang and G. H. Luan, Effect of oxide array on the fatigue property of friction stir welds, Scripta Materialia, 54 (2006) 1515-1520.

[98] C.E. Housecroft, A.G. Sharpe, Inorganic Chemistry (3rd ed.), Prentice Hall, (2008) 305306. ISBN 978-0131755536.

[99] ASTM international Standard ASTM B90, Standard Specification for Magnesium-Alloy Sheet and Plate.

[100] Properties and Selection: Nonferrous Alloys and Special-Purpose Materials, ASM Handbook vol. 2, ASM International, 1993.

[101] Elektron AZ31B Sheet, Plate and Coil. Data Sheet, 482, Magnesium Elektron UK, May (2006), Web. <www.magnesium-elektron.com>.

[102] http://www.ptable.com/\#Property/State. 
[103] P.J. Mc Gonigal, A. D. Kirshenbaum, A. V. Grosse, The Liquid Temperature Range, Density, and Critical Constants of Magnesium, Journal of Physics and Chemistry, 66 (1962) 737-739.

[104] International Magnesium Association, Magnesium Fosters Rebirth of an Automotive Engine, Mg Showcase, 1 May (2007), Web. 29 June (2010).

[105] Magnesium. Wikipedia, the Free Encyclopedia. Web. 08 June (2010). http://en.wikipedia.org/wiki/Magnesium.

[106] B.B. He, Two Dimensional X-Ray Diffraction, John Wiley \& Sons, Inc., 19, 2009.

[107] A. Macwan, D.L. Chen, M. Marr, O. Kesler, Residual stresses in suspension plasma sprayed electrolytes in metal-supported solid oxide fuel cell half cells, Journal of Power Sources, 221 (2013) 397-405.

[108] Draft international standard ISO/DIS 25239-1.2. Friction stir welding-aluminum-part 1, vocabulary, (2009).

[109] S.M. Chowdhury, D.L. Chen, S.D. Bhole, and X. Cao, Tensile properties of a friction stir welded magnesium alloy: effect of pin tool thread orientation and weld pitch, Material Science and Engineering A, 527(21-22) (2010) 6064-6075.

[110] T. Jene, G. Dobmann, G. Wagner, D. Eifler, In proceedings of the 6th International symposium on friction stir welding. Montreal, Canada, (2006) 1-6.

[111] Y.S. Sato, F. Yamashita, Y. Sugiura, S.H.C. Park, H. Kokawa, FIB-assisted TEM study of an oxide array in the root of a friction stir welded aluminium alloy, Scripta Materialia, 50 (2004) 365-369. 
[112] N. Afrin, D.L. Chen, X. Cao, M. Jahazi, Microstructure and Tensile Properties of Friction Stir Welded AZ31B Magnesium Alloy, Material Science and Engineering A, 472 (2008) $179-186$.

[113] S.H. Chowdhury, D.L. Chen, S.D. Bhole, X. Cao, P. Wanjara, Friction stir welded AZ31 magnesium alloy, Microstructure, texture, and tensile properties, Metallurgical and Materials Transactions A, 44A (2013) 323-336.

[114] S.H. Chowdhury, D.L. Chen, S.D. Bhole, X. Cao, P. Wanjara, Lap shear strength and fatigue life of friction stir spot welded AZ31 magnesium and 5754 aluminum alloys, Material Science and Engineering A, 556 (2012) 500-509.

[115] M. Fairman, N. Afrin, D.L. Chen, X.J. Cao, M. Jahazi, Microstructural evaluation of friction stir processed AZ31B-H24 magnesium alloy, Canadian Metallurgical Quarterly, 46 (2007) 425-432.

[116] O. Frigaard, O. Grong, O.T. Midling, A process model for friction stir welding of age hardening aluminum alloys, Metallurgical and Materials Transactions A, 32 (2001) 11891199.

[117] Y.G. Kim, H. Fujji, T. Tsumura, T. Komazaki, K. Nakata, Three defect types in friction stir welding of aluminum die casting alloy, Material Science and Engineering A, 415 (2006) 250-254.

[118] G.M. Cantin, S.A. David, E. Lara-Curzio, S.S. Babu, In Proceedings of the 8th international conference on Trends in welding research, (2005) 185-190.

[119] L. Cederqvist, and A.P. Reynolds, Factors affecting the properties of friction stir welded aluminum lap joints Weld J (Res. Supplement), 12 (2001) 281-287. 
[120] X. Xu, X. Yang, G. Zhou, J. Tong, Microstructures and fatigue properties of friction stir lap welds in aluminum alloy AA6061-T6, Materials and Design, 35 (2012) 175-183.

[121] C. Laird: ASTM STP, 415 (1967)131-168.

[122] S. Begum, D.L. Chen, S. Xu, A. A. Luo, Low cycle fatigue properties of an extruded AZ31 magnesium alloy, International Journal of Fatigue, 31 (2009) 726-735.

[123] S. Begum, D.L. Chen, S. Xu, A.A. Luo, Strain-controlled low cycle fatigue properties of a newly developed extruded magnesium alloy, Metallurgical and Materials Transactions A, 39A (2008) 3014-3026.

[124] C. Liu, D.L. Chen, S. Bhole, X. Cao, M. Jahazi, Polishing-assistedgalvanic corrosion in the dissimilar friction stir welded joint of AZ31 magnesium alloy to 2024 aluminum alloy, Materials Characterization, 60 (2009) 370-376.

[125] S.M. Chowdhury, D.L. Chen, S.D. Bhole, X. Cao, E. Powidajko, D.C. Weckman, Y. Zhou, Tensile properties and strain hardening behavior of double-sided arc welded and friction stir welded AZ31B magnesium alloy, Material Science and Engineering A, 527(12) (2010) 2951-2961.

[126] M. Ohno and R. Schmid-Fetzer, Thermodynamic assessment of Mg-Al-Mn phase equilibria, focusing on Mg-rich alloys, International Journal of Materials Research, 96 (2005) 857-869.

[127] C.Y. Liu, R. Jing, Q. Wang, B. Zhang, Y.Z. Jia, M.Z. Ma, R.P. Liu, Fabrication of $\mathrm{A} / \mathrm{Al} 3 \mathrm{Mg} 2$ composite by vacuum annealing and accumulative roll-bonding process, Material Science and Engineerng A, 558 (2012) 510-516. 
[128] J. Yan, Z. Xu, Z. Li, L. Li, S. Yang, Microstructure characteristics and performance of dissimilar welds between magnesium alloy and aluminum formed by friction stirring, Scripta Materialia, 53 (2005) 585-589.

[129] L. Xiao, L. Liu, Y. Zhou, S. Esmaeili, Resistance-spot-welded AZ31 magnesium alloys: Part I. Dependence of fusion zone microstructures on second-phase particles, Metalllurgical and Materials Transactions A, 41 (2010) 1511-1522.

[130] G. Gottstein an T. AL-Samman, Texture development in pure Mg and Mg alloy AZ31, Material Science Forum, 495-497 (2005) 623-632.

[131] Y.N. Wang and J.C. Huang, Texture analysis in hexagonal materials, Materials Chemistry and Physics, 81 (2003) 11-26.

[132] D. Sarker and D.L. Chen, Texture transformation in an extruded magnesium alloy under pressure, Material Science and Engineering A, 582 (2013) 63-67.

[133] T. Al-Samman and G. Gottstein, Room temperature formability of a magnesium AZ31 alloy: Examining the role of texture on the deformation mechanisms, Material Science and Engineering A, 488 (2008) 406-414.

[134] I. Ulacia, S. Yi, M.T. Perez-Prado, N.V. Dudamell, F. Galvez, D. Letzig, I. Hurtado, Proceedings in 4th International Conference on High Speed forming, Columbus, Ohio, March 9-10, (2010) 189-197.

[135] K.U. Kainer, Proceedings 7th International Conference on Magensium Alloys and Their Application, Dresden, Germany, November 6-9 (2006) 161-163.

[136] X. Li, F. Jiao, T. Al-Samman, S.G. Chowdhury, Influence of second-phase precipitates on the texture evolution of Mg-Al-Zn alloys during hot deformation, Scripta Materialia, 66 (2012) 159-162. 
[137] X. Li, T. Al-Samman, S. Mu, G. Gottstein, Texture and microstructure development during hot deformation of ME20 magnesium alloy, Experiments and simulations, Material Science and Engineering A, 528 (2011) 7915-7925.

[138] J. Hirsch and T. Al-Samman, Superior light metals by texture engineering, Optimized aluminum and magnesium alloys for automotive applications, Acta Materialia, 61 (2013) 818-843.

[139] A. Couret and D. Caillard, An in situ study of prismatic glide in magnesium-I, The rate controlling mechanism, Acta Metallurgica, 33 (1985) 1447-1454.

[140] L. Helis, K. Okayasu, H. Fukutomi, Microstructure evolution and texture development during high-temperature uniaxial compression of magnesium alloy AZ31, Material Science and Engineering A, 430 (2006) 98-103.

[141] K.J. Kim, H.T. Jeong, K.S. Shin, C.W. Kim, Texture evolution of rolled AA5052 alloy sheets after annealing, Journal of Materials Processing Technology, 187-188 (2007) 578581.

[142] R.W. Fonda, K.E. Knipling, Texture development in friction stir welds, Journal of Science and Technology of Welding and Joining, 16 (2011) 288-294.

[143] H.W. Lee and T.S. Lui, L.H. Chen, Studies on the improvement of tensile ductility of hot-extrusion AZ31 alloy by subsequent friction stir process, Journal of Alloys and Compound, 475 (2009) 139-144.

[144] S.H.C. Park, Y.S. Sato, H. Kokawa, Effect of micro-texture on fracture location in friction stir weld of Mg alloy AZ61 during tensile test, Scripta Materialia, 49 (2003) 161166. 
[145] V.K. Patel, S.D. Bhole, D.L. Chen, Ultrasonic spot welded AZ31 magnesium alloy: Microstructure, texture, and lap shear strength, Material Science and Engineering A, 569 (2013) 78-85.

[146] F.A. Mirza, D.L. Chen, D.J. Li, X.Q. Zeng, Low cycle fatigue of a rare-earth containing extruded magnesium alloy, Material Science and Engineering A, 575 (2013) 65-73.

[147] F.A. Mirza, D.L. Chen, D.J. Li, X.Q. Zeng, Effect of rare earth elements on deformation behavior of an extruded Mg-10Gd-3Y-0.5Zr alloy during compression, Materials and Design, 46 (2013) 411-418.

[148] X.Z. Lin, D.L. Chen, Strain hardening and strain-rate sensitivity of an extruded magnesium alloy, Journal of Materials Engineering and Performance, 17(6) (2008) 894901.

[149] E. Schmid: Z. Elektrochem, 37 (1931) 447-459.

[150] M.R. Barnett, Twinning and the ductility of magnesium alloys Part II. "Contraction" twins, Materials Science and Engineering A, Structural Materials, Properties, Microstructures and Processing, Material Science and Engineering A, 464 (2007) 8-16.

[151] C. Yan, W. Ma, V. Burg, M. W. Chen, Experimental and numerical investigation on ductile-brittle fracture transition in a magnesium alloy, Journal of Material Science, 42 (2007) 7702-7707.

[152] Z. Keshavarz and M.R. Barnett, EBSD analysis of deformation modes in Mg-3Al-1Zn, Scripta Materialia, 55 (2006) 915-918.

[153] P. Cizek andd M.R. Barnett, Characteristics of the contraction twins formed close to the fracture surface in Mg-3A1-1Zn alloy deformed in tension, Scripta Materialia, 59 (2008) 959-962. 
[154] F.A. Mirza and D.L. Chen, "Fatigue of lightweight magnesium alloys" (Chapter 13), Aerospace Materials Handbook, edited by S. Zhang and D.L. Zhao, CRC Press/Taylor \& Francis Group, Boca Raton, FL, USA, (2013) 647-698.

[155] Y.N. Wang and J.C. Huang, The role of twinning and untwinning in yielding behavior in hot-extruded Mg - Al - Zn alloy, Acta Materialia, 55 (2007) 897-905.

[156] D. Sarker and D.L. Chen, Dependence of compressive deformation on pre-strain and loading direction in an extruded magnesium alloy, texture, twinning and de-twinning, Material Science and Engineering A, 596 (2014) 134-144.

[157] K. Deplus, A. Simar, W. Van Haver, B. De Meester, Residual stresses in aluminium alloy friction stir welds, International Journal of Advanced Manufacture and Technology, 56 (2011) 493-504.

[158] O.J. Dada, C. Polese, L.A. Cornish, Proceedings of the International Multi Conference of Engineers and Computer Scientists, Hong Kong, 2013, Vol II, IMECS 2013, March 13$15,2013$.

[159] L. Commin, M. Dumont, R. Rotinat, F. Pierron, J. E. Masse, L. Barrallier, Influence of the microstructural changes and induced residual stresses on tensile properties of wrought magnesium alloy friction stir welds, Material Science and Engineering A, 551 (2012) 288-292.

[160] X. Cao and M. Jahazi, Effect of tool rotational speed and probe length on lap joint quality of a friction stir welded magnesium alloy, Materials and Design, 32 (2011) 1-11.

[161] Y.Chino, K. Sassa, A. Kamiya, M. Mabuchi, Ehanced formability at elevated temperature of a cross-rolled magnesium alloy sheet, Material Science and Engineering A, 441(1-2) (2006) 349-356. 
[162] J. Koike, Y. Sato, D. Ando, Origin of the anomalous $\{10-12\}$ twinning during tensile deformation of Mg alloy sheet, Materials Transactions, 49(12) (2008) 2792-2800.

[163] B.H. Lee, K.S. Shin, C.S. Lee, High temperature deformation behavior of AZ31 Mg alloy Material Science Forum, 475-479 (2005) 2927-2930.

[164] H. Takuda, T. Morishita, and T. Kinoshita, Modelling of formula for flow stress of a magnesium alloy AZ31 sheet at elevated temperatures, Journal of Materials Processing Technology, 164-165 (2005) 1258-1262. 